NBER WORKING PAPER SERIES

\title{
IMPORTERS, EXPORTERS, AND EXCHANGE RATE DISCONNECT
}

\author{
Mary Amiti \\ Oleg Itskhoki \\ Jozef Konings \\ Working Paper 18615 \\ http://www.nber.org/papers/w18615
}

\author{
NATIONAL BUREAU OF ECONOMIC RESEARCH \\ 1050 Massachusetts Avenue \\ Cambridge, MA 02138 \\ December 2012
}

We gratefully acknowledge the National Bank of Belgium for the use of its research facilities and data, and in particular Valere Bogaerts for help with the data collection, and Emmanuel Dhyne and Catherine Fuss for comments and data clarifications. We thank George Alessandria, Ariel Burstein, Elhanan Helpman, Doireann Fitzgerald, Linda Goldberg, Logan Lewis, Nick Li, Ben Mandel, Ulrich Müller, Steve Redding, Esteban Rossi-Hansberg, DavidWeinstein, Hylke Vandenbussche and seminar participants at multiple venues for insightful comments. We also thank Sydnee Caldwell, Stefaan Decramer, Cecile Gaubert, Diego Gilsanz, and Mark Razhev for excellent research assistance. The views expressed in this paper are those of the authors and do not necessarily represent those of the Federal Reserve Bank of New York or the National Bank of Belgium, or the National Bureau of Economic Research.

NBER working papers are circulated for discussion and comment purposes. They have not been peerreviewed or been subject to the review by the NBER Board of Directors that accompanies official NBER publications.

(C) 2012 by Mary Amiti, Oleg Itskhoki, and Jozef Konings. All rights reserved. Short sections of text, not to exceed two paragraphs, may be quoted without explicit permission provided that full credit, including (C) notice, is given to the source. 
Importers, Exporters, and Exchange Rate Disconnect

Mary Amiti, Oleg Itskhoki, and Jozef Konings

NBER Working Paper No. 18615

December 2012, Revised October 2013

JEL No. F14,F31,F41

\begin{abstract}
Large exporters are simultaneously large importers. In this paper, we show that this pattern is key to understanding low aggregate exchange rate pass-through as well as the variation in pass-through across exporters. First, we develop a theoretical framework that combines variable markups due to strategic complementarities and endogenous choice to import intermediate inputs. The model predicts that firms with high import shares and high market shares have low exchange rate pass-through. Second, we test and quantify the theoretical mechanisms using Belgian firm-product-level data with information on exports by destination and imports by source country. We confirm that import intensity and market share are the prime determinants of pass-through in the cross-section of firms. A small exporter with no imported inputs has a nearly complete pass-through, while a firm at the 95th percentile of both import intensity and market share distributions has a pass-through of just above $50 \%$, with the marginal cost and markup channels playing roughly equal roles. The largest exporters are simultaneously highmarket-share and high-import-intensity firms, which helps explain the low aggregate pass-through and exchange rate disconnect observed in the data.
\end{abstract}

Mary Amiti

International Research

Federal Reserve Bank of New York

33 Liberty St

New York, NY 10045-0001

Mary.Amiti@ny.frb.org

Oleg Itskhoki

Department of Economics

Princeton University

Fisher Hall 306

Princeton, NJ 08544-1021

and NBER

itskhoki@princeton.edu
Jozef Konings

Department of Economics

University of Leuven

Naamsestraat 69

3000 Leuven

Belgium

and National Bank of Belgium

Joep.Konings@econ.kuleuven.be 


\section{Introduction}

One of the central puzzles in international macroeconomics is why large movements in exchange rates have small effects on the prices of internationally traded goods. This exchange rate disconnect has generated a vast literature, yet no empirical pass-through study has taken into account one of the most salient features of international trade, that is that the largest exporters are simultaneously the largest importers. In this paper, we show that this pattern is key to understanding the low aggregate pass-through, as well as the variation in pass-through across firms.

Using detailed Belgian micro data, we find that more import-intensive exporters have significantly lower exchange rate pass-through into their export prices, as they face offsetting exchange rate effects on their marginal costs. These data reveal that the distribution of import intensity among exporters is highly skewed, with the import-intensive firms being among the largest exporters, accounting for a major share of international trade. Consequently, the import-intensive firms also have high export market shares and hence set high markups and actively move them in response to changes in marginal cost, providing a second channel that limits the effect of exchange rate shocks on export prices. These two mechanisms reinforce each other and act to introduce a buffer between local costs and international prices of the major exporters, thus playing a central role in limiting the transmission of exchange rate shocks across countries. The availability of firm-level data with imports by source country and exports by destination, combined with domestic cost data, enables us to estimate the magnitude of these two channels.

To guide our empirical strategy, we develop a theoretical framework to study the forces that jointly determine a firm's decisions to source its intermediate inputs internationally and to set markups in each destination of its exports. The two building blocks of our theoretical framework are an oligopolistic competition model of variable markups following Atkeson and Burstein (2008) and a model of the firm's choice to import intermediate inputs at a fixed cost following Halpern, Koren, and Szeidl (2011). These two ingredients allow us to capture the key patterns in the data that we focus on, and their interaction generates new insights on the determinants of exchange rate pass-through. ${ }^{1}$ In equilibrium, the more productive firms end up having greater market shares and choose to source a larger share of their inputs internationally, which in turn further amplifies the productivity advantage of these firms. The theory further predicts that a firm's import intensity and export market share form

\footnotetext{
${ }^{1}$ The combination of these two mechanisms is central to our results, while the choice of a particular model of variable markups or of selection into importing is less important.
} 
a sufficient statistic for its exchange rate pass-through within industry-destination, with import intensity proxying for marginal cost sensitivity to the exchange rate and market shares proxying for markup elasticity.

We test the predictions of the theory with a rich data set of Belgian exporters for the period 2000 to 2008. A distinctive feature of these data is that they comprise firm-level imports by source country and exports by destination at the CN 8-digit product codes (close to 10,000 distinct product codes), which we match with firm-level characteristics, such as wages and expenditure on inputs. This allows us to construct an import intensity measure for each firm as the share of imports in total variable costs and a measure of firm's market share for each export destination, which are the two key firm characteristics in our analysis. Further, with the information on imports by source country, we can separate inputs from Euro and non-Euro countries, which is an important distinction since imported inputs from within the Euro area are in the Belgian firms' currency.

We start our empirical analysis by documenting some new stylized facts related to the distribution of import intensity across firms, lending support to the assumptions and predictions of our theoretical framework. We show that in the already very select group of exporters relative to the overall population of manufacturing firms, there still exists a substantial heterogeneity in the share of imported inputs sourced internationally, in particular from the more distant source countries outside the Euro Zone. The import intensity is strongly correlated with firm size and other firm characteristics and is heavily skewed toward the largest exporters.

Our main empirical specification, as suggested by the theory, relates exchange rate pass-through with the firm's import intensity capturing the marginal cost channel and the destination-specific market shares capturing the markup channel. We estimate the crosssectional relationship between pass-through and its determinants within industries and destinations, holding constant the general equilibrium forces common to all firms. ${ }^{2}$ Our methodological contribution is to show that such a relationship holds independently of the general equilibrium environment, thus we do not need to make any assumptions about the sources of variation in the exchange rate. The exchange-rate pass-through coefficients in this relationship can be directly estimated without imposing any partial equilibrium or exogeneity assumptions. Theory further provides closed-form expressions for these coefficients, which allows us to directly test for the structural mechanism emphasized in the model. ${ }^{3}$

\footnotetext{
${ }^{2}$ Such common forces include the correlations of sector-destination-specific price index, sector-specific productivity and cost index with the exchange rate.

${ }^{3}$ In particular, we show in the data that import-intensive exporters have lower pass-through due to greater sensitivity of their marginal costs to exchange rates. Furthermore, the effect of import intensity
} 
The results provide strong support for the theory. First, we show that import intensity is an important correlate of a firm's exchange rate pass-through, with each additional 10 percentage points of imports in total costs reducing pass-through by over 6 percentage points. Second, we show that this effect is due to both the marginal cost channel, which import intensity affects directly, and the markup channel through the selection effect. Finally, when we include market share, which proxies for the markup channel, together with import intensity, we find these two variables jointly to be robust predictors of exchange rate passthrough across different sub-samples and specifications, even after controlling for other firm characteristics such as productivity and employment size.

Quantitatively, these results are large. A firm at the 5th percentile of both import intensity and market share (both approximately equal to zero) has a nearly complete passthrough (94\% and statistically indistinguishable from 100\%). In contrast, a firm at the 95th percentile of both import intensity and market share distributions has a pass-through slightly above 50\%, with import intensity and market share contributing nearly equally to this variation across firms. In other words, while small exporters barely adjust their producer prices and fully pass on the exchange rate movements to foreign consumers, the largest exporters offset almost half of the exchange rate movement by adjusting their prices already at the factory gates. Active markup adjustment by the large firms explains this only in part, and an equally important role is played by the marginal cost channel by means of imported inputs. These results have important implications for aggregate pass through since the low pass-through firms account for a disproportionately large share of exports.

Related literature Our paper is related to three strands of recent literature. First, it relates to the recent and growing literature on the interaction of importing and exporting decisions of firms. Earlier work, for example, Bernard, Jensen, and Schott (2009), has documented a large overlap in the import and export activity of firms. ${ }^{4}$ Indeed, major exporters are almost always major importers, and this is also true in our dataset. We focus exclusively on the already select group of exporters, most of whom are also importers from multiple source countries. We instead emphasize the strong selection that still operates within the group of exporters, in particular the heterogeneity in the intensity with which firms import their intermediate inputs and its consequences for export-price pass-through.

Second, our paper is related to the recent empirical and structural work on the relation-

on pass-through is larger when the import and export exchange rates are closely correlated and when the pass-through into the import prices is high, confirming the theoretical predictions.

${ }^{4}$ Other related papers include Kugler and Verhoogen (2009), Manova and Zhang (2009), Feng, Li, and Swenson (2012), and Damijan, Konings, and Polanec (2012). 
ship between firm import intensity and firm productivity. Although we base our model on Halpern, Koren, and Szeidl (2011), who estimate the effects of import use on total factor productivity for Hungarian firms, similar models were developed in Amiti and Davis (2012) to study the effects of import tariffs on firm wages and in Gopinath and Neiman (2012) to study the effects of the Argentine trade collapse following the currency devaluation of 2001 on the economy-wide productivity. ${ }^{5}$ In our study, we focus instead on how the interplay between import intensity and markup variability contributes to incomplete exchange rate pass-through.

Third, our paper contributes to the vast literature on the exchange rate disconnect (see Obstfeld and Rogoff, 2001; Engel, 2001) and in particular on the incomplete pass-through of exchange rate shocks into international prices. In the past decade, substantial progress has been made in the study of this phenomenon, both theoretically and empirically. ${ }^{6}$ This literature has explored three channels leading to incomplete pass-through. The first channel, as surveyed in Engel (2003), is short-run nominal rigidities with prices sticky in the local currency of the destination market, labeled in the literature as local currency pricing (LCP). Under LCP, the firms that do not adjust prices have zero short-run pass-through. Gopinath and Rigobon (2008) provide direct evidence on the extent of LCP in US import and export prices. The second channel-pricing-to-market (PTM) — arises in models of variable markups in which firms optimally choose different prices for different destinations depending on local market conditions. Atkeson and Burstein (2008) provide an example of a recent quantitative investigation of the PTM channel and its implication for international aggregate prices. ${ }^{7}$ Finally, the third channel of incomplete pass-through into consumer prices often considered in the literature is local distribution costs, as for example in Burstein, Neves, and Rebelo (2003) and Goldberg and Campa (2010). Our imported inputs channel is similar in spirit to the local distribution costs in that they make the costs of the firm more stable in the local currency of export destination. The difference with the distribution cost channel is that the

\footnotetext{
${ }^{5}$ Blaum, Lelarge, and Peters (2013) document stylized facts about import behavior of French firms and provide another related model. Amiti and Konings (2007) provide an empirical analysis of the micro-level effects of imports on firm productivity.

${ }^{6}$ For a survey of earlier work, see Goldberg and Knetter (1997), who in particular emphasize that "[1]ess is known about the relationship between costs and exchange rates..." (see p. 1244). The handbook chapter by Burstein and Gopinath (2012) provides a summary of recent developments in this area.

${ }^{7}$ Gopinath and Itskhoki (2011) show the importance of PTM in matching patterns in the international aggregate and micro price data. Fitzgerald and Haller (2012) provide the most direct evidence on PTM by comparing the exchange rate response of prices of the same item sold to both the domestic and the international market. Gopinath, Itskhoki, and Rigobon (2010) and Gopinath and Itskhoki (2010) show that the PTM and LCP channels of incomplete pass-through interact and reinforce each other, with highly variable-markup firms endogenously choosing to price in local currency as well as adopting longer price durations.
} 
use of imported inputs results in incomplete pass-through not only into consumer prices, but also into producer factory gate prices.

A related line of literature, surveyed in Goldberg and Hellerstein (2008), has identified the PTM channel by structurally estimating industry demand to back out model-implied markups of the firms. Goldberg and Verboven (2001) apply this methodology in the context of the European car market, while Nakamura and Zerom (2010) and Goldberg and Hellerstein (2011) study the coffee and the beer markets, respectively, incorporating sticky prices into the analysis. Based on the finding that markups do not vary enough to capture the variation in exporter prices arising from exchange rate volatility, these studies conclude there must be a residual role for the marginal cost channel, due to either the local distribution margin or imported inputs. Our paper is the first to directly estimate the importance of the marginal cost channel for incomplete pass-through into exporter prices arising from the use of imported intermediate inputs.

Our work is closely related to Berman, Martin, and Mayer (2012) in that we also study the variation in pass-through across heterogeneous firms. While they focus on the role of firm productivity and size, we emphasize the role of imported inputs and destination-specific market shares. ${ }^{8}$ Our approach also enables us to provide a quantitative decomposition of the contribution of the marginal cost and variable markup channels to incomplete exchange rate pass-through.

The rest of the paper is structured as follows. Section 2 lays out the theoretical framework and provides the theoretical results that motivate the empirical analysis that follows. Section 3 introduces the dataset and describes the stylized patterns of cross-sectional variation in the data. Section 4 describes our main empirical findings. Section 5 concludes. The technical derivations and additional results are provided in the appendix.

\footnotetext{
${ }^{8} \mathrm{~A}$ number of earlier papers have linked pass-through with market share of exporters. Feenstra, Gagnon, and Knetter (1996), Alessandria (2004), and Garetto (2012) emphasize the U-shape relationship between market share and pass-through. The Atkeson and Burstein (2008) model can in general produce such a non-monotonic relationship, however when the price index is held constant, consistent with our empirical strategy, pass-through monotonically decreases in market share. Empirically, we also find no evidence of a U-shape relationship between market share and pass-through (see Section 4.3). A recent paper by Auer and Schoenle (2012) shows that greater sector-level market share of exporters from a particular country contributes to higher pass-through. We instead focus on the firm-level interaction between market share and pass-through, and find a negative relationship. These seemingly contradictory findings are consistent with each other in a model of strategic complementarities due to counteracting general equilibrium effects operating at the sectoral level and held constant in our analysis (see also Burstein and Gopinath, 2012).
} 


\section{Theoretical Framework}

In this section, we develop a theoretical framework linking a firm's exchange rate passthrough to its import intensity and export market shares, all of which are endogenously determined. We use this framework to formulate testable implications and to derive an equilibrium relationship, which we later estimate in the data. We start by laying out the two main ingredients of our framework - the Atkeson and Burstein (2008) model of strategic complementarities and variable markups and the Halpern, Koren, and Szeidl (2011) model of the firm's choice to import intermediate inputs. We then show how the interaction of these two mechanisms generates new theoretical insights on the determinants of exchange rate pass-through. The key predictions of this theory are that a firm's import intensity and market shares are positively correlated in the cross-section and together constitute a sufficient statistic for the exchange rate pass-through of the firm within sector-export market, with import intensity capturing the marginal cost sensitivity to the exchange rate and market share capturing the markup elasticity.

We characterize the equilibrium relationship between market share, import intensity and pass-through, which holds parametrically independently of the particular general equilibrium environment. The parameter values in this relationship depend on the specifics of the general equilibrium, in particular the equilibrium co-movement between aggregate variables such as exchange rates, price levels and cost indexes. Nonetheless, we need not take a stand on the specific general equilibrium assumptions as we directly estimate these parameters using cross-sectional variation between firms within industries and export destinations, without relying on any partial equilibrium or exchange rate exogeneity assumptions.

To focus our analysis on the relationship between import intensity and pass-through of the firms, we make a number of simplifying assumptions. First, we condition our analysis on the subset of exporting firms, and hence we do not model entry, exit, or selection into exporting (as, for example, in Melitz, 2003), but rather focus on the import decisions of the firms. Similarly, we do not model the decision to export to multiple destinations, but simply take this information as exogenously given. Furthermore, we assume all firms are singleproduct. In the empirical section we discuss the implications of relaxing these assumptions.

Second, we assume flexible price setting as in Atkeson and Burstein (2008) and hence do not need to characterize the currency choice (i.e., local versus producer currency pricing). This modeling choice is motivated by the nature of our dataset in which we use unit values as proxies for prices. Empirically, incomplete pass-through is at least in part due to price stickiness in local currency, and in light of this we provide a careful interpretation of our 
results in the concluding Section $5 .^{9}$

Last, while the marginal cost channel emphasized in the paper is inherently a mechanism of real hedging, in modeling firms' import decisions we abstract from choosing or switching import source countries to better hedge their export exchange rate risk. Empirically, we find that the positive correlation between a firm's destination-specific exchange rate and its import-weighted exchange rate does not vary with the main firm variables that are the focus of our analysis (see Section 4.4). ${ }^{10}$

\subsection{Demand and markups}

Consider a firm producing a differentiated good $i$ in sector $s$ and supplying it to destination market $k$ in period $t$. Consumers in each market have a nested CES demand over the varieties of goods, as in Atkeson and Burstein (2008). The elasticity of substitution across the varieties within sectors is $\rho$, while the elasticity of substitution across sectoral aggregates is $\eta$, and we assume $\rho>\eta \geq 1$.

Under these circumstances, a firm $i$ faces the following demand for its product:

$$
Q_{k, i}=\xi_{k, i} P_{k, i}^{-\rho} P_{k}^{\rho-\eta} D_{k}
$$

where $Q_{k, i}$ is quantity demanded, $\xi_{k, i}$ is a relative preference (quality) parameter of the firm, $P_{k, i}$ is the firm's price, $P_{k}$ is the sectoral price index, and $D_{k}$ is the sectoral demand shifter, which the firm takes as given. Index $k$ emphasizes that all these variables are destination specific. For brevity, we drop the additional subscripts $s$ and $t$ for sector and time, since all of our analysis focuses on variation within a given sector.

The sectoral price index is given by $P_{k} \equiv\left[\sum_{i} \xi_{k, i} P_{k, i}^{1-\rho}\right]^{1 /(1-\rho)}$, where the summation is across all firms in sector $s$ serving market $k$ in time period $t$, and we normalize $\sum_{i} \xi_{k, i}=1$. As a convention, we quote all prices in the local currency of the destination market.

\footnotetext{
${ }^{9}$ It is useful to keep in mind that, as shown in Gopinath, Itskhoki, and Rigobon (2010), the flexible-price pass-through forces shape the currency choice of the firms, i.e. firms with a low pass-through conditional on a price change choose to price in local currency, which further reduces the short-run pass-through of these firms. In this paper, we focus on the endogenous determinants of flexible-price (or long-run) pass-through in the cross-section of firms, which in the sticky price environment would also contribute to the prevalence of local currency pricing, yet the two forces work in the same direction.

${ }^{10}$ Note that under the assumption of risk neutrality of the firm and in the absence of liquidity constraints (for example, of the type modeled in Froot, Scharfstein, and Stein, 1993), financial hedging constitutes only a side bet to the firm and does not affect its import and pricing decisions. Fauceglia, Shingal, and Wermelinger (2012) provide evidence on the role of imported inputs in "natural" hedging of export exchange rate risk by Swiss firms and Martin and Méjean (2012) provide survey evidence on the role of currency hedging in international transactions of firms in the Euro Zone.
} 
An important characteristic of the firm's competitive position in a market is its market share given by:

$$
S_{k, i} \equiv \frac{P_{k, i} Q_{k, i}}{\sum_{i^{\prime}} P_{k, i^{\prime}} Q_{k, i^{\prime}}}=\xi_{k, i}\left(\frac{P_{k, i}}{P_{k}}\right)^{1-\rho} \in[0,1],
$$

where market share is sector-destination-time specific. The effective demand elasticity for the firm is then

$$
\sigma_{k, i} \equiv-\frac{\mathrm{d} \log Q_{k, i}}{\mathrm{~d} \log P_{k, i}}=\rho\left(1-S_{k, i}\right)+\eta S_{k, i},
$$

since $\partial \log P_{k} / \partial \log P_{k, i}=S_{k, i}$. In words, the firm faces a demand elasticity that is a weighted average of the within-sector and the across-sector elasticities of substitution with the weight on the latter equal to the market share of the firm. High-market-share firms exert a stronger impact on the sectoral price index, making their demand less sensitive to their own price.

When firms compete in prices, they set a multiplicative markup $\mathcal{M}_{k, i} \equiv \sigma_{k, i} /\left(\sigma_{k, i}-1\right)$ over their costs. Firms face a demand with elasticity decreasing in the market share, and hence high-market-share firms charge high markups. We now define a measure of the markup elasticity with respect to the price of the firm, holding constant the sector price index: ${ }^{11}$

$$
\Gamma_{k, i} \equiv-\frac{\partial \log \mathcal{M}_{k, i}}{\partial \log P_{k, i}}=\frac{S_{k, i}}{\left(\frac{\rho}{\rho-\eta}-S_{k, i}\right)\left(1-\frac{\rho-\eta}{\rho-1} S_{k, i}\right)}>0
$$

A lower price set by the firm leads to an increase in the firm's market share, making optimal a larger markup. Furthermore, the markup elasticity is also increasing in the market share of the firm: firms with larger markups choose to adjust them by more in response to shocks and to keep their prices and quantities more stable. We summarize this discussion in:

Proposition 1 Market share of the firm $S_{k, i}$ is a sufficient statistic for its markup; both markup $\mathcal{M}_{k, i}$ and markup elasticity $\Gamma_{k, i}$ are increasing in the market share of the firm.

The monotonicity of markup and markup elasticity in market share is a sharp prediction of this framework. Although this prediction is not universal for other demand structures, it emerges in a wide class of models, as surveyed in Burstein and Gopinath (2012). In Section 4.3, we directly test this prediction and find no evidence of non-monotonicity in the data.

\footnotetext{
${ }^{11}$ We focus on this partial measure of markup elasticity because it emerges as the relevant object in our cross-sectional comparisons across firms that all face the same sector-destination price index. Note that the monotonicity result in Proposition 1 does not in general apply to other measures of markup elasticity without further parameter restrictions.
} 


\subsection{Production and imported inputs}

We build on Halpern, Koren, and Szeidl (2011) to model the cost structure of the firm and its choice to import intermediate inputs. Consider a firm $i$, which uses labor $L_{i}$ and intermediate inputs $X_{i}$ to produce its output $Y_{i}$ according to the production function:

$$
Y_{i}=\Omega_{i} X_{i}^{\phi} L_{i}^{1-\phi}
$$

where $\Omega_{i}$ is firm productivity. Parameter $\phi \in[0,1]$ measures the share of intermediate inputs in firm expenditure and is sector specific but common to all firms in the sector.

Intermediate inputs consist of a bundle of intermediate goods indexed by $j \in[0,1]$ and aggregated according to a Cobb-Douglas technology:

$$
X_{i}=\exp \left\{\int_{0}^{1} \gamma_{j} \log X_{i, j} \mathrm{~d} j\right\}
$$

The types of intermediate inputs vary in their importance in the production process as

measured by $\gamma_{j}$, which satisfy $\int_{0}^{1} \gamma_{j} \mathrm{~d} j=1$. Each type $j$ of intermediate good comes in two varieties - domestic and foreign — which are imperfect substitutes:

$$
X_{i, j}=\left[Z_{i, j}^{\frac{\zeta}{1+\zeta}}+a_{j}^{\frac{1}{1+\zeta}} M_{i, j}^{\frac{\zeta}{1+\zeta}}\right]^{\frac{1+\zeta}{\zeta}}
$$

where $Z_{i, j}$ and $M_{i, j}$ are, respectively, the quantities of domestic and imported varieties of the intermediate good $j$ used in production. The elasticity of substitution between the domestic and the foreign varieties is $(1+\zeta)>1$, and $a_{j}$ measures the productivity advantage (when $a_{j}>1$, and disadvantage otherwise) of the foreign variety. Note that since home and foreign varieties are imperfect substitutes, production is possible without the use of imported inputs. At the same time, imported inputs are useful due both to their potential productivity advantage $a_{j}$ and to the love-of-variety feature of the production technology (7).

A firm needs to pay a firm-specific sunk cost $f_{i}$ in terms of labor in order to import each type of the intermediate good. The cost of labor is given by the wage rate $W^{*}$, and the prices of domestic intermediates are $\left\{V_{j}^{*}\right\}$, both denominated in units of producer currency (hence starred). The prices of foreign intermediates are $\left\{\mathcal{E}_{m} U_{j}\right\}$, where $U_{j}$ is the price in foreign currency and $\mathcal{E}_{m}$ is the nominal exchange rate measured as a unit of producer currency for one unit of foreign currency. ${ }^{12}$ The total cost of the firm is therefore given by

\footnotetext{
${ }^{12}$ We denote by $m$ a generic source of imported intermediates, and hence $\mathcal{E}_{m}$ can be thought of as an import-weighted exchange rate faced by the firms. The generalization of the model to multiple import
} 
$W^{*} L_{i}+\int_{0}^{1} V_{j}^{*} Z_{i, j} \mathrm{~d} j+\int_{J_{0, i}}\left(\mathcal{E}_{m} U_{j} M_{i, j}+W^{*} f_{i}\right) \mathrm{d} j$, where $J_{0, i}$ denotes the set of intermediates imported by the firm.

With this production structure, we can derive the cost function of the firm. In particular, given output $Y_{i}$ and the set of imported intermediates $J_{0, i}$, the firm chooses inputs to minimize its total costs subject to the production technology in equations (5)-(7). This results in the following total variable cost function net of the fixed costs of importing:

$$
T V C_{i}^{*}\left(Y_{i} \mid J_{0, i}\right)=\frac{C^{*}}{B_{i}^{\phi} \Omega_{i}} Y_{i}
$$

where $C^{*}$ is the cost index for a non-importing firm. ${ }^{13}$ The use of imported inputs leads to a cost-reduction factor $B_{i} \equiv B\left(J_{0, i}\right)=\exp \left\{\int_{J_{0, i}} \gamma_{j} \log b_{j} \mathrm{~d} j\right\}$, where $b_{j} \equiv\left[1+a_{j}\left(\mathcal{E}_{m} U_{j} / V_{j}^{*}\right)^{-\zeta}\right]^{1 / \zeta}$ is the productivity-enhancing effect from importing type- $j$ intermediate good, adjusted for the relative cost of the import variety.

We now describe the optimal choice of the set of imported intermediate goods, $J_{0, i}$, in the absence of uncertainty. First, we sort all intermediate goods $j$ by $\gamma_{j} \log b_{j}$, from highest to lowest. Then, the optimal set of imported intermediate inputs is an interval $J_{0, i}=\left[0, j_{0, i}\right]$, with $j_{0, i} \in[0,1]$ denoting the cutoff intermediate good. The optimal choice of $j_{0, i}$ trades off the fixed cost of importing $W^{*} f_{i}$ for the reduction in total variable costs from the access to an additional imported input, which is proportional to the total material cost of the firm. ${ }^{14}$ This reflects the standard trade-off that the fixed cost activity is undertaken provided that the scale of operation (here total spending on intermediate inputs) is sufficiently large.

With this cost structure, the fraction of total variable cost spent on imported intermediate inputs equals:

$$
\varphi_{i}=\phi \int_{0}^{j_{0, i}} \gamma_{j}\left(1-b_{j}^{-\zeta}\right) \mathrm{d} j
$$

where $\phi$ is the share of material cost in total variable cost and $\gamma_{j}\left(1-b_{j}^{-\zeta}\right)$ is the share of material cost spent on imports of type- $j$ intermediate good for $j \in J_{0, i}$. We refer to $\varphi_{i}$ as the import intensity of the firm, and it is one of the characteristics of the firm we measure directly in the data.

Finally, holding the set of imported varieties $J_{0, i}$ constant, this cost structure results in

source countries is straightforward; in the data, we measure $\mathcal{E}_{m}$ as an import-weighted exchange rate at the firm-level, as well as split imports by source country (see Section 4.4).

${ }^{13}$ This cost index is given by $C^{*}=\left(V^{*} / \phi\right)^{\phi}\left(W^{*} /(1-\phi)\right)^{1-\phi}$ with $V^{*}=\exp \left\{\int_{0}^{1} \gamma_{j} \log \left(V_{j}^{*} / \gamma_{j}\right) \mathrm{d} j\right\}$.

${ }^{14}$ The marginal imported input satisfies $\gamma_{j_{0, i}} \log b_{j_{0, i}} \cdot T M C_{i}=W^{*} f_{i}$, where the left-hand side is the incremental benefit proportional to the total material cost of the firm $T M C_{i} \equiv \phi C^{*} Y_{i} /\left[B_{i}^{\phi} \Omega_{i}\right]$ and the cost-saving impact of additional imports $\gamma_{j_{0, i}} \log b_{j_{0, i}}$. 
the following marginal cost:

$$
M C_{i}^{*}=C^{*} /\left[B_{i}^{\phi} \Omega_{i}\right] .
$$

The partial elasticity of this marginal cost with respect to the exchange rate $\mathcal{E}_{m}$ equals the expenditure share of the firm on imported intermediate inputs, $\varphi_{i}=\partial \log M C_{i}^{*} / \partial \log \mathcal{E}_{m}$, which emphasizes the role of import intensity in the analysis that follows.

We summarize these results in:

Proposition 2 (i) Within sectors, firms with larger total material cost or smaller fixed cost of importing have a larger import intensity, $\varphi_{i}$. (ii) The partial elasticity of the marginal cost of the firm with respect to the (import-weighted) exchange rate equals $\varphi_{i}$.

\subsection{Equilibrium relationships}

We now combine the ingredients introduced above to derive the optimal price setting of the firm, as well as the equilibrium determinants of the market share and import intensity of the firm. Consider firm $i$ supplying an exogenously given set $K_{i}$ of destination markets $k$. The firm sets destination-specific prices by solving

$$
\max _{Y_{i},\left\{P_{k, i}, Q_{k, i}\right\}_{k}}\left\{\sum_{k \in K_{i}} \mathcal{E}_{k} P_{k, i} Q_{k, i}-\frac{C^{*}}{B_{i}^{\phi} \Omega_{i}} Y_{i}\right\},
$$

subject to $Y_{i}=\sum_{k \in K_{i}} Q_{k, i}$ and demand equation (1) in each destination $k$. We quote the destination- $k$ price $P_{k, i}$ in the units of destination- $k$ local currency and use the bilateral nominal exchange rate $\mathcal{E}_{k}$ to convert the price to the producer currency, denoting with $P_{k, i}^{*} \equiv \mathcal{E}_{k} P_{k, i}$ the producer-currency price of the firm for destination $k$. An increase in $\mathcal{E}_{k}$ corresponds to the depreciation of the producer currency. The total cost of the firm is quoted in units of producer currency and hence is starred. ${ }^{15}$ Note that we treat the choice of the set of imported goods $J_{0, i}$ and the associated fixed costs as sunk by the price setting stage when the uncertainty about exchange rates is realized. The problem of choosing $J_{0, i}$ under this circumstance is defined and characterized in the appendix and Section 3.2 provides empirical evidence supporting this assumption.

Taking the first-order conditions with respect to $P_{k, i}$, we obtain the optimal price setting conditions:

$$
P_{k, i}^{*}=\frac{\sigma_{k, i}}{\sigma_{k, i}-1} M C_{i}^{*}=\mathcal{M}_{k, i} \frac{C^{*}}{B_{i}^{\phi} \Omega_{i}}, \quad k \in K_{i},
$$

\footnotetext{
${ }^{15}$ We do not explicitly model variable trade costs, but if they take an iceberg form, they are without loss of generality absorbed into the $\xi_{k, i} D_{k}$ term in the firm- $i$ demand (1) in destination $k$.
} 
where $M C_{i}^{*}$ is the marginal cost as defined in (10) and $\mathcal{M}_{k, i}=\sigma_{k, i} /\left(\sigma_{k, i}-1\right)$ is the multiplicative markup with the effective demand elasticity $\sigma_{k, i}$ defined in (3). This set of first-order conditions together with the constraints fully characterizes the allocation of the firm, given industry-level variables. In the appendix, we exploit these equilibrium conditions to derive how relative market shares and import intensities are determined in equilibrium across firms, and since these results are very intuitive, here we provide only a brief summary.

We show that other things equal and under mild regularity conditions, a firm with higher productivity $\Omega_{i}$, higher quality/demand $\xi_{k, i}$, lower fixed cost of importing $f_{i}$, and serving a larger set of destinations $K_{i}$ has a larger market share $S_{k, i}$ and a higher import intensity $\varphi_{i}$. Intuitively, a more productive or high-demand firm has a larger market share and hence operates on a larger scale which justifies paying the fixed cost for a larger set of imported intermediate inputs, $J_{0, i}$. This makes the firm more import intensive, which through the cost-reduction effect of imports (larger $B_{i}$ in (8)) enhances the productivity of the firm and, in turn, results in higher market shares. This implies that, independently of the specifics of the general equilibrium environment, we should expect market shares and import intensities to be positively correlated in the cross-section of firms, a pattern that we document in the data in Section 3.

\subsection{Imported inputs, market share, and pass-through}

We are now in a position to relate the firm's exchange rate pass-through into its export prices with its market share and import intensity. The starting point for this analysis is the optimal price setting equation (11), which we rewrite as a full log differential:

$$
\mathrm{d} \log P_{k, i}^{*}=\mathrm{d} \log \mathcal{M}_{k, i}+\mathrm{d} \log M C_{i}^{*} .
$$

Consider first the markup term. Using (2)-(4), we have:

$$
\mathrm{d} \log \mathcal{M}_{k, i}=-\Gamma_{k, i}\left(\mathrm{~d} \log P_{k, i}-\mathrm{d} \log P_{s, k}\right)+\frac{\Gamma_{k, i}}{\rho-1} \mathrm{~d} \log \xi_{k, i}
$$

where converting the export price to local currency yields $\mathrm{d} \log P_{k, i}=\mathrm{d} \log P_{k, i}^{*}-\mathrm{d} \log \mathcal{E}_{k}$, and we now make explicit the subscript $s$ indicating that $P_{s, k}$ is the industry-destinationspecific price index. The markup declines in the relative price of the firm and increases in the firm's demand shock. From Proposition 1, $\Gamma_{k, i}$ is increasing in the firm's market share, and hence price increases for larger market-share firms are associated with larger declines in the markup. 
Next, the change in the marginal cost in equation (10) can be decomposed as follows:

$$
\mathrm{d} \log M C_{i}^{*}=\varphi_{i} \mathrm{~d} \log \frac{\mathcal{E}_{m} \bar{U}_{s}}{\bar{V}_{s}^{*}}+\mathrm{d} \log \frac{C_{s}^{*}}{\bar{\Omega}_{s}}+\epsilon_{i}^{M C} .
$$

This expression generalizes the result of Proposition 2 on the role of import intensity $\varphi_{i}$ by providing the full decomposition of the change in the log marginal cost. Here $\bar{U}_{s}$ and $\bar{V}_{s}^{*}$ are the price indexes for the imported intermediates (in foreign currency) and domestic intermediates (in producer currency), respectively. The subscript $s$ emphasizes that these indexes can be specific to sector $s$ in which firm $i$ operates. Finally, $\mathrm{d} \log \bar{C}_{s}^{*} / \bar{\Omega}_{s}$ is the $\log$ change in the industry-average marginal cost for a firm that does not import any intermediates, and $\epsilon_{i}^{M C}$ is a firm-idiosyncratic residual term defined explicitly in the appendix and assumed orthogonal with the exchange rate. ${ }^{16}$

Combining and manipulating equations (12)-(14), we prove our key theoretical result:

Proposition 3 In any general equilibrium, the first-order approximation to the exchange rate pass-through elasticity into producer-currency export prices of the firm is given by

$$
\Psi_{k, i}^{*} \equiv \mathbb{E}\left\{\frac{\mathrm{d} \log P_{k, i}^{*}}{\mathrm{~d} \log \mathcal{E}_{k}}\right\}=\alpha_{s, k}+\beta_{s, k} \varphi_{i}+\gamma_{s, k} S_{k, i}
$$

where $\left(\alpha_{s, k}, \beta_{s, k}, \gamma_{s, k}\right)$ are sector-destination specific and depend only on average moments of equilibrium co-movement between aggregate variables common to all firms.

The pass-through elasticity $\Psi_{k, i}^{*}$ measures the equilibrium log change of the destination- $k$ producer-currency price of firm $i$ relative to the log change in the bilateral exchange rate, averaged across all possible states of the world and shocks that hit the economy. ${ }^{17}$ Under this definition, the pass-through elasticity is a measure of equilibrium co-movement between the price of the firm and the exchange rate, and not a partial equilibrium response to an exogenous movement in the exchange rate. Thus, we do not need to assume that movements in exchange rates are exogenous, nor do we rely on any source of exogenous variation in our estimation. In fact, we allow for arbitrary equilibrium co-movement between exchange rates

\footnotetext{
${ }^{16}$ This orthogonality assumption is necessary for Proposition 3, and it holds provided that firm idiosyncratic shocks are not systematically correlated with exchange rate movements. More precisely, we allow firm demand, productivity and import prices to move with exchange rates in arbitrary ways, but we require that the relative demand, productivity and import prices of any two firms within sector-destination do not systematically change with exchange rate movements.

${ }^{17}$ Formally, the expectation in (15) is over all possible exogenous shocks that affect the exchange rate in general equilibrium, as well as over all state variables (e.g., the distribution of firm productivities). Further, the expectation in (15) is conditional on the persistent characteristics of a given firm $\left(\Omega_{i}, \xi_{k, i}, f_{i}\right)$, which, as Proposition 3 emphasizes, affect the firm's pass-through only through the sufficient statistic $\left(\varphi_{i}, S_{k, i}\right)$.
} 
and other aggregate variables, including price and cost indexes.

Proposition 3 shows that we can relate firm-level pass-through to market share and import intensity of the firm, which form a sufficient statistic for cross-section variation in passthrough within sector-destination, independently of the specifics of the general equilibrium environment and, in particular, independently of what shocks hit the economy and shape the dynamics of the exchange rate. This relationship is the focus of our empirical investigation in the next section. The values of the coefficients in this relationship $\left(\alpha_{s, k}, \beta_{s, k}, \gamma_{s, k}\right)$ are sectordestination specific, and, although they depend on the general equilibrium environment in which firms operate, we show in Section 4.1 that we can directly estimate them in the data without imposing any general equilibrium assumptions. ${ }^{18}$

Furthermore, the theory provides closed form expressions for the coefficients in (15). The coefficients $\alpha_{s, k}$ and $\gamma_{s, k}$ depend on the unconditional moments of equilibrium co-movement between the exchange rate and aggregate variables such as the price index in the destination market and the domestic cost index (see appendix). For example, pass-through into destination prices is lower (i.e., $\alpha_{s, k}$ is higher) in an equilibrium environment where the domestic cost index offsets some of the effects of the exchange rate on marginal costs. And pass-through is relatively lower (i.e., $\gamma_{s, k}$ is higher) for large market-share firms when the destination price index responds weakly to the exchange rate, because of the stronger strategic complementarities in their price setting.

The closed form expression for $\beta_{s, k}$ highlights the structural determinants of the relationship between pass-through and import intensity as captured by:

$$
\beta_{s, k}=\frac{1}{1+\bar{\Gamma}_{s, k}} \mathbb{E}\left\{\frac{\mathrm{d} \log \mathcal{E}_{m}}{\mathrm{~d} \log \mathcal{E}_{k}} \cdot \frac{\mathrm{d} \log \left(\mathcal{E}_{m} \bar{U}_{s} / \bar{V}_{s}^{*}\right)}{\mathrm{d} \log \mathcal{E}_{m}}\right\},
$$

where $\bar{\Gamma}_{s, k}$ is the markup elasticity evaluated at some average measure of market share $\bar{S}_{s, k}$. Intuitively, $\beta_{s, k}$ depends on the co-movement between export and import exchange rates and the pass-through of import exchange rate into the relative price of imported intermediates, as reflected by the two terms inside the expectation in (16). Indeed, import intensity proxies for the marginal cost correlation with the export exchange rate only to the extent that import and export exchange rates are correlated and movements in the import exchange rate are associated with the changes in the import prices of the intermediate inputs. Importantly,

\footnotetext{
${ }^{18}$ We estimate the coefficients by exploiting the cross-sectional variation in the panel data within industries and destinations in the responses to shocks across firms. These estimates, however, are not suitable for undertaking counterfactuals across general equilibrium environments, as when the source of variation in exchange rate changes, so do the coefficients. Such counterfactuals need to be carried out in the context of a specific calibrated general equilibrium model.
} 
we do not restrict the exchange rate pass-through into import prices to be complete. In our empirical work, we directly examine our theoretical mechanism by using the variation in exchange rate correlation and import price pass-through across import source countries.

Proposition 3 predicts that pass-through into destination-currency prices, equal to $\left(1-\Psi_{k, i}^{*}\right)$, is lower for more import-intensive firms and for firms with higher destination market share, provided $\beta_{s, k}$ and $\gamma_{s, k}$ are positive. ${ }^{19}$ Although theoretically these coefficients can have either sign (or equal to zero), we expect them to be positive, and this is what we find in the data. Intuitively, a more import-intensive firm is effectively hedged from a domestic currency appreciation via decreasing import prices and hence keeps its destination-currency price more stable. Further, a high-market-share firm has a lower pass-through as it chooses to accommodate the marginal cost shocks with a larger markup adjustment as opposed to a larger movement in its destination-currency price.

\section{$3 \quad$ Data and Stylized Facts}

In this section we describe the dataset that we use for our empirical analysis and the basic stylized facts on exporters and importers.

\subsection{Data description and construction of variables}

Our main data source is the National Bank of Belgium, which provided a comprehensive panel of Belgian trade flows by firm, product (CN 8-digit level), exports by destination, and imports by source country. We merge these data, using a unique firm identifier, with firmlevel characteristics from the Belgian Business Registry, comprising information on firms' inputs, which we use to construct total cost measures and total factor productivity estimates. Our sample includes annual data for the period 2000 to 2008, beginning the year after the euro was introduced. We focus on manufacturing exports to the OECD countries outside the Euro Zone: Australia, Canada, Iceland, Israel, Japan, the Republic of Korea, New Zealand, Norway, Sweden, Switzerland, the United Kingdom and the United States, accounting for 58 percent of total non-Euro exports. ${ }^{20}$ We also include a robustness test with the full set of

\footnotetext{
${ }^{19}$ Note that Proposition 3 provides a linear approximation (15) to the generally nonlinear equilibrium relationship. In the data, we test directly for the nonlinearity in this relationship and find no statistically significant evidence. Our interpretation is that this is not because nonlinearities are unimportant in general, but because these finer features of the equilibrium relationship are less robust across broad industries that we consider in our analysis. This is why we choose to focus on the first-order qualitative prediction of the theory captured by the approximation in (15).

${ }^{20}$ The Euro Zone was formed on January 1, 1999, in Austria, Belgium, Finland, France, Germany, Ireland, Italy, Luxembourg, the Netherlands, Portugal, and Spain. Greece joined on January 1, 2001, Slovenia joined in 2007, Cyprus and Malta joined in 2008. We also exclude Denmark from the set of export destinations
} 
non-Euro destinations. We provide a detailed description of all the data sources in the data appendix.

The dependent variable in our analysis is the log change in a firm $f$ 's export price of good $i$ to destination country $k$ at time $t$, proxied by the change in a firm's export unit value, defined as the ratio of export values to export quantities:

$$
\Delta p_{f, i, k, t}^{*} \equiv \Delta \log \left(\frac{\text { Export value }_{f, i, k, t}}{\text { Export quantity }_{f, i, k, t}}\right)
$$

where quantities are measured as weights or units. We use the change in the ratio of value to weights, where available, and the change in the ratio of value to units otherwise. We note that unit values are an imprecise proxy for prices because there may be more than one distinct product within a CN 8-digit code despite the high degree of disaggregation constituting close to 10,000 distinct manufacturing product categories over the sample period. Some price changes may be due to compositional changes within a product code or due to errors in measuring quantities. ${ }^{21}$ To try to minimize this problem, we drop all year-to-year unit value changes of plus 200 percent or minus 67 percent (around seven percent of the observations.)

A distinctive feature of these data that is critical for our analysis is that they contain firm-level import values and quantities for each CN 8-digit product code by source country. We include all 234 source countries and all 13,000 product codes in the sample. Studies that draw on price data have not been able to match import and export prices at the firm level. In general, many firms engaged in exporting also import their intermediate inputs. In Belgium, around 80 percent of manufacturing exporters import some of their inputs. We use these import data to construct three key variables - the import intensity from outside the Euro Zone $\varphi_{f, t}$, the log change in the marginal cost $\Delta m c_{f, t}^{*}$ and the firm's market share $S_{f, s, k, t}$. Specifically,

$$
\varphi_{f, t} \equiv \frac{\text { Total non-euro import value }}{f, t},
$$

where total variable costs comprise a firm's total wage bill and total material cost. We often average this measure over time to obtain a firm-level average import intensity denoted by $\varphi_{f}$.

because its exchange rate hardly moves relative to the Euro.

${ }^{21}$ This is the typical drawback of customs data (as, for exmaple, is also the case with the French dataset used in Berman, Martin, and Mayer, 2012), where despite the richness of firm-level variables, we do not observe trade prices of individual items. As a result, there are two potential concerns: one, aggregation across heterogeneous goods even at the very fine level of disaggregation (firm-destination-CN 8-digit product code level); and, two, aggregation over time of sticky prices. This means we cannot condition our analysis on a price change of a good, as was done in Gopinath, Itskhoki, and Rigobon (2010) using BLS IPP item-level data. The BLS data, however, is limited in the available firm characteristics and hence is not suitable for our analysis. We address these two caveats by conducting a number of robustness tests and providing a cautious interpretation of our findings in Section 5. 
The change in marginal cost is defined as the log change in unit values of firm imports from all source countries weighted by respective expenditure shares:

$$
\Delta m c_{f, t}^{*} \equiv \sum_{j \in J_{f, t}} \sum_{m \in M_{f, t}} \omega_{f, j, m, t} \Delta \log U_{f, j, m, t}^{*}
$$

where $U_{f, j, m, t}^{*}$ is the euro price (unit value) of firm $f$ 's imports of intermediate good $j$ from country $m$ at time $t$, the weights $\omega_{f, j, m, t}$ are the average of period $t$ and $t-1$ shares of respective import values in the firm's total costs, and $J_{f, t}$ and $M_{f, t}$ denote the set of all imported goods and import source countries (including inside the Euro Zone) for the firm at a given time. Note that this measure of the marginal cost is still a proxy since it does not reflect the costs of domestic inputs and firm productivity. We control separately for estimated firm productivity and average firm wage rate, however, detailed data on the prices and values of domestic inputs are not available. Nonetheless, controlling for our measure of the firm-level marginal cost is a substantial improvement over previous pass-through studies that typically control only for the aggregate manufacturing wage rate or producer price level. Furthermore, our measure of marginal cost arguably captures the component of the marginal cost most sensitive to exchange rate movements.

Ideally, we would like to construct $\varphi_{f, t}$ and $\Delta m c_{f, t}^{*}$ for each of the products $i$ a firm produces; however, this measure is available only at the firm- $f$ level, which may not be the same for all of the products produced by multiproduct firms. To address this multiproduct issue, we keep only the firm's main export products, which we identify using Belgium's input-output table for the year 2005, comprising 56 IO manufacturing codes. For each firm, we identify an IO code that accounts for its largest export value over the whole sample period and keep only the CN 8-digit products within this major-IO code. The objective is to keep only the set of products for each firm that have similar production technologies. This leaves us with 60 percent of the observations but 90 percent of the value of exports. We also present results with the full set of export products and experiment with defining the major product using more disaggregated product lines, such as HS 4-digit. ${ }^{22}$ Further, it is possible that some of the firm's imports might be final goods rather than intermediate inputs. We attempt to identify imported intermediate inputs using a number of different approaches. First, we omit any import from the construction of $\varphi_{f, t}$ that is defined as a final product

\footnotetext{
${ }^{22}$ By only keeping the firm's major products, we also deal with the potential problem of including products that firms export but do not produce - a phenomenon referred to as carry-along trade (Bernard, Blanchard, Van Beveren, and Vandenbussche, 2012). As a further robustness check, in Section 4.5 we use IO tables to isolate the inputs that are used in the production of firms' major products, and only use these inputs to construct the firm's import intensity variable. See De Loecker, Goldberg, Khandelwal, and Pavcnik (2012) for an alternative structural treatment of multiproduct firms.
} 
using Broad Economic Codes (BEC). Second, we construct $\varphi_{f}$ using only the intermediate inputs for a given industry according to the IO tables.

The last key variable in our analysis is a firm's market share, which we construct as follows:

$$
S_{f, s, k, t} \equiv \frac{\text { Export value }_{f, s, k, t}}{\sum_{f^{\prime} \in F_{s, k, t}} \text { Export value }_{f^{\prime}, s, k, t}},
$$

where $s$ is the sector in which firm $f$ sells product $i$ and $F_{s, k, t}$ is the set of Belgian exporters to destination $k$, in sector $s$ at time $t$. Therefore, $S_{f, s, k, t}$ measures a Belgium firm's market share in sector $s$, export destination $k$ at time $t$ relative to all other Belgium exporters. Note that, following the theory, this measure is destination specific. The theory also suggests that the relevant measure is the firm's market share relative to all firms supplying the destination market in a given sector, including exporters from other countries as well as domestic competitors in market $k$. But, since our analysis is across Belgian exporters within sector-destinations, the competitive stance in a particular sector-destination is common for all Belgian exporters, and hence our measure of $S_{f, s, k, t}$ captures all relevant variation for our analysis (see Section 4.1). ${ }^{23}$ We define sectors at the HS 4-digit level, at which we both obtain a nontrivial distribution of market shares and avoid having too many sectordestinations served by a single firm. ${ }^{24}$

\subsection{Stylized facts about exporters and importers}

A salient pattern in our dataset is that most exporters are also importers, a pattern also present in many earlier studies cited in the introduction. As reported in Table 1, in the full sample of Belgian manufacturing firms, the fraction of firms that are either exporters or importers is $33 \%$. Out of these firms, $57 \%$ both import and export, $28 \%$ only import and $16 \%$ only export. That is, $22 \%$ of manufacturing firms in Belgium export and $78 \%$ of exporters also import. ${ }^{25}$ This high correlation between exporting and importing suggests that the

\footnotetext{
${ }^{23}$ In an extension of the theory, a multiproduct firm facing a nested-CES demand (1) sets the same markup for all its varieties within a sector, as in (11), where its markup depends on the cumulative market share of all these varieties (). Therefore, $S_{f, s, k, t}$ is indeed the appropriate measure of market power for all varieties $i$ exported by firm $f$ to destination $k$ in sector $s$ at time $t$. See Chatterjee, Dix-Carneiro, and Vichyanond (2012) for a study of pass-through of multiproduct firms under an alternative demand structure.

${ }^{24}$ The median of $S_{f, s, k, t}$ is $7.8 \%$, yet the 75 th percentile is over $40 \%$ and the export-value-weighted median is $55 \%$. $24 \%$ of $S_{f, s, k, t}$ observations are less than $1 \%$, yet these observations account for only $1.4 \%$ of export sales. $3 \%$ of $S_{f, s, k, t}$ observations are unity, yet they account for less than $2.5 \%$. Our results are robust (and, in fact, become marginally stronger) to the exclusion of observations with very small and very large market shares. We depict the cumulative distribution function of $S_{f, s, k, t}$ in Figure A1 in the appendix.

${ }^{25}$ These statistics are averaged over the sample length, but they are very stable year-to-year. In the subsample of exporters we use for our regression analysis in Section 4.2, the fraction of importing firms is somewhat higher at $85.5 \%$, reflecting the fact that data availability is slightly biased toward larger firms.
} 
Table 1: Exporter and importer incidence

\begin{tabular}{lcc}
\hline \hline & $\begin{array}{c}\text { Exporters } \\
\text { and/or importers }\end{array}$ & $\begin{array}{c}\text { All } \\
\text { exporters }\end{array}$ \\
\hline Fraction of all firms & $32.6 \%$ & $23.7 \%$ \\
of them: & $57.0 \%$ & $78.4 \%$ \\
- exporters and importers & $15.8 \%$ & $21.6 \%$ \\
- only exporters & $27.2 \%$ & - \\
- only importers & & \\
\hline \hline
\end{tabular}

Note: The data includes all manufacturing firms. The frequencies are averaged over the years 2000-2008.

selection into both activities is driven by the same firm characteristics, such as productivity, which determines the scale of operations. We show how this overlap in importing and exporting activities turns out to be important for understanding the incomplete exchange rate pass-through.

Interestingly, the data reveal a lot of heterogeneity within exporting firms, which are an already very select subsample of firms. The large differences between exporters and nonexporters are already well-known and are also prevalent in our data. The new stylized facts we highlight here are the large differences within exporters between high and low import-intensity exporting firms. We show in Table 2 that these two groups of exporting firms differ in fundamental ways. We report various firm-level characteristics for high and low import-intensity exporters, splitting exporters into two groups based on the median import intensity outside the Euro Zone $\left(\varphi_{f}\right)$ equal to $4.2 \%{ }^{26}$ For comparison, we also report the available analogous statistics for non-exporting firms with at least 5 employees.

From Table 2, we see that import-intensive exporters operate on a larger scale and are more productive. The share of imported inputs in total costs for import-intensive exporters is $37 \%$ compared to $17 \%$ for nonimport-intensive exporters, and similarly for imports sourced outside the Euro Zone it is $17 \%$ compared to $1.2 \%$. And of course, these numbers are much lower for non-exporters at $1.6 \%$ for imports outside Belgium and $0.3 \%$ for imports outside the Euro Zone. Import-intensive exporters are 2.5 times larger in employment than non-importintensive exporters and 13 times larger than non-exporters; they pay a 15 percent wage premium relative to non-import-intensive firms and a 40 percent wage premium relative to non-exporters. Similarly, import-intensive exporters have much larger total material costs, total factor productivity, and market share. These firms also export and import on a much larger scale, and are more likely to trade with more distant countries outside the Euro Zone.

\footnotetext{
${ }^{26}$ The unit of observation here is a firm-year. If we split our sample based on firm-product-destination-year (which is the unit of observation in our regression analysis), the median import intensity is higher at $8.2 \%$, however, this has no material consequences for the patterns we document in Table 2.
} 
Table 2: High- versus low-import-intensity exporters

\begin{tabular}{lccc}
\hline \hline & \multicolumn{2}{c}{ Exporters } & \\
\cline { 2 - 3 } & $\begin{array}{c}\text { Import } \\
\text { intensive }\end{array}$ & $\begin{array}{c}\text { Not import } \\
\text { intensive }\end{array}$ & Non-exporters \\
\hline Share of total imports in total cost & 0.37 & 0.17 & 0.02 \\
Share of non-Euro imports in total cost $\left(\varphi_{f}\right)$ & 0.17 & 0.01 & 0.00 \\
\hline Employment (\# full-time equiv. workers) & 270.6 & 112.2 & 20.7 \\
Average wage bill (thousands of Euros) & 48.8 & 42.3 & 34.9 \\
Material cost & 103.3 & 28.2 & 3.0 \\
Total Factor Productivity (log) & 0.33 & 0.07 & \\
\hline Total exports (manufacturing goods) & 66.5 & 14.1 & \\
- to non-Euro OECD countries & 14.4 & 2.4 & \\
Total imports (all products) & 49.3 & 6.8 & \\
- outside Euro Zone & 20.8 & 0.5 & \\
\# of import source countries & 14.4 & 6.6 & \\
\# of HS 8-digit products imported & 79.3 & 38.2 & \\
\hline \hline
\end{tabular}

Note: The exporter sub-sample is split at the median of non-Euro import intensity (share of non-Euro imports in total costs) equal to 4.2\%. The non-exporter subsample is all non-exporting manufacturing firms with 5 or more employees. Material cost, import and export values are in millions of Euros. 28\% of low import intensity firms do not import at all, and 33\% of them do not import from outside the Euro Zone. The construction of the measured TFP is described in the data appendix.

These firms import more in terms of total value, in terms of number of imported goods, and from a larger set of import source countries. These results highlight that both types of exporting firms are active in importing from a range of countries both within and outside the Euro Zone but that the two types of firms differ substantially in import intensity, consistent with the predictions of our theoretical framework.

We now provide more details on the distribution of import intensity outside the Euro Zone $\left(\varphi_{f}\right)$ among the exporting firms and its relationship with other firm-level variables. We see that the distribution of import intensity among exporters in Table 3, although somewhat skewed toward zero, has a wide support and substantial variation, which we exploit in our regression analysis in Section 4 . Over $24 \%$ of exporters do not import from outside the Euro Zone, yet they account for only $1 \%$ of Belgian manufacturing exports. For the majority of firms, the share of imported inputs in total costs ranges between 0 and 10\%, while the export-value-weighted median of import intensity is $13 \%$. At the same time, nearly $28 \%$ of export sales are generated by the firms with import intensity in excess of $30 \% .{ }^{27} \mathrm{We}$

\footnotetext{
${ }^{27}$ While the unweighted distribution (firm count) has a single peak, the export-value-weighted distribution has two peaks. This is due to the fact that one exporter with $\varphi_{f}=0.33$ accounts for almost $14 \%$ of export sales. Our results are not sensitive to the exclusion of this largest exporter, which accounts for only 134 observations out of a total of over 90,000 firm-destination-product-year observations in our sample.
} 
Table 3: Distribution of import intensity among exporters

\begin{tabular}{crrc}
\hline \hline & \# firms & $\begin{array}{r}\text { fraction } \\
\text { of firms }\end{array}$ & $\begin{array}{r}\text { fraction of } \\
\text { export value }\end{array}$ \\
\hline$\varphi_{f}=0$ & 717 & $24.9 \%$ & $1.4 \%$ \\
$0<\varphi_{f} \leq 0.1$ & 1,478 & $51.3 \%$ & $38.2 \%$ \\
$0.1<\varphi_{f} \leq 0.2$ & 348 & $12.1 \%$ & $23.8 \%$ \\
$0.2<\varphi_{f} \leq 0.3$ & 155 & $5.4 \%$ & $8.8 \%$ \\
$0.3<\varphi_{f} \leq 0.4$ & 94 & $3.3 \%$ & $23.0 \%$ \\
$\varphi_{f}>0.4$ & 89 & $3.1 \%$ & $4.9 \%$ \\
\hline \hline
\end{tabular}

Note: Import intensity, $\varphi_{f}$, is the share of imported intermediate inputs from outside the Euro Zone in the total variable cost of the firm, averaged over the sample period.

further depict the cumulative distribution function of import intensity $\varphi_{f}$ in Figure A1 in the appendix, which also provides a cumulative distribution function for our market share variable $S_{f, s, k, t}$.

Table 4 displays the correlations of import intensity with other firm-level variables in the cross-section of firms. Confirming the predictions of Section 2.3, import intensity is positively correlated with market share, as well as with firm TFP, employment, and revenues. The strongest correlate of import intensity is the total material cost of the firm, consistent with the predictions of Proposition 2. Overall, the correlations in Table 4 broadly support the various predictions of our theoretical framework. At the same time, although import intensity and market share are positively correlated with productivity and other firm performance measures, there is sufficient independent variation to enable us to distinguish between the determinants of incomplete pass-through in the following subsections.

We close this section with a brief discussion of the patterns of time-series variation in import intensity for a given firm. Import intensity appears to be a relatively stable characteristic of the firm, moving little over time and in response to exchange rate fluctuations. Specifically, the simple regression of $\varphi_{f, t}$ on firm fixed effects has an $R^{2}$ of over $85 \%$, implying that the cross-sectional variation in time-averaged firm import intensity $\varphi_{f}$ is nearly 6 times larger than the average time-series variation in $\varphi_{f, t}$ for a given firm. When we regress the change in $\varphi_{f, t}$ on firm fixed effects and the lags of the log change in firm-level importweighted exchange rates, the contemporaneous effect is significant with the semi-elasticity of only 0.057 , and with offsetting, albeit marginally significant, lag effects. That is, a $10 \%$ depreciation of the euro temporarily increases import intensity by 0.57 of a percentage point. Furthermore, we find that the firm hardly adjusts its imports on the extensive margin in response to changes in its import-weighted exchange rate. ${ }^{28}$ All of this evidence provides

\footnotetext{
${ }^{28}$ We measure the extensive margin as the change in firm imports due to adding a new variety or dropping
} 
Table 4: Correlation structure of import intensity

\begin{tabular}{lccccc}
\hline \hline & $\begin{array}{c}\text { Import } \\
\text { intensity }\end{array}$ & TFP & Revenues & Empl't & $\begin{array}{c}\text { Material } \\
\text { cost }\end{array}$ \\
\hline Market share & 0.16 & 0.20 & 0.28 & 0.25 & 0.27 \\
Material cost & 0.23 & 0.70 & 0.99 & 0.83 & \\
Employment & 0.10 & 0.60 & 0.86 & & \\
Revenues & 0.21 & 0.72 & & & \\
TFP & 0.15 & & & & \\
\hline \hline
\end{tabular}

Note: Cross-sectional correlations of firm-level variables averaged over time. Material costs, employment, revenues and TFP are in logs. Import intensity is the share of imported intermediate inputs from outside the Euro Zone in the total cost of the firm. Market share corresponds to our measure $S_{f, s, k, t}$, defined in (20), aggregated to the firm-level by averaging across sector-destination-time.

support for our assumption in Section 2 that the set of imported goods is a sunk decision at the horizons we consider, and hence the extensive margin plays a very limited role in the response of a firm's marginal cost to exchange rate movements, justifying the use of $\varphi_{f}$ as a time-invariant firm characteristic in the empirical regressions that follow.

To summarize, we find substantial variation in import intensity among exporters, and this heterogeneity follows patterns consistent with the predictions of our theoretical framework. Next, guided by the theoretical predictions, we explore the implications of this heterogeneity for the exchange rate pass-through patterns across Belgian firms.

\section{Empirical Evidence}

This section presents our main empirical results. We start by introducing and estimating our main empirical specification. We then provide nonparametric evidence and explore the forces behind our empirical results, confirming the specific mechanisms identified by the theory. We conclude with a battery of robustness tests.

\subsection{Empirical specification}

We now turn to the empirical estimation of the relationship between import intensity, market share and pass-through in the cross-section of exporters (Proposition 3). The theoretical pass-through regression equation (15) cannot be directly estimated since pass-through $\Psi_{k, i}^{*}$ is not a variable that can be observed in the data. Therefore, we step back to the decomposition of the log price change in equations (12)-(14), which we again linearize in import intensity an existing variety at $\mathrm{CN}$ 8-digit-country level. 
and market share. After replacing differentials with changes over time $\Delta$, we arrive at our main empirical specification, where we regress the annual change in log export price on the change in the log exchange rate, interacted with import intensity and market share:

$$
\Delta p_{f, i, k, t}^{*}=\left[\alpha_{s, k}+\beta \varphi_{f, t-1}+\tilde{\gamma} S_{f, s, k, t-1}\right] \Delta e_{k, t}+\left[\delta_{s, k}+b \varphi_{f, t-1}+c S_{f, s, k, t-1}\right]+\tilde{u}_{f, i, k, t},
$$

where $p_{f, i, k, t}^{*}$ is the log euro producer price to destination $k$ (as opposed to local-currency price), and an increase in the log nominal exchange rate $e_{k, t}$ corresponds to the bilateral depreciation of the euro relative to the destination- $k$ currency. ${ }^{29}$ In our analysis we estimate parameters $\beta$ and $\tilde{\gamma}$ with values averaged across sector-destinations-time. In order to keep the pool of averaged coefficients $\left(\beta_{s, k}, \gamma_{s, k}\right)$ relatively homogenous, we focus on manufacturing exports to high-income OECD countries in our benchmark specifications. The regression equation (21) is a structural relationship that emerges from the theoretical model of Section 2, and $S_{f, s, k, t-1}$ corresponds to our measure of market share defined in equation (20). Under a mild assumption that $\Delta e_{k, t}$ is uncorrelated with $\left(\varphi_{f, t-1}, S_{f, s, k, t-1}\right)$, we prove in the appendix:

Proposition 4 The OLS estimates of $\beta$ and $\tilde{\gamma}$ in (21) identify the weighted averages across sector-destination-years of $\beta_{s, k}$ and $\gamma_{s, k} \cdot \mathbf{S}_{s, k, t-1}$ respectively, where $\mathbf{S}_{s, k, t-1}$ is the sectordestination-time-specific cumulative market share of all Belgian exporters and $\left(\beta_{s, k}, \gamma_{s, k}\right)$ are the theoretical coefficient in the pass-through relationship (15).

This result shows that, despite the fact that we cannot directly estimate the theoretical regression (15), we can nonetheless identify the theoretical coefficients in the relationship between pass-through, import intensity and market share. Furthermore, it formally confirms the validity of our measure of the market share relative to other Belgian exporters.

Equation (21) is our benchmark empirical specification. Note that it is very demanding in that it requires including sector-destination dummies and their interactions with exchange rate changes at a very disaggregated level. Therefore, we start by estimating equation (21) with a common coefficient $\alpha$, and later replace sector-destination fixed effects $\delta_{s, k}$ with sectordestination-year fixed effects $\delta_{s, k, t}$ which absorb $\alpha_{s, k} \Delta e_{k, t}$. We also estimate (21) for exports to a single destination (United States) only. In our main regressions we replace $\varphi_{f, t-1}$ with a time-invariant $\varphi_{f}$ to reduce the measurement error, and also to maximize the size of the sample since some of the lagged $\varphi_{f, t-1}$ were unavailable. This has little effect on the results since, as we show, $\varphi_{f, t}$ is very persistent over time. In the main specifications we also replace

\footnotetext{
${ }^{29}$ The nominal exchange rates are average annual rates from the IMF. These are provided for each country relative to the US dollar, which we convert to be relative to the euro.
} 
$S_{f, s, k, t-1}$ with the contemporaneous $S_{f, s, k, t}$, as both give the same results. ${ }^{30}$ In the robustness section we report the estimates from the specification with the lagged $\varphi_{f, t-1}$ and $S_{f, s, k, t-1}$.

\subsection{Main empirical findings}

To explore the underlying mechanisms behind the equilibrium relationship between passthrough, import intensity, and market shares, we begin with a more simple specification and build up to the specification in equation (21). Table 5 reports the results. We include industry-destination specific effects (where industry is defined at the HS 4-digit level) to be consistent with the theory, and year effects to control for common marginal cost variation. First, in column 1, we report that at the annual horizon the unweighted average exchange rate pass-through elasticity into producer prices in our sample is 0.2 , or, equivalently, 0.8 $(=1-0.2)$ into destination prices. We refer to it as $80 \%$ pass-through.

In column 2, we include an interaction between exchange rates and a firm's import intensity. We see that the simple average coefficient reported in column 1 masks a considerable amount of heterogeneity, as firms with different import intensities have very different passthrough rates. Firms with a high share of imported inputs relative to total variable costs exhibit lower pass-through into destination-currency export prices - a 10 percentage point higher import intensity is associated with a 6 percentage point lower pass-through. A typical firm with zero import intensity has a pass-through of $87 \%(=1-0.13)$, while a firm with a $38 \%$ import intensity (in the 95th percentile of the distribution) has a pass-through of only $64 \%(=1-0.13-0.60 \cdot 0.38)$.

Next, we explore whether import intensity operates through the marginal-cost channel or through selection and the markup channel. In columns 3 and 4, we add controls for the marginal cost of the firm to see whether the effect of import intensity on pass-through persists beyond the marginal cost channel. In column 3, we control for the change in marginal $\operatorname{cost} \Delta m c_{f, t}^{*}$, measured as the import-weighted change in the firm's import prices of material inputs (see equation (19)), which is likely to be sensitive to exchange rate changes if the firm relies heavily on imported intermediate inputs. Comparing columns 2 and 3, we see that the coefficient on the import intensity interaction nearly halves in size once we control for marginal cost, dropping from 0.6 to 0.37 , but still remains strongly significant with a $t$-stat of 3.2. We confirm this finding with an alternative control for marginal cost changes, by including firm-product-year fixed effects $\left(\delta_{f, i, t}\right)$ in column 4 . In this specification, the only variation that remains is across destinations for a given firm and hence, among other

\footnotetext{
${ }^{30}$ We do not use the time-averaged market share as firms move in and out of sector-destinations over time.
} 
Table 5: Import intensity, market share, and pass-through

\begin{tabular}{lccccccc}
\hline \hline Dep. var.: $\Delta p_{f, i, k, t}^{*}$ & $(1)$ & $(2)$ & $(3)$ & $(4)$ & $(5)$ & $(6)$ & $(7)$ \\
\hline$\Delta e_{k, t}$ & $0.203^{* * *}$ & $0.127^{* * *}$ & $0.157^{* * *}$ & $0.149^{* * *}$ & $0.098^{* * *}$ & $0.057^{*}$ & - \\
& $(0.026)$ & $(0.027)$ & $(0.028)$ & $(0.037)$ & $(0.030)$ & $(0.031)$ & \\
$\Delta e_{k, t} \cdot \varphi_{f}$ & & $0.604^{* * *}$ & $0.370^{* * *}$ & $0.341^{*}$ & $0.263^{* *}$ & $0.473^{* * *}$ & $0.470^{* *}$ \\
& & $(0.112)$ & $(0.117)$ & $(0.201)$ & $(0.115)$ & $(0.104)$ & $(0.236)$ \\
$\Delta e_{k, t} \cdot S_{f, s, k, t}$ & & & & & $0.238^{* * *}$ & $0.284^{* * *}$ & $0.299^{* * *}$ \\
& & & & & $(0.060)$ & $(0.063)$ & $(0.100)$ \\
$\Delta m c_{f, t}^{*}$ & & & $0.512^{* * *}$ & & $0.506^{* * *}$ & & \\
& & & $(0.030)$ & & $(0.031)$ & & \\
\hline Fixed effects: & & & & & & & \\
$\delta_{s, k}+\delta_{t}$ & yes & yes & yes & no & yes & yes & no \\
$\delta_{s, k, t}$ & no & no & no & no & no & no & yes \\
$\delta_{f, i, t}+\delta_{k}$ & no & no & no & yes & no & no & no \\
$\#$ obs. & 93,395 & 93,395 & 93,395 & 93,395 & 93,395 & 93,395 & 93,395 \\
$R^{2}$ & 0.057 & 0.057 & 0.062 & 0.487 & 0.062 & 0.057 & 0.344 \\
\hline \hline
\end{tabular}

Note: Observations are at the firm-destination-product-year level. $\Delta$ corresponds to annual changes. Columns(2)-(3) and (5)-(7) include a control for the level of $\varphi_{f}$, and columns (5)-(7) also include a control for the level of the market share, $S_{f, s, k, t}$. Fixed effects: $\delta_{s, k}+\delta_{t}$ is the combination of sector-destination and year fixed effects; $\delta_{s, k, t}$ are sector-destination-year fixed effects; $\delta_{f, i, t}+\delta_{k}$ is the combination of firm-productyear and country fixed effects (the sector is defined at $\mathrm{HS}$-4 and the product at $\mathrm{HS}$-8-digit level). The results without the year fixed effects are almost identical. ${ }^{*},{ }^{* *}$ and ${ }^{* * *}$ correspond to $10 \%, 5 \%$ and $1 \%$ significance levels respectively. Standard errors are clustered at the country-year level, reported in brackets. Alternative clustering at the firm level and at the country-HS4-digit level yield the same conclusions.

things, controls for all components of the marginal cost of the firms. ${ }^{31}$ The coefficient on the import intensity interaction in column 4 is almost the same as that in column 3, but much less precisely estimated with a $t$-stat of 1.7 . This result is impressive, given that this specification is saturated with fixed effects, and the similarity of the results in columns 3 and 4 provides confidence in our measure of marginal cost.

The results in columns 3 and 4 suggest that, although the marginal cost is an important channel through which import intensity affects pass-through (see Proposition 2), there is still a considerable residual effect operating through the markup channel after conditioning on the marginal cost. This finding is consistent with the theoretical predictions, since import intensity correlates with market share in the cross-section of firms and market share determines the markup elasticity, causing omitted variable bias. To see this, in column 5 we augment

\footnotetext{
${ }^{31}$ Although firm-product-year fixed effects $\left(\delta_{f, i, t}\right)$ arguably provide the best possible control for marginal cost, the disadvantage of this specification is that it only exploits the variation across destinations and thus excludes all variation within industry-destinations that is the main focus of our analysis. Consequently, we cannot use our measure of market share in a specifications with $\delta_{f, i, t}$ since our market share measure only makes sense within industry-destinations, as we discuss in Section 3.1.
} 
the specification of column 3 (controlling for $\Delta m c_{f, t}^{*}$ ) with a market share interaction with the log change in exchange rate to proxy for markup elasticity, as suggested by Proposition 3. Given that we now control for both marginal cost and markup, we expect import intensity to stop having predictive power. Although the effect of import intensity does not disappear completely, the coefficient does fall in size (from 0.37 to 0.26 ) and becomes less significant. ${ }^{32}$

Finally, column 6 implements our main specification in equation (21) by including the import intensity and market share interactions, without controlling for marginal cost. Proposition 3 suggests that import intensity and market share are two prime predictors of exchange rate pass-through, and indeed we find that the two interaction terms in column 6 are strongly statistically significant. Interpreting our results quantitatively, we find that a firm with a zero import intensity and a nearly zero market share (corresponding respectively to the 5th percentiles of both distributions) has a pass-through of $94 \%(=1-0.06)$. Complete $(100 \%)$ pass-through for such firms cannot be rejected at the $95 \%$ confidence level. A hypothetical non-importing firm with a $75 \%$ market share relative to other Belgian exporters within sector-destination (corresponding to the 95th percentile of the firm-level distribution of market shares) has a pass-through of $73 \%$, that is 21 percentage points $(=0.28 \cdot 0.75)$ lower. Holding this market share constant and increasing the import intensity of the firm from zero to $38 \%$ (corresponding again to the 95 th percentile of the respective distribution) reduces the pass-through by another 18 percentage points $(=0.47 \cdot 0.38)$, to $55 \%$. Therefore, variation in import intensity and market share explains a vast range of variation in pass-through across firms. The marginal cost channel (proxied by import intensity) and the markup channel (proxied by market share) contribute roughly equally to this variation in pass-through.

Column 7 concludes this analysis by estimating our main specification (as in column 6) controlling for the industry-destination-year fixed effects $\left(\delta_{s, k, t}\right)$. Therefore, the only variation used in this estimation is within industry-destination-year, as suggested by our theory in Section 2.4. In this regression, the coefficient on the exchange rate is effectively allowed to vary at the industry-destination level (i.e., $\alpha_{s, k}$ ) but is absorbed in the fixed effects. Comparing columns 6 and 7, we see that the point estimates on the import intensity and market share barely change, and the estimates remain strongly statistically significant in column 7 despite thousands of fixed effects.

\footnotetext{
${ }^{32}$ The coefficient on $\Delta m c_{f, t}^{*}$ in both specifications of columns 3 and 5 is remarkably stable at 0.51 . The theory suggests that this coefficient should be $1 /(1+\bar{\Gamma})$, that is the average pass-through elasticity of idiosyncratic shocks into prices, corresponding to an average markup elasticity of $\bar{\Gamma} \approx 1$, close to the estimates provided in Gopinath and Itskhoki (2011) using very different data and methods.
} 


\subsection{Nonparametric Results}

Our main empirical findings in Table 5 provide strong support for the theoretical predictions developed in Section 2. However, we want to ensure that these results are smooth (e.g., not driven by outliers) and are not artifacts of the linearized specification. We re-estimate the specifications in Table 5 nonparametrically, by splitting the distribution of import intensity $\varphi_{f}$ into quartiles. Specifically, we estimate a separate pass-through coefficient for each quartile of the import intensity distribution and plot these coefficients in Figure 1. All estimated coefficients, standard errors, and $p$-values are reported in Table A1 in the appendix. The graph shows that the coefficient is estimated to be monotonically higher (thus lower passthrough) as we move from low to higher import intensity bins when we do not include both marginal cost and market share controls. The steepest line corresponds to the unconditional regression (a counterpart to column 2 of Table 5), and is somewhat flatter with controls for marginal cost (column 3), and it is much flatter after controlling jointly for the change in the marginal cost and the market share interaction (column 5). The dashed line corresponds to our main specification (column 6), which controls for both market share and import intensity, but not marginal cost, and it also exhibits a considerable slope across the import intensity bins. Furthermore, in all of these cases the difference between the pass-through coefficient in the first and fourth quartiles is significant with a $p$-value of $1 \%$, with the exception of when we control for both marginal cost and markup (market share interaction). In this case, consistent with the theory, the profile of pass-through coefficients across the bins of the import intensity distribution becomes nearly flat with the differences between the pass-through values in different bins statistically insignificant.

An alternative nonparametric specification is to divide the observations by both import intensity and market share. In Table 6, we split all firms into low and high import intensity bins at the median import intensity, and all observations into low and high market share bins depending on whether the firm-sector-destination market share is below or above the 75th percentile of the market share distribution within sector-destination. With this split roughly $50 \%$ of firm-product-destination-year observations fall within each market share bin. For each of the four bins, we estimate a simple pass-through regression of the change in producer export prices on the change in the exchange rate. Consistent with the results in column 6 of Table 5, we find that pass-through into destination-currency export prices decreases significantly either as we move toward the bin with a higher market share or toward the bin with a higher import intensity. The lowest pass-through of $66 \%(=1-0.34)$ is found for the bin with high market share and above-median import intensity, compared with the 


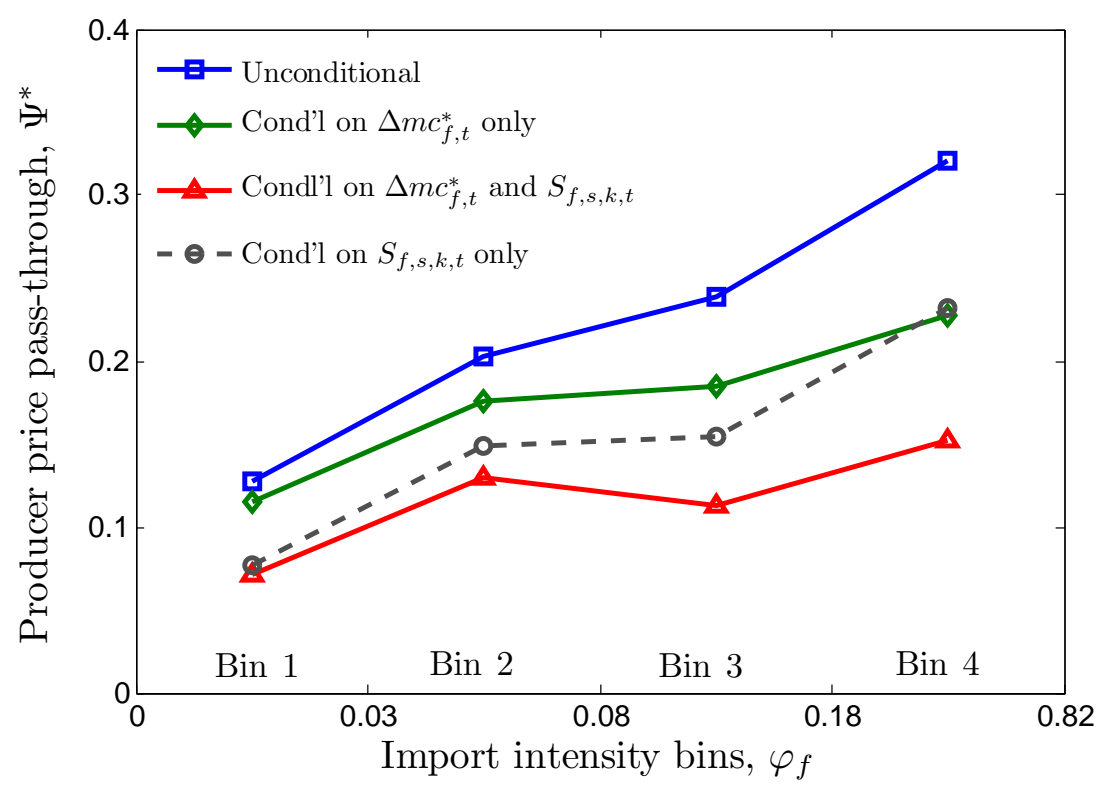

Figure 1: Pass-through by quartile of import intensity

Note: Equal-sized bins in terms of firm-product-destination-year observations, sorted by $\varphi_{f}$. The means of $\varphi_{f}$ in the four bins are 1.3\%, 5.5\%,13.1\% and 30.1\%, respectively. The figure reports pass-through coefficients of $\Delta p_{f, i, k, t}^{*}$ on $\Delta e_{k, t}$ within each $\varphi_{f}$-quartile, where the regressions include additional controls in levels and interacted with $\Delta e_{k, t}$, as indicated in the legend of the figure, to parallel columns (2)-(3) and (5)-(6) of Table 5. The pass-through coefficient in Bin 4 is significantly different from that in Bin 1 at the $1 \%$ level for all specifications except the third one (controlling for both $\Delta m c_{f, t}^{*}$ and $S_{f, s, k, t}$ ) for which it is not significant at the 5\%. Additional information is reported in Table A1 in the appendix.

pass-through of $87 \%(=1-0.13)$ for firms with below-median import intensity and low market share, quantitatively consistent with the results in Table 5 .

From Table 6, we see that there are more observations along the main diagonal (around $30 \%$ in each bin) relative to the inverse diagonal (around $20 \%$ in each bin), which is due to the positive correlation between the market share and the import intensity in the cross-section of firms. This notwithstanding, the share of export value in the first bin with both low market share and low import intensity is only $8 \%$. The fourth bin with both above-median import intensity and high market share accounts for the majority of exports, over $61 \%$. This suggests that the pass-through coefficient into destination prices from a regression weighted by their respective export values should be substantially lower than from a regression in which observations are unweighted. Indeed, when weighting by export values, we find a passthrough coefficient of $62 \%$, much lower than the $80 \%$ result in the unweighted specification (column 1 of Table 5). Our evidence further shows that part of this difference is due to greater markup variability among the large exporters, but of a quantitatively similar importance is the higher import intensity of these firms.

Finally, we explore the possibility of nonmonotonic and nonlinear effects of market share 
Table 6: Pass-through by import-intensity and market-share bins

\begin{tabular}{l|c|c}
\hline \hline & Low import intensity & High import intensity \\
\hline Low market share & $0.131^{* * *}$ & $0.194^{* * *}$ \\
Fraction of observations & $30.0 \%$ & $21.0 \%$ \\
Share in export value & $8.1 \%$ & $9.6 \%$ \\
\hline High market share & $0.214^{* * *}$ & $0.339^{* * *}$ \\
Fraction of observations & $20.0 \%$ & $29.2 \%$ \\
Share in export value & $21.3 \%$ & $61.1 \%$ \\
\hline \hline
\end{tabular}

Note: Coefficients from regression of $\Delta p_{f, i, k, t}^{*}$ on $\Delta e_{k, t}$ within respective bins without fixed effects; bin-specific intercepts included (all estimated to be close to zero). Firms are sorted by import intensity $\varphi_{f}$ into below and above median equal to $8.1 \%$; and by market share $S_{f, s, k, t}$ averaged across the years the firm served a given sector-destination into below and above the 75th percentile within each sector(HS4)-destination, which ensures a roughly even number of firm-product-destination-year observations in each high and low category. The coefficient in the high-high bin is significantly different from the other coefficients at least at a $2 \%$ level.

and import intensity on pass-through by augmenting the main specification in column 6 of Table 5 with second-order terms. We find that the coefficient on the squared market share term interacted with exchange rate is negative, but insignificant and small. Even using the point estimate, the estimated relationship between pass-through and market share remains monotonically increasing over the whole range $[0,1]$ of the market share variable, which confirms the theoretical prediction in Proposition 1. Further, although the coefficient on the interaction of import intensity with market share is positive, it is also small and insignificant. These results justify our focus on the linear specification of Table 5 (see discussion in footnote 19).

\subsection{Deciphering the mechanism}

Now that we have established that high-import-intensive firms have lower pass-through into export prices, we delve into the underlying mechanisms. According to the theory, higher import intensity is associated with higher marginal cost sensitivity to exchange rates (Proposition 2). We test this directly by regressing the change in the marginal cost $\Delta m c_{f, t}^{*}$ on the change in the destination-specific exchange rate $\Delta e_{k, t}$ and separately on the change in the firm-level import-weighted exchange rate $\Delta e_{f, t}^{M}$, within each quartile of the import-intensity distribution. ${ }^{33}$ Figure 2, which plots these coefficients, illustrates a very tight monotonically increasing pattern of marginal cost sensitivity to the destination-specific exchange rates across the bins with increasing import intensity (and columns 5 and 6 in Table A1 in the

\footnotetext{
${ }^{33}$ The import-weighted exchange rate $\Delta e_{f, t}^{M}$ is a weighted average of bilateral exchange rates with weights equal to the import expenditure shares from outside the Euro Zone at the firm level.
} 


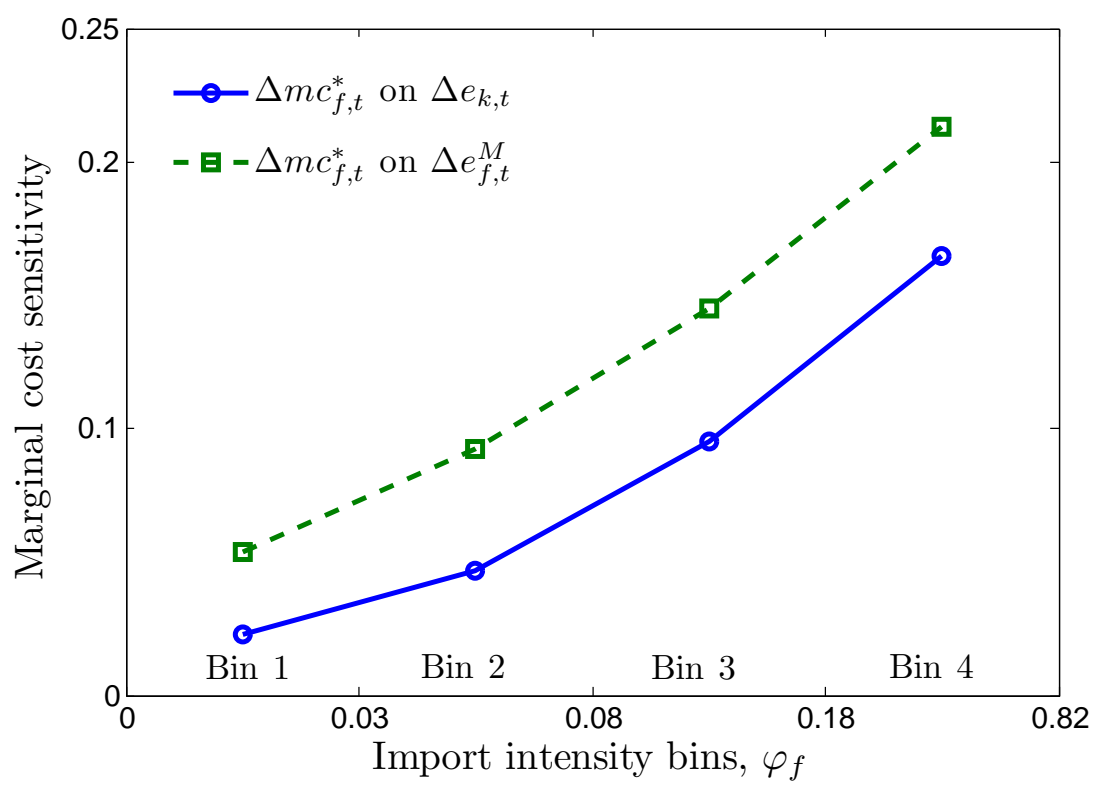

Figure 2: Marginal cost sensitivity to exchange rates

Note: The figure plots the pass-through coefficients from regressions of the log change in our measure of the marginal cost of the firm $\Delta m c_{f, t}^{*}$ on both bilateral export exchange rates $\Delta e_{k, t}$ and firm-level import-weighted exchange rate $\Delta e_{f, t}^{M}$, by quartiles of the $\varphi_{f}$-distribution (as in Figure 1). Additional information is reported in Table $A 1$ in the appendix.

appendix report additional details). Quantitatively, an increase in import intensity from 1\% on average in the first quartile to $30 \%$ on average in the fourth quartile leads to an increase in marginal cost sensitivity to the exchange rate from 0.02 to 0.17 . This variation is quantitatively consistent with the effects of import intensity on pass-through we studied earlier (see Figure 1). The response of the marginal cost to the import-weighted exchange rate is also monotonically increasing in $\varphi_{f}$ and lies strictly above the response to the destination-specific exchange rate, ranging from 0.05 to 0.21 .

The theory predicts the patterns depicted in Figure 2 hold when both the correlation between export and import-weighted exchange rates and the pass-through into import prices are positive (see equations (14) and (16)). We now provide evidence for each of these two key structural determinants of the relationship between import intensity and pass-through. Column 8 of Table A1 shows there is a positive correlation between import and export exchange rates by reporting the projection coefficients of firm-level import-weighted exchange rates $\Delta e_{f, t}^{M}$ on destination-specific exchange rates $\Delta e_{k, t}$ across the quartiles of import-intensity distribution. We find these projection coefficients to be stable at around 0.45 , with no statistically-detectable variation across bins of import intensity. Therefore, we find no systematic relationship between import intensity and the extent to which firms align their import sources and export destinations to hedge their exchange rate risks (i.e., real hedging). 
We next show the importance of this positive correlation between import and export exchange rates for exchange rate pass-through into export prices. Intuitively, we would expect the effects of import intensity to be stronger when inputs are imported from the same country to which the firm sells its products. To capture this idea systematically, we split all source-destination pairs of countries into a high and a low correlation bin depending on whether the correlation between (the annual log changes in) the two respective exchange rates is above or below 0.7. For each firm-destination we create two measures of import intensity $-\varphi_{f, k}^{\text {High }}$ and $\varphi_{f, k}^{\text {Low }}$-from high- and low-correlation source countries respectively. ${ }^{34}$ The average correlation between exchange rates in the two bins is 0.92 and 0.25 respectively, and according to the theory (see equation (16)) this difference should directly translate into the differential effect of the two import intensities on the exchange rate pass-through of the firm. This is exactly what we find in column 1 of Table 7, which estimates the augmented specification (21) splitting the firm import intensity into the two components just introduced. The estimated coefficients on the high- and low-correlation import intensity interactions are 0.86 and 0.38 respectively.

We further show that the effect of import intensity on export price pass-through is stronger the higher the exchange rate pass-through into import prices. We construct the different import intensity measures by splitting the 210 non-Euro import source countries in our sample into three groups: high pass-through, low pass-through, and other. The group of other countries contains source countries for which there are either insufficient observations or not enough variation in the exchange rate to estimate pass-through accurately. The remaining countries are assigned to the high bin if pass-through exceeds 0.5. With this procedure we have 19 countries in the high pass-through bin with average pass-through into Belgian import prices of $63 \%$ and accounting for $38 \%$ of Belgian firm imports. The low pass-through bin contains 32 countries with average pass-through of $25 \%$ and accounting for $44 \%$ of Belgian firm imports. The list of countries, their pass-through and import shares are reported in Table A3 in the appendix. We use the three corresponding import intensity variables to estimate an augmented specification (21) in column 2 of Table 7. As predicted by the theory, we find a higher coefficient, equal to 0.76 , for import intensity from highpass-through countries, while the coefficient for the low-pass-through imports is 0.35 and

\footnotetext{
${ }^{34}$ Note that our overall measure of import intensity equals $\varphi_{f} \equiv \varphi_{f, k}^{H i g h}+\varphi_{f, k}^{L o w}$ for all destinations $k$ served by firm $f$. Table A2 reports information on the pairs of high and low correlation countries. Our results are robust to the specific correlation threshold, however raising it too high (e.g., setting it at 1, which amounts to placing in the high bin only the imports from the destination country itself in most cases), leaves the high-correlation bin too thin for reliable statistical inference. With the threshold of 0.7 , imports from the high-correlation source countries account on average for $22 \%$ of the overall import intensity across firms.
} 
Table 7: Which imports matter?

\begin{tabular}{|c|c|c|c|}
\hline Dep. var.: $\Delta p_{f, i, k, t}^{*}$ & $\begin{array}{c}\text { Exchange rate } \\
\text { correlation } \\
(1)\end{array}$ & $\begin{array}{c}\text { Import } \\
\text { pass-through } \\
(2)\end{array}$ & $\begin{array}{c}\text { OECD and } \\
\text { Euro Area } \\
(3)\end{array}$ \\
\hline$\Delta e_{k, t}$ & $\begin{array}{c}0.053^{*} \\
(0.031)\end{array}$ & $\begin{array}{c}0.052 \\
(0.032)\end{array}$ & $\begin{array}{c}0.044 \\
(0.040)\end{array}$ \\
\hline$\Delta e_{k, t} \cdot \varphi_{f, k}^{H i g h}$ & $\begin{array}{l}0.864^{* * *} \\
(0.277)\end{array}$ & $\begin{array}{l}0.763^{* * *} \\
(0.239)\end{array}$ & $\begin{array}{l}0.472^{\text {*** }} \\
(0.154)\end{array}$ \\
\hline$\Delta e_{k, t} \cdot \varphi_{f, k}^{L o w}$ & $\begin{array}{l}0.376^{* * *} \\
(0.131)\end{array}$ & $\begin{array}{c}0.348 \\
(0.241)\end{array}$ & $\begin{array}{c}0.505^{* *} \\
(0.210)\end{array}$ \\
\hline$\Delta e_{k, t} \cdot \varphi_{f}^{\text {Other }}$ & - & $\begin{array}{c}0.058 \\
(0.314)\end{array}$ & $\begin{array}{c}0.057 \\
(0.126)\end{array}$ \\
\hline$\Delta e_{k, t} \cdot S_{f, s, k, t}$ & $\begin{array}{l}0.284^{* * *} \\
(0.063)\end{array}$ & $\begin{array}{c}0.285^{* * *} \\
(0.063)\end{array}$ & $\begin{array}{c}0.282^{\text {*** }} \\
(0.064)\end{array}$ \\
\hline $\begin{array}{l}\text { FE: } \delta_{s, k}+\delta_{t} \\
\# \text { obs. } \\
R^{2}\end{array}$ & $\begin{array}{c}\text { yes } \\
93,395 \\
0.058\end{array}$ & $\begin{array}{c}\text { yes } \\
93,395 \\
0.058\end{array}$ & $\begin{array}{c}\text { yes } \\
93,395 \\
0.058\end{array}$ \\
\hline
\end{tabular}

Note: Results from the augmented specification

$$
\Delta p_{f, i, k, t}^{*}=\left[\alpha+\beta^{H i g h} \varphi_{f, k}^{\text {High }}+\beta^{\text {Low }} \varphi_{f, k}^{\text {Low }}+\beta^{\text {Other }} \varphi_{f, k}^{\text {Other }}+\gamma S_{f, s, k, t}\right] \Delta e_{k, t}+\ldots+\epsilon_{f, i, k, t} .
$$

Column 1: splits imports into high and low correlation bins for each firm-destination depending on whether the correlation (based on annual log changes) between import and export exchange rate is above 0.7; de-

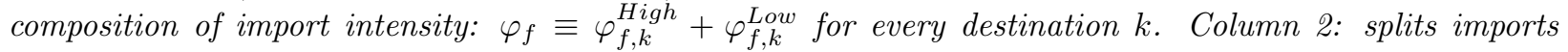
by pass-through into import prices into three bins - high (above 0.5), low (below 0.5) and other (imprecisely estimated), as explained in the text $\left(\varphi_{f} \equiv \varphi_{f}^{\text {High }}+\varphi_{f}^{\text {Low }}+\varphi_{f}^{\text {Other }}\right)$. Column 3: splits non-Euro imports into imports from high-income OECD and low-income non-OECD countries $\left(\varphi_{f} \equiv \varphi_{f}^{\text {High }}+\varphi_{f}^{\text {Low }}\right)$ and additionally includes import intensity from within the Euro Area $\left(\varphi_{f}^{\text {Other }}\right)$. All regressions additionally control for the levels of all interaction terms and include country-destination and time fixed effects. Other details as in Table 5 .

insignificant. 35

The results in columns 1 and 2 of Table 7 provide direct evidence of the theoretical mechanisms linking import intensity and exchange rate pass-through. Lastly, we ask whether there may be additional forces correlated with the firm's import intensity that could potentially confound its relationship with the exchange rate pass-through. For example, low importintensity firms tend to import relatively more imports from within the Euro Area (see Table 2). Another noticeable difference across firms is in their share of imports that comes from non-OECD countries, which tends to be substantially higher for the high-import-intensive firms. The import share from non-OECD countries in total non-Euro imports increases

\footnotetext{
${ }^{35}$ While the share of high-correlation imports is stable at around $22 \%$ across firms with different import intensity, the share of high-pass-through imports increases from $34 \%$ to $44 \%$ across import intensity quartiles, slightly reinforcing the role of import intensity in our main specification.
} 
monotonically from $25 \%$ to $45 \%$ across the quartiles of import intensity. ${ }^{36}$

Column 3 of Table 7 explores the effects of this heterogeneity by splitting the overall measure of the firm's import intensity $\varphi_{f}$ into the import intensities from the high-income OECD and low-income non-OECD countries, both outside the Euro Area, as well as additionally controlling for the import intensity from within the Euro Area (denoted with $\varphi_{f}^{\text {Other }}$ ). First, as expected, we find that import intensity from within the Euro Area has no effect on pass-through, since the prices of these imports, just like those of the Belgium inputs, are insensitive to the Euro exchange rate. This regression can be viewed as a placebo test confirming that our import intensity measure $\varphi_{f}$ indeed picks up the marginal cost sensitivity to exchange rates rather than proxying for other dimensions of heterogeneity across firms related to import intensity.

Second, surprisingly, we find no difference in the effects of import intensity from OECD and non-OECD countries, with both coefficients estimated to be around 0.5. As expected, OECD countries tend to have higher pass-through into import prices of Belgian firms: $44 \%$ on average versus $15 \%$ on average from non-OECD countries, though there is significant variation within these groups as reflected in Table A3. However, the effects of these import pass-through differences are counterbalanced by the correlation pattern between import and export exchange rates. Indeed, almost all source countries in the high-correlation pairs with destination countries are non-OECD, which is to a large extent driven by the full or partial exchange rate pegs adopted by many non-OECD countries. Overall, we find that the composition of imports from OECD versus non-OECD countries has no detectable effect on the export pass-through of Belgian firms. ${ }^{37}$

To summarize, the data strongly supports the specific mechanisms identified by the theory, and we find no evidence that our import intensity measure proxies for other mechanisms or variables that may affect pass-through.

\footnotetext{
${ }^{36}$ Both patterns are consistent with the presence of a fixed cost of importing which increases with the geographic and economic distance to the source country, making it worthwhile only for the largest importers to source inputs from the distant origin countries.

${ }^{37}$ The other two possibilities we explored were whether pass-through into import prices of Belgian firms varies by the type of the product imported (manufactured or not) and/or by the type (size) of the importing firm. Although the share of manufactured products in imports decreases from $95 \%$ to $86 \%$ across the quartiles of import intensity, we find no systematic difference in pass-through for manufacturing and nonmanufacturing imports, once we control for the source country of imports. Similarly, controlling for the source country, we find no systematic difference in import pass-through between small and large firms. Section 4.5 presents further robustness tests controlling for the size of the firm and types of imported inputs.
} 


\subsection{Robustness}

In this section, we consider three sets of robustness tests: including additional controls, considering alternative definitions of import intensity, and using alternative samples in terms of included destinations, firms and products. We conclude the section by a discussion of the possible selection and measurement issues.

Additional controls Our theory provides a sharp prediction that firm import intensity and market share form a sufficient statistic for pass-through. We test this prediction by augmenting our main empirical specification (from column 6 of Table 5) with alternative proxies for markup and marginal cost variability such as firm employment size and measured TFP. ${ }^{38}$ The results reported in columns 1 and 2 of Table 8 show that our empirical findings are robust to the inclusion of these additional interaction terms. Controlling for employment and TFP interactions reduces slightly the estimated coefficients on import intensity and market share interactions, but they remain large and strongly statistically significant. The coefficients on employment and TFP interactions, although significant, are in turn quantitatively moderate. Column 3 of Table 8 augments the specification in column 2 by controlling for the local component of the marginal cost — proxied by the log changes in the measure of the firm-level wage rate and the firm TFP - to isolate the effect of import intensity through the foreign-sourced component of the marginal cost of the firm. These controls have essentially no effect on the estimated coefficients of interest.

\section{Alternative definitions of import intensity To ensure that the results are not sensitive} to our definition of $\varphi_{f}$, we experimented extensively with alternative definitions. We report these robustness checks in Table A4 in the appendix, where we estimate our main empirical specification using different definitions of import intensity. First, in column 1, we verify that our results are unchanged when as in specification (21) we use lagged time-varying $\varphi_{f, t-1}$ and $S_{f, s, k, t-1}$, as suggested by Proposition 4, instead of $\varphi_{f}$ and $S_{f, s, k, t}$ respectively. Remarkably, the estimated coefficients are virtually the same as in Table 5.

Next, in column 2 of Table A4 we include only manufacturing products in the construction

\footnotetext{
${ }^{38}$ In theories where productivity is the only source of heterogeneity, market share, employment, and productivity itself are all perfectly correlated. However, when there is more than one source of heterogeneity, these variables are correlated positively but imperfectly (as we document in Table 4), which allows us to jointly include these variables in one specification. Berman, Martin, and Mayer (2012) emphasized firm productivity as the sufficient statistic for markup variability, and specifications in Table 8 are counterparts to some of their regressions with the exception that we include both the import intensity and market share interactions. Overall, our empirical results are consistent with their findings in that more productive firms have lower pass-through, but we split this effect into the markup and marginal cost channels by controlling separately for market share and import intensity, and show that these two controls are at least as strong as employment and productivity, consistent with our theoretical model.
} 
Table 8: Robustness with additional controls

\begin{tabular}{lccc}
\hline \hline Dep. var.: $\Delta p_{f, i, k, t}^{*}$ & $(1)$ & $(2)$ & $(3)$ \\
\hline$\Delta e_{k, t} \cdot \varphi_{f}$ & $0.413^{* * *}$ & $0.433^{* * *}$ & $0.418^{* * *}$ \\
& $(0.106)$ & $(0.109)$ & $(0.119)$ \\
$\Delta e_{k, t} \cdot S_{f, s, k, t}$ & $0.219^{* * *}$ & $0.249^{* * *}$ & $0.245^{* * *}$ \\
& $(0.065)$ & $(0.064)$ & $(0.065)$ \\
$\Delta e_{k, t} \cdot \log L_{f, t}$ & $0.044^{* * *}$ & & \\
& $(0.012)$ & & \\
$\Delta e_{k, t} \cdot \log T F P_{f, t}$ & & $0.070^{* * *}$ & $0.080^{* * *}$ \\
& & $(0.023)$ & $(0.024)$ \\
$\Delta \log W_{f, t}^{*}$ & & & $0.004^{*}$ \\
& & & $(0.002)$ \\
$\Delta \log T F P_{f, t}$ & & & $0.035^{* * *}$ \\
& & & $(0.007)$ \\
\hline FE: $\delta_{s, k}+\delta_{t}$ & yes & yes & yes \\
$\#$ obs. & 92,576 & 92,106 & 87,608 \\
$R^{2}$ & 0.058 & 0.058 & 0.061 \\
\hline \hline
\end{tabular}

Note: The same specification as in column 6 of Table 5, augmented with additional controls. $L_{f, t}$ is firm employment, $W_{f, t}^{*}$ is firm average wage rate, and $T F P_{f, t}$ is the estimate of firm total factor productivity.

of the import intensity variable. In columns 3 and 4, we respectively restrict the definition of imports to exclude consumer goods and capital goods. In the subsequent columns, we use IO tables to identify a firm's intermediate inputs. In column 5, we include only imports identified as intermediate inputs in the IO tables for all of the firm's exports, and in column 6 we only include IO inputs for a firm's IO major exports. Finally, in column 7, we exclude any import at the CN-8-digit industrial code if the firm simultaneously exports in this category. In all cases, the results are essentially unchanged, except that in the last case the coefficient on the import intensity substantially increases, but it should be noted that the average import intensities here are much lower as we drop a large share of imports from the import intensity calculation.

Alternative samples We further check the robustness of our results within alternative subsamples of the dataset, both in the coverage of export destinations and in the types of products and firms. Table A5 in the appendix reports the results in eight alternative subsamples. By and large, it reveals the same qualitative and quantitative patterns we find in our benchmark sample.

Columns 1-3 of Table A5 report the results for three alternative sets of export destinationsall non-Euro countries, non-Euro OECD countries excluding the US, and the US only. It is 
noteworthy that for the US subsample we estimate both a lower baseline pass-through (for firms with zero import intensity and market share) and a stronger effect of import intensity on pass-through, than for other countries. ${ }^{39}$ Our analysis in Section 4.4 suggests that the larger effect of import intensity on pass-through into export price to the US is at least in part due to the stronger correlation between the euro-dollar exchange rate and a typical Belgian firm's import-weighted exchange rate (see Table A2).

The remaining columns in Table A5 consider different sets of products and firms. So far, all of the specifications have been restricted to the subsample of only manufacturing firms because our $\varphi_{f}$ measure is likely to be a better proxy of import intensity in manufacturing than for wholesalers, who may purchase final goods within Belgium to export them or alternatively import final goods for distribution within Belgium. In column 4, which adds in all wholesale firms to our baseline sample, we see that although the import intensity and market share interactions are still positive and significant, their magnitudes and $t$-stats are smaller. The wholesalers represent around 40 percent of the combined sample. Next, in column 5, we drop all intra-firm transactions from our baseline sample (around 15 percent of observations), and this has little effect on the estimated coefficients. ${ }^{40}$

Finally, our sample has included only the firm's major export products, based on its largest IO code, in order to address the issue of multiproduct firms. In columns 6-8, we show that the results are not sensitive to this choice of "main products". In column 6, we include all of the firm's manufacturing exports rather than restricting it only to IO major products. In column 7, we adopt an alternative way to identify a firm's major products, using the HS 4-digit category, which is much more disaggregated than the IO categories. And in column 8, we only include a firm if its HS 4-digit major category accounts for at least 50 percent of its total exports. In all three cases, we find the magnitudes on the import intensity and market share interactions are very close to our main specification.

Measurement and selection We conclude the empirical section with a brief discussion of measurement error and selection bias. One concern is that some firms, particularly small ones, may import their intermediate inputs through other Belgian firms (e.g., specialized importers), which we cannot observe in our data, and hence cannot adjust accordingly our

\footnotetext{
${ }^{39}$ Specifically, small non-importing firms exporting to the US market pass-through on average only $82 \%$ of the euro-dollar exchange rate changes, while the firms with high import-intensity and high market share (at the 95 th percentile) pass-through only $33 \%$. This low pass-through is consistent with previous work using US data.

${ }^{40}$ Using data from the Belgium National Bank, we classify intra-firm trade as any export transaction from a Belgium firm to country $k$ in which there is either inward or outward foreign direct investment to or from that country.
} 
measure of import intensity. Note, however, that this would work against our findings since some of the fundamentally import-intensive firms would be wrongly classified into low import-intensity. This measurement error should cause an upward bias in the estimate of our baseline pass-through (coefficient $\alpha$ in (21)) and a downward bias in our estimate of the import-intensity effect on pass-through (coefficient $\beta$ ), which we find to be large nonetheless. Similarly, we expect the measurement error in import intensity for multiproduct firms to work against our findings. The measurement error for the market share variable is likely to have classical properties, and hence we expect to have a downward bias in the estimates of coefficient $\gamma$ as well.

Further, in the appendix we provide a formal theoretical argument that sample selection is also likely to lead to an upward bias in the estimates of $\alpha$ and a downward bias in the estimates of $\beta$ and $\gamma$, as well as provide corroborating empirical evidence. Intuitively, the firms that drop out from the sample in response to an exchange rate appreciation $\left(\Delta e_{k, t}<0\right)$ are more likely to be the ones simultaneously hit by an adverse marginal cost shock (e.g., negative productivity shock), and hence desiring to raise prices more than firms staying in the sample. Censoring of these firms from the sample leads to an upward bias in $\alpha$. Since the

probability of exit decreases with import intensity and market share (proxying for firm's profitability), we expect this upward bias to be less severe for firms with high import intensity and high market shares, in other words a more shallow relationship between these variables and pass-through. To summarize, this analysis suggests that both measurement and selection issues are likely to lead us to estimate lower bounds on both $\beta$ and $\gamma$, and hence our quantitative account of the variation in pass-through should be viewed as conservative.

\section{Conclusion}

In this paper, we show that taking into account that the largest exporting firms are also the largest importers is key to understanding the low aggregate exchange rate pass-through and the variation in pass-through across firms. We find that import intensity affects passthrough both directly, by inducing an offsetting change in the marginal cost when exchange rates change, and indirectly, through selection into importing of the largest exporters with the most variable markups. We use firms' import intensities and export market shares as proxies for the marginal cost and markup channels, respectively, and show that variation in these variables across firms explains a substantial range of variation in pass-through. A small firm using no imported intermediate inputs has a nearly complete pass-through, while a firm at the 95th percentile of both market share and import intensity distributions has a pass- 
through of just over 50\%. Around half of this incomplete pass-through is due to the marginal cost channel, as captured by our import intensity measure. Since import intensity is heavily skewed toward the largest exporters, our findings help explain the observed low aggregate pass-through elasticities, which play a central role in the study of exchange rate disconnect. Finally, we show that the patterns we document emerge naturally in a theoretical framework, which combines standard ingredients of oligopolistic competition and variable markups with endogenous selection into importing at the firm level.

Our findings suggest that the marginal cost channel contributes substantially -reinforcing and amplifying the markup channel - to low aggregate pass-through and pass-through variation across firms. The decomposition of incomplete pass-through into its marginal cost and markup components is necessary for the analysis of the welfare consequences of exchange rate volatility (as emphasized by Burstein and Jaimovich, 2008) and the desirability to fix exchange rates, for example, by means of integration into a currency union. Furthermore, price sensitivity to exchange rates is central to the expenditure switching mechanism at the core of international adjustment and rebalancing. A sign of inefficiency is when exchange rate movements affect mostly the distribution of markups across exporters from different countries, leading to little expenditure switching. However, if the lack of pass-through is largely due to the complex international web of intermediate input sourcing, incomplete pass through of exchange rates into prices may well be an efficient response. A complete analysis of the welfare consequences requires a general equilibrium model disciplined with the evidence on the importance of marginal cost and markup channels of the type we provide, and we leave this important question for future research.

Even after controlling for the marginal cost channel, our evidence still assigns an important role for the markup channel of incomplete pass-through. In particular, we find that large high-market-share firms adjust their markups by more in response to cost shocks. This is consistent with a model in which larger firms also choose higher levels of markups, a pattern that can rationalize the evidence on misallocation of resources across firms, as, for example, documented in Hsieh and Klenow (2009). The markup interpretation of this evidence on misallocation differs from the cost-side frictions interpretation conventional in the literature (an exception is Peters, 2011). Our evidence, therefore, is useful for calibration and quantitative assessment of the models of misallocation at the firm-level.

Finally, we briefly comment on the interpretation of our results in an environment with sticky prices, where exporters choose to fix their prices temporarily either in local or in producer currency. Since we cannot condition our empirical analysis on a price change or split the sample by currency of pricing, our results confound together the change in the desired 
markup with the mechanical changes in markup induced by the exchange rate movements when prices are sticky in a given currency. Therefore, one should keep in mind that our results suggest that import intensity and market share contribute either to flexible-price pass-through incompleteness or to the probability of local currency pricing, which in turn leads to low pass-through before prices adjust. In reality, our results are likely to be driven partly by both these sources of incomplete pass-through. ${ }^{41}$ Indeed, Gopinath, Itskhoki, and Rigobon (2010) show that the two share the same primitive determinants and provide evidence that the choice to price in local currency is closely correlated in the cross-section of firms with the pass-through incompleteness conditional on price adjustment. Nonetheless, we favor the flexible-price interpretation of our results, as we focus on a relatively long horizon using annual data.

\footnotetext{
${ }^{41}$ Our data do not allow us to do a decomposition into these two sources, but one can make such inference by taking a stand on a particular structural model of incomplete pass-through with sticky prices, and using outside information to calibrate its parameters related to price stickiness and currency of pricing. We do not attempt this exercise in the current paper.
} 


\section{References}

(2006): "Distribution Margins, Imported Inputs, and the Sensitivity of the CPI to Exchange Rates," Federal Reserve Bank of New York.

AckerberG, D., K. Caves, and G. Frazer (2006): "Structural identification of production functions," http://www.econ.ucla.edu/ackerber/.

Alessandria, G. (2004): "International Deviations From The Law Of One Price: The Role Of Search Frictions And Market Share," International Economic Review, 45(4), 1263-1291.

Amiti, M., And D. R. DAvis (2012): "Trade, Firms, and Wages: Theory and Evidence," Review of Economic Studies, 79(1), 1-36.

Amiti, M., And J. Konings (2007): "Trade liberalization, intermediate inputs, and productivity: Evidence from Indonesia," American Economic Review, 97(5), 1611-1638.

Atkeson, A., and A. Burstein (2008): "Trade Costs, Pricing-to-Market, and International Relative Prices," American Economic Review, 98(5), 1998-2031.

Auer, R. A., And R. S. Schoenle (2012): "Market Structure and Exchange Rate PassThrough," http://people.brandeis.edu/ schoenle/research.htm.

Berman, N., P. Martin, and T. Mayer (2012): "How do different exporters react to exchange rate changes?," Quarterly Journal of Economics, 127(1), 437-492.

Bernard, A. B., E. J. Blanchard, I. Van Beveren, and H. Y. Vandenbussche (2012): "Carry-Along Trade," NBER Working Papers No. 18246.

Bernard, A. B., J. B. Jensen, and P. K. Schott (2009): "Importers, Exporters and Multinationals: A Portrait of Firms in the U.S. that Trade Goods," in Producer Dynamics: New Evidence from Micro Data, pp. 513-552. National Bureau of Economic Research.

Blaum, J., C. Lelarge, and M. Peters (2013): "Non-Homothetic Import Demand: Firm Productivity and Quality Bias," http://www.econ.brown.edu/fac/joaquin_blaum/.

Burstein, A., And G. Gopinath (2012): "International Prices and Exchange Rates," in Handbook of International Economics, ed. by G. Gopinath, E. Helpman, and K. Rogoff, vol. IV. forthcoming.

Burstein, A., And N. Jaimovich (2008): "Understanding Movements in Aggregate and Product-level Real Exchange rates," http://econ.as.nyu.edu/docs/I0/8836/ productRER.pdf.

Burstein, A. T., J. C. Neves, and S. Rebelo (2003): "Distribution costs and real exchange rate dynamics during exchange-rate-based stabilizations," Journal of Monetary Economics, 50(6), 1189-1214.

Chatterjee, A., R. Dix-Carneiro, and J. Vichyanond (2012): "Multi-Product Firms and Exchange Rate Fluctuations," American Economic Journal: Economic Policy, forthcoming.

Damijan, J. P., J. Konings, and S. Polanec (2012): "Import Churning and Export Performance of Multi-Product Firms," LICOS Discussion Paper 307.

De Loecker, J., P. K. Goldberg, A. K. Khandelwal, and N. Pavcnik (2012): 
"Prices, Markups and Trade Reform," NBER Working Paper No. 17925.

Engel, C. (2001): "The Six Major Puzzles in International Macroeconomics: Is There a Common Cause?: Comment," in NBER Macroeconomics Annual 2000, vol. 15, pp. 403411.

(2003): "Expenditure Switching and Exchange Rate Policy," in NBER Macroeconomics Annual 2002, vol. 17, pp. 231-272.

Fauceglia, D., A. Shingal, and M. Wermelinger (2012): “'Natural hedging' of exchange rate risk: The role of imported input prices," http://www.alexandria.unisg . ch/publications/citation/Martin_Wermelinger/.

Feenstra, R. C., J. E. Gagnon, and M. M. Knetter (1996): "Market share and exchange rate pass-through in world automobile trade," Journal of International Economics, 40(1-2), 187-207.

Feng, L., Z. Li, And D. L. Swenson (2012): "The Connection between Imported Intermediate Inputs and Exports: Evidence from Chinese Firms," NBER Working Paper No. 18260.

Fitzgerald, D., And S. Haller (2012): "Pricing-to-Market: Evidence From Plant-Level Prices," Working Paper, Stanford University.

Froot, K. A., D. S. Scharfatein, and J. C. Stein (1993): "Risk Management: Coordinating Corporate Investment and Financing Policies," Journal of Finance, 48(5), 1629-58.

Garetto, S. (2012): "Firms' Heterogeneity and Incomplete Pass-Through," http:// people.bu.edu/garettos/research.html.

GoldberG, L., And J. CAmpa (2010): "The Sensitivity of the CPI to Exchange Rates: Distribution Margins, Imported Inputs, and Trade Exposure," Review of Economics and Statistics, 92(2), 392-407.

Goldberg, P., and M. Knetter (1997): "Goods Prices and Exchange Rates: What Have We Learned?," Journal of Economic Literature, 35(3), 1243-1272.

Goldberg, P. K., and R. Hellerstein (2008): "A Structural Approach to Explaining Incomplete Exchange-Rate Pass-Through and Pricing-to-Market," American Economic Review, 98(2), 423-29.

(2011): "A Structural Approach to Identifying the Sources of Local-Currency Price Stability," Review of Economic Studies, forthcoming.

GoldberG, P. K., And F. Verboven (2001): "The Evolution of Price Dispersion in the European Car Market," Review of Economic Studies, 68(4), 811-48.

Gopinath, G., And O. Itskhoki (2010): "Frequency of Price Adjustment and Passthrough," Quarterly Journal of Economics, 125(2), 675-727.

(2011): "In Search of Real Rigdities," in NBER Macroeconomics Annual 2010, vol. 25, pp. 261-310.

Gopinath, G., O. Itskhoki, and R. Rigobon (2010): "Currency Choice and Exchange Rate Pass-through," American Economic Review, 100(1), 306-336.

Gopinath, G., And B. Neiman (2012): "Trade Adjustment and Productivity in Large 
Crises," http://faculty.chicagobooth.edu/brent.neiman/research/.

Gopinath, G., And R. Rigobon (2008): "Sticky Borders," Quarterly Journal of Economics, 123(2), 531-575.

Halpern, L., M. Koren, and A. Szeidl (2011): "Imported Inputs and Productivity," http://miklos.koren.hu/view/kmwprs/32/.

Hsien, C.-T., And P. Klenow (2009): "Misallocation and Manufacturing TFP in China and India," The Quarterly Journal of Economics, 124(4), 1403-1448.

Kugler, M., And E. Verhoogen (2009): "Plants and Imported Inputs: New Facts and an Interpretation," American Economic Review Papers and Proceedings, 99(2), 501-507.

Levinsohn, J., And A. Petrin (2003): "Estimating production functions using inputs to control for unobservables," Review of Economic Studies, 70(2), 317-342.

Manova, K., And Z. Zhang (2009): "China's Exporters and Importers: Firms, Products and Trade Partners," NBER Working Paper No. 15249.

Martin, J., And I. MÉJeAn (2012): "Invoicing Currency, Firm Size, and Hedging," http: //www. isabellemejean.com/publications.html.

Melitz, M. J. (2003): "The Impact of Trade on Intra-Industry Reallocations and Aggregate Industry Productivity," Econometrica, 71(6), 1695-1725.

NAKAmurA, E., And D. Zerom (2010): "Accounting for Incomplete Pass-through," Review of Economic Studies, 77(3), 1192-1230.

Obstfeld, M., and K. Rogoff (2001): "The Six Major Puzzles in International Macroeconomics: Is There a Common Cause?," in NBER Macroeconomics Annual 2000, vol. 15, pp. 339-390.

Olley, G. S., And A. PAKes (1996): "The dynamics of productivity in the telecommunications equipment industry," Econometrica, 64, 1263-1297.

Peters, M. (2011): "Heterogeneous Mark-Ups and Endogenous Misallocation," http:// economics.mit.edu/grad/mipeters/papers.

Pierce, J. R., And P. K. SchotT (2012): "On estimating firm-level production functions using proxy variables to control for unobservables," Journal of Economic and Social Measurement, forthcoming.

WoOldRIDGE, J. (2009): "On estimating firm-level production functions using proxy variables to control for unobservables," Economics Letters, 104, 112-114. 


\section{A Online Appendix}

\section{A.1 Theoretical Appendix}

\section{A.1.1 Cost function and import intensity}

For brevity, we drop the firm identifier $i$ in this derivation. Given output $Y$ and the set of imported intermediate goods $J_{0}$, the objective of the firm is

$$
T C^{*}\left(Y \mid J_{0}\right) \equiv \min _{L, X,\left\{X_{j}, Z_{j}\right\},\left\{M_{j}\right\}}\left\{W^{*} L+\int_{0}^{1} V_{j}^{*} Z_{j} \mathrm{~d} j+\int_{J_{0}}\left(\mathcal{E}_{m} U_{j} M_{j}+W^{*} f\right) \mathrm{d} j\right\},
$$

Denote by $\lambda, \psi$ and $\chi$ the Lagrange multiplier on constraints (5), (6) and (7) respectively. The first order conditions of cost minimization are respectively:

$$
\begin{aligned}
W^{*} & =\lambda(1-\phi) Y / L, & & \\
\psi & =\lambda \phi Y / X, & & \\
\chi & =\psi \gamma_{j} X / X_{j}, & & j \in[0,1], \\
V_{j}^{*} & =\chi\left(X_{j} / Z_{j}\right)^{1 /(1+\zeta)}, & & j \in[0,1], \\
\mathcal{E}_{m} U_{j} & =\chi\left(a_{j} X_{j} / M_{j}\right)^{1 /(1+\zeta)}, & & j \in J_{0},
\end{aligned}
$$

with $M_{j}=0$ and $X_{j}=Z_{j}$ for $j \in \tilde{J}_{0} \equiv[0,1] \backslash J_{0}$. Expressing out $\psi$ and $\chi$, taking the ratio of the last two conditions and rearranging, we can rewrite:

$$
\begin{aligned}
W^{*} L & =\lambda(1-\phi) Y, \\
V_{j}^{*} X_{j} & =\lambda \phi \gamma_{j} Y\left(X_{j} / Z_{j}\right)^{1 /(1+\zeta)}, \quad j \in[0,1], \\
\frac{\mathcal{E}_{m} U_{j} M_{j}}{V_{j}^{*} Z_{j}} & =a_{j}\left(\frac{\mathcal{E}_{m} U_{j}}{V_{j}^{*}}\right)^{-\zeta}, \quad j \in J_{0} .
\end{aligned}
$$

Substituting the last expression into (7), we obtain $X_{j}=Z_{j}\left[1+a_{j}\left(\mathcal{E}_{m} U_{j} / V_{j}^{*}\right)^{-\zeta}\right]^{\frac{1+\zeta}{\zeta}}$ for $j \in J_{0}$, which together with the expression for $V_{j}^{*} X_{j}$ above yields:

$$
V_{j}^{*} X_{j}= \begin{cases}\lambda \phi \gamma_{j} Y b_{j}, & j \in J_{0} \\ \lambda \phi \gamma_{j} Y, & j \in \tilde{J}_{0}\end{cases}
$$

where

$$
b_{j} \equiv\left[1+a_{j}\left(\mathcal{E}_{m} U_{j} / V_{j}^{*}\right)^{-\zeta}\right]^{1 / \zeta} .
$$

Based on this, we express $L$ and $X_{j}$ for all $j \in[0,1]$ as functions of $\lambda Y$ and parameters. Substituting these expressions into (5)-(6), we solve for

$$
\lambda=\frac{1}{\Omega}\left(\frac{\exp \left\{\int_{0}^{1} \gamma_{j} \log \left(\frac{V_{j}^{*}}{\gamma_{j}}\right) \mathrm{d} j\right\}}{\phi \exp \left\{\int_{J_{0}} \gamma_{j} \log b_{j} \mathrm{~d} j\right\}}\right)^{\phi}\left(\frac{W^{*}}{1-\phi}\right)^{1-\phi}=\frac{C^{*}}{B^{\phi} \Omega},
$$


where

$$
B=\exp \left\{\int_{J_{0}} \gamma_{j} \log b_{j} \mathrm{~d} j\right\}
$$

and $C^{*}$ is defined in footnote 13. Finally, we substitute the expression for $W^{*} L, V_{j}^{*} Z_{j}=$ $V_{j}^{*} X_{j} \cdot\left(Z_{j} / X_{j}\right)$ and $\mathcal{E}_{m} U_{j} M_{j}=V_{j}^{*} Z_{j} \cdot\left(\mathcal{E}_{m} U_{j} M_{j} /\left(V_{j}^{*} Z_{j}\right)\right)$ into the cost function to obtain

$$
T C^{*}\left(Y ; J_{0}\right)=\lambda Y+\int_{J_{0}} W^{*} f \mathrm{~d} j
$$

Choice of $J_{0}$ without uncertainty solves $\min _{J_{0}} T C^{*}\left(Y \mid J_{0}\right)$, given output $Y$. Consider adding an additional variety $j_{0} \notin J_{0}$ to the set $J_{0}$. The net change in the total cost from this is given by

$$
Y \frac{\partial \lambda}{\partial B} B \gamma_{j_{0}} \log b_{j_{0}}+W^{*} f=-\phi \lambda Y \cdot \gamma_{j_{0}} \log b_{j_{0}}+W^{*} f,
$$

since $\gamma_{j_{0}} \log b_{j_{0}}$ is the increase in $\log B$ from adding $j_{0}$ to the set of imports $J_{0}$. Note that $\phi \lambda Y=\int_{0}^{1} V_{j}^{*} Z_{j} \mathrm{~d} j+\int_{J_{0}} \mathcal{E}_{m} U_{j} M_{j} \mathrm{~d} j$ is the total material cost of the firm.

Therefore, the optimal choice of $J_{0}$ must satisfy the following fixed point:

$$
J_{0}=\left\{j \in[0,1]: \phi \frac{C^{*} / \Omega}{\exp \left\{\phi \int_{J_{0}} \gamma_{\ell} \log b_{\ell} \mathrm{d} \ell\right\}} Y \cdot \gamma_{j} \log b_{j} \geq W^{*} f\right\} .
$$

This immediately implies that once $j$ 's are sorted such that $\gamma_{j} \log b_{j}$ is decreasing in $j$, the set of imported inputs is an interval $J_{0}=\left[0, j_{0}\right]$ for some $j_{0} \in[0,1]$. Furthermore, the condition for $j_{0}$ can be written as:

$$
j_{0}=\max \left\{j \in[0,1]: \phi \frac{C^{*} / \Omega}{\exp \left\{\phi \int_{0}^{j} \gamma_{\ell} \log b_{\ell} \mathrm{d} \ell\right\}} Y \cdot \gamma_{j} \log b_{j} \geq W^{*} f\right\},
$$

and such $j_{0}$ is unique since the LHS of the inequality is decreasing in $j$. Figure A2 provides an illustration.

Proof of Proposition 2 The fraction of variable cost spent on imports is given by

$$
\varphi=\frac{\int_{J_{0}} \mathcal{E}_{m} U_{j} M_{j} \mathrm{~d} j}{\lambda Y}=\int_{J_{0}} \gamma_{j}\left(1-b_{j}^{\zeta}\right) \mathrm{d} j
$$

where we used the first order conditions from the cost minimization above to substitute in for $\mathcal{E}_{m} U_{j} M_{j}$. Note that $\varphi$ increases in $J_{0}$, and in particular when $J_{0}=\left[0, j_{0}\right], \varphi$ increases in $j_{0}$. Therefore, from (A5) it follows that $\varphi$ increases in total material cost $T M C=\phi \lambda Y=$ $\phi\left[C^{*} Y\right] /\left[B^{\phi} \Omega\right]$ and decreases in fixed cost $W^{*} f$.

From the definition of total cost (A4), holding $J_{0}$ constant, the marginal cost equals 
$M C^{*}\left(J_{0}\right)=\lambda$ defined in (A2). We have:

$$
\frac{\partial \log M C^{*}\left(J_{0}\right)}{\partial \log \mathcal{E}_{m}}=\frac{\partial \log \lambda}{\partial \log B} \frac{\partial \log B}{\partial \log \mathcal{E}_{m}}=-\phi \cdot \int_{J_{0}} \gamma_{j} \frac{\partial \log b_{j}}{\partial \log \mathcal{E}_{m}} \mathrm{~d} j=\varphi,
$$

since from $(\mathrm{A} 1) \partial \log b_{j} / \partial \log \mathcal{E}_{m}=-\left(1-b_{j}^{\zeta}\right)$.

\section{A.1.2 Price setting and ex ante choice of $J_{0}$}

Under the assumption that $J_{0}$ is a sunk decision chosen before uncertainty is realized, we can write the full problem of the firm (bringing back the firm identifier $i$ ) as:

$$
\max _{J_{0, i}} \mathbb{E}\left\{\max _{Y_{i},\left(P_{k, i}, Q_{k, i}\right)}\left\{\sum_{k \in K_{i}} \mathcal{E}_{k} P_{k, i} Q_{k, i}-T C_{i}^{*}\left(Y_{i} \mid J_{0, i}\right)\right\}\right\},
$$

subject to $Y_{i}=\sum_{k \in K_{i}} Q_{k, i}$, with $\left(P_{k, i}, Q_{k, i}\right)$ satisfying demand (1) in each market $k \in K_{i}$, and total cost given in (A4). We assume that $J_{0, i}$ is chosen just prior to the realization of uncertainty about aggregate variables, and for simplicity we omit a stochastic discount factor which can be added without any conceptual complications.

Substituting the constraints into the maximization problem and taking the first order condition (with respect to $P_{k, i}$ ), we obtain:

$$
\mathcal{E}_{k} Q_{k, i}+\mathcal{E}_{k} P_{k, i} \frac{\partial Q_{k, i}}{\partial P_{k, i}}-\frac{\partial T C_{i}^{*}\left(Y \mid J_{0, i}\right)}{\partial Y} \frac{\partial Q_{k, i}}{\partial P_{k, i}}=0
$$

which we rewrite as

$$
\mathcal{E}_{k} Q_{k, i}\left(1-\sigma_{k, i}\right)+\sigma_{k, i} Q_{k, i} \frac{\lambda_{i}}{P_{k, i}}=0
$$

where $\sigma_{k, i}$ is defined in (3) and $\lambda_{i}=M C_{i}^{*}\left(J_{0, i}\right)$ is defined in (A2). Rearranging and using $P_{k, i}^{*}=\mathcal{E}_{k} P_{k, i}$, results in the price setting equation (11).

Now consider the choice of $J_{0, i}$. By the Envelope Theorem, it is equivalent to

$$
\min _{J_{0, i}} \mathbb{E}\left\{T C_{i}^{*}\left(Y_{i} \mid J_{0, i}\right)\right\}
$$

where $Y_{i}$ is the equilibrium output of the firm in each state of nature. Therefore, this problem is nearly identical to that of choosing $J_{0, i}$ without uncertainty, with the exception that now we have the expectation and $Y_{i}$ varies across states of the world along with exogenous variables affecting $T C_{i}^{*}$. As a result, we can write the fixed point equation for $J_{0, i}$ in this case as:

$$
J_{0, i}=\left\{j \in[0,1]: \mathbb{E}\left\{\phi \frac{C^{*} / \Omega_{i}}{\exp \left\{\phi \int_{J_{0, i}} \gamma_{\ell} \log b_{\ell} \mathrm{d} \ell\right\}} Y_{i} \cdot \gamma_{j} \log b_{j}\right\} \geq \mathbb{E}\left\{W^{*} f_{i}\right\}\right\}
$$

Therefore, $J_{0, i}$ still has the structure $\left[0, j_{0, i}\right]$, but now we need to sort goods $j$ in decreasing 
order by the value of the LHS in the inequality in (A6) (in expected terms).

\section{A.1.3 Equilibrium Relationships}

To illustrate the implications of the model for the equilibrium determinants of market share and import intensity, we study the following simple case. Consider two firms, $i$ and $i^{\prime}$, in a given industry and both serving a single destination market $k$. The firms face the same industry-destination specific market conditions reflected in $\mathcal{E}_{k}, P_{k}, D_{k}, C^{*}$ and $\phi$. We allow the firms to be heterogeneous in terms of productivity $\Omega_{i}$, demand/quality shifter $\xi_{k, i}$ and the fixed cost of importing $f_{i}$. For a single-destination firm we have $Y_{i}=Q_{k, i}$, and we drop index $k$ in what follows for brevity.

We want to characterize the relative market shares and import intensities of these two firms. In order to do so, we take the ratios of the equilibrium conditions (demand (1), market share (2) and price (11)) for these two firms: ${ }^{42}$

$$
\frac{Y_{i}}{Y_{i^{\prime}}}=\frac{\xi_{i}}{\xi_{i^{\prime}}}\left(\frac{P_{i}}{P_{i^{\prime}}}\right)^{-\rho}, \quad \frac{S_{i}}{S_{i^{\prime}}}=\frac{\xi_{i}}{\xi_{i^{\prime}}}\left(\frac{P_{i}}{P_{i^{\prime}}}\right)^{1-\rho} \quad \text { and } \quad \frac{P_{i}}{P_{i^{\prime}}}=\frac{\mathcal{M}_{i}}{\mathcal{M}_{i^{\prime}}} \frac{B_{i^{\prime}}^{\phi} \Omega_{i^{\prime}}}{B_{i}^{\phi} \Omega_{i}},
$$

where $\mathcal{M}_{i}=\sigma_{i} /\left(\sigma_{i}-1\right)$ and $\sigma_{i}=\rho\left(1-S_{i}\right)+\eta S_{i}$. Log-linearizing relative markup, we have:

$$
\log \frac{\mathcal{M}_{i}}{\mathcal{M}_{i^{\prime}}}=\frac{\bar{\Gamma}}{\rho-1} \log \frac{S_{i}}{S_{i^{\prime}}}
$$

where $\bar{\Gamma}$ is markup elasticity given in (4) evaluated at some average $\bar{S}$. Using this, we linearize the equilibrium system to solve for:

$$
\log \frac{S_{i}}{S_{i^{\prime}}}=\frac{1}{1+\bar{\Gamma}} \log \frac{\xi_{i}}{\xi_{i^{\prime}}}+\frac{\rho-1}{1+\bar{\Gamma}}\left(\log \frac{\Omega_{i}}{\Omega_{i^{\prime}}}+\phi \log \frac{B_{i}}{B_{i^{\prime}}}\right)
$$

and the interim variable (total material cost), which determines the import choice:

$$
\log \frac{T M C_{i}}{T M C_{i^{\prime}}}=\left[\log \frac{Y_{i}}{Y_{i^{\prime}}}-\log \frac{\Omega_{i}}{\Omega_{i^{\prime}}}-\phi \log \frac{B_{i}}{B_{i^{\prime}}}\right]=\left(1-\frac{\bar{\Gamma}}{\rho-1}\right) \log \frac{S_{i}}{S_{i^{\prime}}}
$$

Assumption A1 $\bar{\Gamma}<(\rho-1)$.

This assumption implies that the (level of) markup does not vary too much with the productivity of the firm, so that high-market-share firms are simultaneously high-materialcost firms (as we document is the case in the data, see Table 4). ${ }^{43}$ Consequently, under A1, high-market-share firms choose to be more import intensive, as we discuss next.

\footnotetext{
${ }^{42}$ Note that taking these ratios takes out the aggregate variables such as the price index. Intuitively, we characterize the relative standing of two firms in a given general equilibrium environment, and aggregate equilibrium variables such as the price index, which affect outputs and market shares of firms proportionately, drop out.

${ }^{43}$ This assumption is not very restrictive for the parameters of the model, as for a moderate value of $\rho=4$, it only requires $\bar{S}<0.8$ (given the definition of $\Gamma$ in (4) and $\eta \geq 1$ ).
} 
Denote $\chi(j) \equiv \gamma_{j} \mathbb{E} \log b_{j}$, where the expectation is over aggregate equilibrium variables (i.e., aggregate states of the world), and sort $j$ so that $\chi^{\prime}(\cdot)<0$ on $[0,1]$. Assuming the choice of the import set is internal for both firms, we can rewrite (A6) as a condition for a cutoff $j_{0}(i)$ :

$$
\mathbb{E}\left\{\gamma_{j_{0}(i)} \log b_{j_{0}(i)} \frac{\phi C^{*} Y_{i}}{B_{i}^{\phi} \Omega_{i}}\right\}=\mathbb{E}\left\{W^{*} f_{i}\right\}
$$

and $\log$-linearize it to yield:

$$
\frac{-\chi^{\prime}\left(\bar{j}_{0}\right)}{\chi\left(\bar{j}_{0}\right)} \cdot\left(j_{0}(i)-j_{0}\left(i^{\prime}\right)\right)=\mathbb{E}\left\{\log \frac{Y_{i}}{Y_{i^{\prime}}}-\log \frac{\Omega_{i}}{\Omega_{i^{\prime}}}-\phi \log \frac{B_{i}}{B_{i^{\prime}}}\right\}-\log \frac{f_{i}}{f_{i^{\prime}}}
$$

where $\bar{j}_{0}$ is some average cutoff variety. Finally, using definition (A3), we have

$$
\mathbb{E} \log \frac{B_{i}}{B_{i^{\prime}}}=\chi\left(\bar{j}_{0}\right) \cdot\left(j_{0}(i)-j_{0}\left(i^{\prime}\right)\right)
$$

Combining the above two equations with (A8), we have:

$$
\frac{-\chi^{\prime}\left(\bar{j}_{0}\right)}{\phi \chi\left(\bar{j}_{0}\right)^{2}} \phi \mathbb{E} \log \frac{B_{i}}{B_{i^{\prime}}}=\left(1-\frac{\bar{\Gamma}}{\rho-1}\right) \mathbb{E} \log \frac{S_{i}}{S_{i^{\prime}}}-\log \frac{f_{i}}{f_{i^{\prime}}}
$$

Combining with (A7), we solve for:

$$
\begin{aligned}
\phi \mathbb{E} \log \frac{B_{i}}{B_{i^{\prime}}} & =\frac{1}{\bar{\kappa}_{0}-\left(\frac{\rho}{1+\bar{\Gamma}}-1\right)}\left[\frac{1-\frac{\bar{\Gamma}}{\rho-1}}{1+\bar{\Gamma}}\left(\log \frac{\xi_{i}}{\xi_{i^{\prime}}}+(\rho-1) \log \frac{\Omega_{i}}{\Omega_{i^{\prime}}}\right)-\log \frac{f_{i}}{f_{i^{\prime}}}\right] \\
\mathbb{E} \log \frac{S_{i}}{S_{i^{\prime}}} & =\frac{1}{\bar{\kappa}_{0}-\left(\frac{\rho}{1+\bar{\Gamma}}-1\right)}\left[\frac{\bar{\kappa}_{0}}{1+\bar{\Gamma}}\left(\log \frac{\xi_{i}}{\xi_{i^{\prime}}}+(\rho-1) \log \frac{\Omega_{i}}{\Omega_{i^{\prime}}}\right)-\frac{\rho-1}{1+\bar{\Gamma}} \log \frac{f_{i}}{f_{i^{\prime}}}\right],
\end{aligned}
$$

where $\bar{\kappa}_{0} \equiv-\chi^{\prime}\left(\bar{j}_{0}\right) /\left[\phi \chi\left(\bar{j}_{0}\right)^{2}\right]>0$.

Assumption A2 $\bar{\kappa}_{0} \equiv \frac{-\chi^{\prime}\left(\bar{j}_{0}\right)}{\phi \chi\left(\bar{j}_{0}\right)^{2}}>\frac{\rho}{1+\bar{\Gamma}}-1$.

The parameter restriction in A2 is a local stability condition: the function $\chi(j)=$ $\mathbb{E} \gamma_{j} \log b_{j}$ must be decreasing in $j$ fast enough, otherwise small changes in exogenous firm characteristics can have discontinuously large changes in the extensive margin of imports. We view it as a technical condition, and assume equilibrium is locally stable.

Finally, we relate import intensity of the firm $\varphi_{i}$ to $B_{i}$. From definition (9) it follows that

$$
\mathbb{E}\left\{\varphi_{i}-\varphi_{i^{\prime}}\right\}=\nu\left(\bar{j}_{0}\right)\left(j_{0}(i)-j_{0}\left(i^{\prime}\right)\right)=\frac{\nu\left(\bar{j}_{0}\right)}{\chi\left(\bar{j}_{0}\right)} \mathbb{E} \log \frac{B_{i}}{B_{i^{\prime}}}
$$

where $\nu(j)=\gamma_{j} \mathbb{E}\left\{1-b_{j}^{\zeta}\right\}$ and the second equality substitutes in (A9). 
Equations (A10)-(A12) provide the log-linear characterization of (expected) relative market share and relative import intensities of the two firms as a function of their relative exogenous characteristics. These approximations are nearly exact when the exogenous differences between firms are small. In other words, one can think of those relationships as describing elasticities of market share and semi-elasticities of import-intensity with respect to exogenous characteristics of the firm (productivity, demand/quality and fixed cost of importing), holding the general equilibrium environment constant. Therefore, we have:

Proposition A1 Under Assumptions A1 and A2, the (expected) market share and import intensity of the firm are both increasing in its productivity and quality/demand shifter, and are both decreasing in the firm's fixed cost of importing, in a given general equilibrium environment (that is, holding the composition of firms constant).

A similar result can be proved for firms serving multiple and different numbers of destinations.

\section{A.1.4 Pass-through relationship and proof of Proposition 3}

Markup Given (2) and (3), we have the following full differentials:

$$
\begin{aligned}
\mathrm{d} \log \mathcal{M}_{k, i} \equiv \mathrm{d} \log \frac{\sigma_{k, i}}{\sigma_{k, i}-1} & =\frac{(\rho-\eta) S_{k, i}}{\sigma_{k, i}\left(\sigma_{k, i}-1\right)} \mathrm{d} \log S_{k, i}=\Gamma_{k, i} \frac{\mathrm{d} \log S_{k, i}}{\rho-1} \\
\mathrm{~d} \log S_{k, i} & =\mathrm{d} \log \xi_{k, i}-(\rho-1)\left(\mathrm{d} \log P_{k, i}-\mathrm{d} \log P_{k}\right)
\end{aligned}
$$

where $\Gamma_{k, i}$ is as defined in (4). Combining these two expressions results in (13).

Marginal cost Taking the full differential of (10), we have:

$$
\mathrm{d} \log M C_{i}^{*}=\mathrm{d} \log \frac{C^{*}}{\Omega_{i}}-\phi \mathrm{d} \log B_{i}
$$

Using definitions (A1) and (A3), and under the assumption that $J_{0}$ is a sunk decision (that is, the set of imported goods is held constant), we have:

$$
\begin{aligned}
\mathrm{d} \log b_{j} & =-\left(1-b_{j}^{\zeta}\right) \mathrm{d} \log \frac{\mathcal{E}_{m} U_{j}}{V_{j}^{*}} \\
\phi \mathrm{d} \log B_{i} & =\phi \int_{J_{0, i}} \gamma_{j}\left(\mathrm{~d} \log b_{j}\right) \mathrm{d} j \\
& =-\varphi_{i} \mathrm{~d} \log \frac{\mathcal{E}_{m} \bar{U}}{\bar{V}^{*}}-\phi \int_{J_{0, i}} \gamma_{j}\left(1-b_{j}^{\zeta}\right)\left[\mathrm{d} \log \frac{U_{j}}{\bar{U}}-\mathrm{d} \log \frac{V_{j}^{*}}{\bar{V}^{*}}\right] \mathrm{d} j,
\end{aligned}
$$

where $\varphi_{i}$ is defined in (9), and $\mathrm{d} \log \bar{V}^{*}=\int_{0}^{1} \gamma_{j}\left(\mathrm{~d} \log V_{j}^{*}\right) \mathrm{d} j \mathrm{~d} j$ and similarly $\mathrm{d} \log \bar{U}=$ $\int_{0}^{1} \gamma_{j}\left(\mathrm{~d} \log U_{j}\right) \mathrm{d} j \mathrm{~d} j$. Substituting this expression into the full differential of the marginal 
cost above results in (14), where the residual is given by:

$$
\epsilon_{i}^{M C}=\int_{J_{0, i}} \gamma_{j}\left(1-b_{j}^{-\zeta}\right)\left[\mathrm{d} \log \frac{U_{j}}{\bar{U}}-\mathrm{d} \log \frac{V_{j}^{*}}{\bar{V}^{*}}\right] \mathrm{d} j-\mathrm{d} \log \frac{\Omega_{i}}{\bar{\Omega}},
$$

where $\mathrm{d} \log \bar{\Omega}$ is the sectoral average change in firm-level productivity.

Combining (13) and (14) with (12), we have:

$$
\mathrm{d} \log P_{k, i}^{*}=-\Gamma_{k, i}\left(\mathrm{~d} \log P_{k, i}-\mathrm{d} \log \tilde{P}_{k}\right)+\mathrm{d} \log \frac{C^{*}}{\bar{\Omega}}+\varphi_{i} \mathrm{~d} \log \frac{\mathcal{E}_{m} \bar{U}}{\bar{V}^{*}}+\epsilon_{k, i},
$$

where

$$
\epsilon_{k, i} \equiv \epsilon_{i}^{M C}+\frac{\Gamma_{k, i}}{\rho-1} \epsilon_{k, i}^{\mathcal{M}}, \quad \epsilon_{k, i}^{\mathcal{M}} \equiv \mathrm{d} \log \frac{\xi_{k, i}}{\bar{\xi}_{k}},
$$

$\mathrm{d} \log \bar{\xi}_{k}$ is the sector-destination average change in demand/quality across firms, and we denote with $\tilde{P}_{k} \equiv \xi_{k}^{\frac{1}{\rho-1}} P_{k}$ the sector-destination price index adjusted for the average demand/quality shifter for Belgian firms. We make the following:

Assumption A3 $\left(\epsilon_{k, i}^{M C}, \epsilon_{k, i}^{\mathcal{M}}\right)$, and hence $\epsilon_{k, i}$, are mean zero and independent from $\mathrm{d} \log \mathcal{E}_{m}$ and $\mathrm{d} \log \mathcal{E}_{k}$.

Note that $\epsilon_{k, i}$ reflects the firm idiosyncratic differences in the change in input prices, productivity and demand/quality shifter, and therefore Assumption A3 is a natural one to make. Essentially, we assume that there is no systematic relationship between exchange rate movement and firm's idiosyncratic productivity or demand change relative to an average firm from the same country (Belgium) serving the same sector-destination. This nonetheless allows the exchange rates to be correlated with sector-destination average indexes for costs and productivity (that is, $\bar{\Omega}, \bar{U}, \bar{V}^{*}$, as well as $\tilde{P}_{k}$ ).

Substituting $\mathrm{d} \log P_{k, i}=\mathrm{d} \log P_{k, i}^{*}-\mathrm{d} \log \mathcal{E}_{k}$ into (A13) and rearranging, we arrive at:

$$
\mathrm{d} \log P_{k, i}^{*}=\frac{\Gamma_{k, i}}{1+\Gamma_{k, i}} \mathrm{~d} \log \mathcal{E}_{k}+\frac{\varphi_{i}}{1+\Gamma_{k, i}} \mathrm{~d} \log \frac{\mathcal{E}_{m} \bar{U}_{s}}{\bar{V}_{s}^{*}}+\frac{\Gamma_{k, i} \mathrm{~d} \log \tilde{P}_{s, k}+\mathrm{d} \log \frac{C_{s}^{*}}{\tilde{\Omega}_{s, k}}+\epsilon_{k, i}}{1+\Gamma_{k, i}}
$$

where we have now made the sector identifier $s$ an explicit subscript (each $i$ uniquely determines $s$, hence we do not carry $s$ when $i$ is present). Note that $\Gamma_{k, i}$ is increasing in $S_{k, i}$. We now linearize (A14) in $\varphi_{i}$ and $S_{k, i}$ :

Lemma A1 Log price change expression (A14) linearized in $\varphi_{i}$ and $S_{k, i}$ is

$$
\begin{aligned}
& \mathrm{d} \log P_{k, i}^{*} \approx \frac{\bar{\Gamma}_{s, k}}{1+\bar{\Gamma}_{s, k}} \mathrm{~d} \log \mathcal{E}_{k}+\frac{\bar{g}_{s, k}}{1+\bar{\Gamma}_{s, k}} \tilde{S}_{k, i} \mathrm{~d} \log \mathcal{E}_{k}+\frac{1}{1+\bar{\Gamma}_{s, k}} \varphi_{i} \mathrm{~d} \log \frac{\mathcal{E}_{m} \bar{U}_{s}}{\bar{V}_{s}^{*}} \\
& +\left[\frac{\bar{\Gamma}_{s, k} \mathrm{~d} \log \tilde{P}_{s, k}+\mathrm{d} \log \frac{C_{s}^{*}}{\tilde{\Omega}_{s, k}}+\bar{\epsilon}_{k, i}^{\prime}}{1+\bar{\Gamma}_{s, k}}+\frac{\bar{g}_{s, k}\left(\mathrm{~d} \log \tilde{P}_{s, k}-\bar{\varphi}_{s} \mathrm{~d} \log \frac{\mathcal{E}_{m} \bar{U}_{s}}{\bar{V}_{s}^{*}}-\mathrm{d} \log \frac{C_{s}^{*}}{\tilde{\Omega}_{s, k}}+\bar{\epsilon}_{k, i}^{\prime \prime}\right)}{1+\bar{\Gamma}_{s, k}} \tilde{S}_{k, i}\right],
\end{aligned}
$$


where $\bar{\Gamma}_{s, k}=\left.\Gamma_{k, i}\right|_{\bar{S}_{s, k}}, \bar{g}_{s, k} \equiv \partial \log \left(1+\Gamma_{k, i}\right) /\left.\partial S_{k, i}\right|_{\bar{S}_{s, k}}, \bar{S}_{s, k}$ is some average statistic of the $S_{k, i}$ distribution, $\tilde{S}_{k, i}=S_{k, i}-\bar{S}_{k, i}$, and $\bar{\epsilon}_{k, i}^{\prime} \equiv \epsilon_{i}^{M C}+\frac{\bar{\Gamma}_{s, k}}{\rho-1} \epsilon_{k, i}^{\mathcal{M}}, \bar{\epsilon}_{k, i}^{\prime \prime} \equiv \frac{\bar{\Gamma}_{s, k}}{\rho-1} \epsilon_{k, i}^{\mathcal{M}}-\epsilon_{i}^{M C}$.

Proof: Given the definitions of $\bar{\Gamma}_{s, k}$ and $\bar{g}_{s, k}$ in the lemma, we have the following first-order approximations:

$$
\frac{1}{1+\Gamma_{k, i}} \approx \frac{1-\bar{g}_{s, k} \tilde{S}_{k, i}}{1+\bar{\Gamma}_{s, k}}, \quad \frac{\Gamma_{k, i}}{1+\Gamma_{k, i}} \approx \frac{\bar{\Gamma}_{s, k}+\bar{g}_{s, k} \tilde{S}_{k, i}}{1+\bar{\Gamma}_{s, k}} \quad \text { and } \quad \frac{\varphi_{i}}{1+\Gamma_{k, i}} \approx \frac{\varphi_{i}-\bar{\varphi}_{s} \bar{g}_{s, k} \tilde{S}_{k, i}}{1+\bar{\Gamma}_{s, k}}
$$

Substitute these approximations into (A14) and rearrange to obtain (A15).

Proof of Proposition 3 Divide (A15) through by d $\log \mathcal{E}_{k}$ and take expectations to characterize the pass-through elasticity:

$$
\Psi_{k, i}^{*} \equiv \mathbb{E}\left\{\frac{\mathrm{d} \log P_{k, i}^{*}}{\mathrm{~d} \log \mathcal{E}_{k}}\right\} \approx \alpha_{s, k}+\beta_{s, k} \cdot \varphi_{i}+\gamma_{s, k} \cdot S_{k, i}
$$

where

$$
\begin{gathered}
\alpha_{s, k}=\frac{\bar{\Gamma}_{s, k}\left(1+\Psi_{s, k}^{P}\right)+\Psi_{s, k}^{C}}{1+\bar{\Gamma}_{s, k}}-\gamma_{s, k} \bar{S}_{s, k}, \\
\beta_{s, k}=\frac{\Psi_{s, k}^{M}}{1+\bar{\Gamma}_{s, k}} \quad \text { and } \quad \gamma_{s, k}=\frac{\bar{g}_{s, k}\left[\left(1-\bar{\varphi}_{s} \Psi_{s, k}^{M}\right)+\left(\Psi_{s, k}^{P}-\Psi_{s, k}^{C}\right)\right]}{1+\bar{\Gamma}_{s, k}},
\end{gathered}
$$

and with

$$
\Psi_{k, i}^{P} \equiv \mathbb{E}\left\{\frac{\mathrm{d} \log \tilde{P}_{s, k}}{\mathrm{~d} \log \mathcal{E}_{k}}\right\}, \quad \Psi_{s, k}^{C} \equiv \mathbb{E}\left\{\frac{\mathrm{d} \log \left(C_{s}^{*} / \tilde{\Omega}_{s, k}\right)}{\mathrm{d} \log \mathcal{E}_{k}}\right\}, \quad \Psi_{s, k}^{M} \equiv \mathbb{E}\left\{\frac{\mathrm{d} \log \left(\mathcal{E}_{m} \bar{U}_{s} / \bar{V}_{s}^{*}\right)}{\mathrm{d} \log \mathcal{E}_{k}}\right\} .
$$

Note that the terms in $\epsilon_{k, i}$ drop out since, due to Assumption A3, $\mathbb{E}\left\{\epsilon_{k, i} / \mathrm{d} \log \mathcal{E}_{k}\right\}=0$. Finally, note that $\Psi_{s, k}^{\cdot} \approx \operatorname{cov}\left(\cdot, \mathrm{d} \log \mathcal{E}_{k}\right) / \operatorname{var}\left(\mathrm{d} \log \mathcal{E}_{k}\right)$, that is $\Psi$-terms are approximately projection coefficients. The expectations and the definitions of $\Psi$-terms are unconditional, and hence average across all possible initial states and paths of the economy.

\section{A.1.5 Empirical specification and proof of Proposition 4}

We start from the linearized decomposition (A15) by replacing differential $\mathrm{d}$ with a time change operator $\Delta$, making the time index $t$ explicit, and rearranging:

$$
\begin{aligned}
\Delta p_{i, k, t}^{*} & \approx \frac{\bar{\Gamma}_{s, k} \Delta \tilde{p}_{s, k, t}+\Delta c_{s, t}+\bar{\epsilon}_{k, i, t}^{\prime}}{1+\bar{\Gamma}_{s, k}}+\frac{\bar{g}_{s, k}\left(\Delta \tilde{p}_{s, k, t}-\Delta c_{s, t}+\bar{\epsilon}_{k, i, t}^{\prime \prime}\right)}{1+\bar{\Gamma}_{s, k}} \tilde{S}_{k, i, t-1} \\
& +\frac{\bar{\Gamma}_{s, k} \Delta e_{k, t}}{1+\bar{\Gamma}_{s, k}}+\frac{\varphi_{i, t-1}}{1+\bar{\Gamma}_{s, k}} \Delta \log \frac{\mathcal{E}_{m, t} \bar{U}_{s, t}}{\bar{V}_{s, t}^{*}}+\frac{\bar{g}_{s, k} \tilde{S}_{k, i, t-1}}{1+\bar{\Gamma}_{s, k}}\left(\Delta e_{k, t}-\bar{\varphi}_{s, t-1} \Delta \log \frac{\mathcal{E}_{m, t} \bar{U}_{s, t}}{\bar{V}_{s, t}^{*}}\right)
\end{aligned}
$$

where $\Delta p_{i, k, t}^{*} \equiv \log P_{k, i, t}^{*}-\log P_{k, i, t-1}^{*}, \Delta e_{k, t} \equiv \log \mathcal{E}_{k, t}-\log \mathcal{E}_{k, t-1}, \Delta c_{s, t} \equiv \log \left(C_{s, t}^{*} / \bar{\Omega}_{s, t}\right)-$ $\log \left(C_{s, t-1}^{*} / \bar{\Omega}_{s, t-1}\right)$, and $\Delta \tilde{p}_{s, k, t} \equiv \log \tilde{P}_{s, k, t}-\log \tilde{P}_{s, k, t-1}$. Note that we chose $t-1$ as the point 
of approximation for $\tilde{S}_{k, i, t-1}$ and $\varphi_{i, t-1}$. We also chose the approximation coefficients $\bar{\Gamma}_{s, k}$ and $\bar{g}_{s, k}$ not to depend on time by evaluating the respective functions (see Lemma A1) at a time-invariant average $\bar{S}_{s, k}$.

Next consider our main empirical specification (21) which we reproduce as:

$$
\Delta p_{i, k, t}^{*}=\left[\alpha_{s, k}+\beta \varphi_{i, t-1}+\tilde{\gamma} \frac{S_{k, i, t-1}}{\mathbf{S}_{s, k, t-1}}\right] \Delta e_{k, t}+\delta_{s, k}+b \varphi_{i, t-1}+c \frac{S_{k, i, t-1}}{\mathbf{S}_{s, k, t-1}}+\tilde{u}_{k, i, t}
$$

where $\mathbf{S}_{s, k, t}$ is the cumulative market share of all Belgian exporters. Our goal is to establish the properties of the OLS estimator of $\beta$ and $\tilde{\gamma}$ in this regression, given approximate structural relationship (A16). To this end, we introduce two assumptions:

Assumption A4 For every $k, \Delta \log e_{k, t}$ is mean zero, constant variance and independent from $\left(\varphi_{i, t-1}, S_{k, i, t-1}, \mathbf{S}_{s, k, t-1}\right)$.

Assumption A5 The variance and covariance of $\left(\varphi_{i, t-1}, S_{k, i, t-1} / \mathbf{S}_{s, k, t-1}\right)$ within $(s, k, t-1)$ are independent from $\left(\beta_{s, k}, \gamma_{s, k} \mathbf{S}_{s, k, t-1}\right)$, where $\beta_{s, k}$ and $\gamma_{s, k}$ are defined in the proof of Proposition 3 above.

Assumption A4 is a plausible martingale assumption for the exchange rate, which we require in the proof of Proposition 4. One interpretation of this assumption is that the crosssection distribution of firm-level characteristics is not useful in predicting future exchange rate changes. Assumption A5, in turn, is only made for convenience of interpretation, and qualitatively the results of Proposition 4 do not require it. Essentially, we assume that the cross-section distribution of firm-characteristics within sector-destination does not depend on the aggregate comovement properties of sectoral variables which affect the values of $\beta_{s, k}$ and $\gamma_{s, k}$.

Before proving Proposition 4, we introduce the following three projections:

$$
\left\{\begin{aligned}
\Delta \log \frac{\mathcal{E}_{m, t} \bar{U}_{s, t}}{\bar{V}_{s, t}^{*}} & \equiv \rho_{s, k}^{M} \Delta e_{k, t}+v_{s, k, t}^{M}, & & \rho_{s, k}^{M}=\frac{\operatorname{cov}\left(\Delta \log \frac{\mathcal{E}_{m, t} \bar{U}_{s, t}}{\bar{V}_{s, t}^{*}}, \Delta e_{k, t}\right)}{\operatorname{var}\left(\Delta e_{k, t}\right)} \\
\Delta \tilde{p}_{s, k, t} & \equiv \rho_{s, k}^{P} \Delta e_{k, t}+v_{s, k, t}^{P}, & & \rho_{s, k}^{P}=\frac{\operatorname{cov}\left(\Delta \tilde{p}_{s, k, t}, \Delta e_{k, t}\right)}{\operatorname{var}\left(\Delta e_{k, t}\right)} \\
\Delta c_{s, t}^{*} & \equiv \rho_{s, k}^{C} \Delta e_{k, t}+v_{s, k, t}^{C}, & & \rho_{s, k}^{C}=\frac{\operatorname{cov}\left(\Delta c_{s, k, t}, \Delta e_{k, t}\right)}{\operatorname{var}\left(\Delta e_{k, t}\right)}
\end{aligned}\right.
$$

and therefore $\left(v_{s, k, t}^{M}, v_{s, k, t}^{P}, v_{s, k, t}^{C}\right)$ are orthogonal with $\Delta e_{k, t}$. Note that $\left(\rho_{s, k}^{M}, \rho_{s, k}^{P}, \rho_{s, k}^{C}\right)$ are the empirical counterparts to $\left(\Psi_{s, k}^{M}, \Psi_{s, k}^{P}, \Psi_{s, k}^{C}\right)$ defined in the proof of Proposition 3. 
Proof of Proposition 4 Substitute projections (A18) into (A16) and rearrange:

$$
\begin{aligned}
\Delta p_{i, k, t}^{*} \approx & {[\underbrace{\frac{\bar{\Gamma}_{s, k}\left(1+\rho_{s, k}^{P}\right)+\rho_{s, k}^{C}}{1+\bar{\Gamma}_{s, k}}}_{\equiv \alpha_{s, k}}+\underbrace{\frac{\rho_{s, k}^{M}}{1+\bar{\Gamma}_{s, k}} \cdot \varphi_{i, t-1}}_{\equiv \beta_{s, k}}+\underbrace{\frac{\left[\left(1-\bar{\varphi}_{s} \rho_{s, k}^{M}\right)+\left(\rho_{s, k}^{P}-\rho_{s, k}^{C}\right)\right] \bar{g}_{s, k} \mathbf{S}_{s, k, t-1}}{1+\bar{\Gamma}_{s, k}}}_{\equiv \tilde{\gamma}_{s, k, t}} \cdot \frac{S_{k, i, t-1}}{\mathbf{S}_{s, k, t-1}}] \Delta e_{k, t} } \\
+ & \underbrace{\frac{v_{s, k, t}^{M}}{1+\bar{\Gamma}_{s, k}} \cdot \varphi_{i, t-1}}_{\equiv b_{s, k}}+\underbrace{\frac{\left(v_{s, k, t}^{P}-v_{s, k, t}^{C}-\bar{\varphi}_{s, t-1} v_{s, k, t}^{M}\right) \bar{g}_{s, k} \mathbf{S}_{s, k, t-1}}{\left(1+\bar{\Gamma}_{s, k}\right)^{2}}}_{\equiv c_{s, k, t}} \cdot \frac{S_{k, i, t-1}}{\mathbf{S}_{s, k, t-1}}+u_{k, i, t}, \\
u_{k, i, t} & =\frac{\bar{\Gamma}_{s, k} v_{s, k, t}^{P}+v_{s, k, t}^{C}+\bar{\epsilon}_{i, t}^{\prime}}{1+\bar{\Gamma}_{s, k}}++\frac{\bar{g}_{s, k} S_{k, i, t-1}}{\left(1+\bar{\Gamma}_{s, k}\right)^{2}} \bar{\epsilon}_{k, i, t}^{\prime} .
\end{aligned}
$$

Comparing this equation with the empirical specification (A17), the residual in the empirical specification is given by:

$\tilde{u}_{k, i, t}=u_{k, i, t}+\left[\left(\beta_{s, k}-\beta\right) \varphi_{i, t-1}+\left(\tilde{\gamma}_{s, k, t}-\tilde{\gamma}\right) \frac{S_{k, i, t-1}}{\mathbf{S}_{s, k, t-1}}\right] \Delta e_{k, t}+\left(b_{s, k}-b\right) \varphi_{i, t-1}+\left(c_{s, k, t}-c\right) \frac{S_{k, i, t-1}}{\mathbf{S}_{s, k, t-1}}$.

Define $x_{k, i, t}=\left(\mathbf{1}_{s, k}^{\prime}, \varphi_{i, t-1}, \tilde{S}_{k, i, t-1}\right)^{\prime}$, so that we can write our regressors as $z_{k, i, t}^{\prime}=$ $\left(x_{k, i, t}^{\prime}, x_{k, i, t}^{\prime} \Delta e_{k, t}\right)$. From Assumptions A3 and A4 and properties of the projection (A18), it follows that $x_{k, i, t}^{\prime} \Delta e_{k, t}$ is orthogonal with $x_{k, i, t}^{\prime}$, and $x_{k, i, t}^{\prime} \Delta e_{k, t}$ is uncorrelated with $u_{k, i, t}$. Therefore, the properties of the estimates of $\left(\alpha_{s, k}, \beta, \tilde{\gamma}\right)$ are independent from those of $\left(\delta_{s, k}, b, c\right)$. OLS identifies $\left(\alpha_{s, k}, \beta, \tilde{\gamma}\right)$ from the following moment conditions:

$$
0=\mathbb{E}_{k, i, t}\left\{x_{k, i, t} \Delta e_{k, t} \tilde{u}_{k, i, t}\right\}=\mathbb{E}_{k, i, t}\left\{x_{k, i, t} \Delta e_{k, t}\left(\tilde{u}_{k, i, t}-u_{k, i, t}\right)\right\}
$$

where the second equality follows from $\mathbb{E}_{k, i, t}\left\{\Delta e_{k, t} x_{k, i, t} u_{k, i, t}\right\}=0$ (due to Assumption A3 and projection (A18)). We now rewrite this moment condition in the form of summation (across the population of firms, sector-destinations, and time periods/states):

$$
0=\sum_{k, i, t} x_{k, i, t} \Delta e_{k, t}\left(\tilde{u}_{k, i, t}-u_{k, i, t}\right)=\sum_{k, i, t} \Delta e_{k, t}^{2} x_{k, i, t} x_{k, i, t}^{\prime}\left(\mathbf{0}_{s, k}^{\prime}, \beta_{s, k}-\beta, \tilde{\gamma}_{s, k, t}-\tilde{\gamma}\right)^{\prime}
$$

where the second equality substitutes in the expression for $\tilde{u}_{k, i, t}-u_{k, i, t}$ and uses the fact that $\Delta e_{k, t}$ is orthogonal with $x_{k, i, t}$ (Assumption A4). Using the same assumption further, we can rewrite the last expression as:

$$
\sum_{s, k, t} \sigma_{k}^{2} n_{s, k, t} \Sigma_{s, k, t}\left(\begin{array}{c}
\beta_{s, k}-\beta \\
\tilde{\gamma}_{s, k, t}-\tilde{\gamma}
\end{array}\right)=0
$$

where $\sigma_{k}^{2}$ is the variance of $\Delta e_{k, t}, \Sigma_{s, k, t}$ is the covariance matrix for $\left(\varphi_{i, t-1}, S_{k, i, t-1} / \mathbf{S}_{s, k, t-1}\right)$ within $(s, k, t-1)$, and $n_{s, k, t}$ is the respective number of observations.

Equation (A19) already establishes the result of the proposition that $\beta$ and $\tilde{\gamma}$ identify generalized weighted averages of the respective coefficients. Under additional Assumption A5, 
we have a particularly simple expressions for these weighted averages:

$$
\beta=\sum_{s, k, t} \omega_{s, k, t}^{\prime} \beta_{s, k} \quad \text { and } \quad \tilde{\gamma}=\sum_{s, k, t} \omega_{s, k, t}^{\prime \prime} \tilde{\gamma}_{s, k, t}
$$

$\omega_{s, k, t}^{\prime} \propto \sigma_{k}^{2} n_{s, k, t} \operatorname{var}_{s, k, t-1}\left(\varphi_{i, t-1}\right)$ and $\omega_{s, k, t}^{\prime \prime} \propto \sigma_{k}^{2} n_{s, k, t} \operatorname{var}_{s, k, t-1}\left(S_{k, i, t-1} / \mathbf{S}_{s, k, t-1}\right)$ with $\operatorname{var}_{s, k, t-1}(\cdot)$ denoting the variance for observations within $(s, k, t-1)$.

Finally, $\beta_{s, k}$ and $\tilde{\gamma}_{s, k, t}=\gamma_{s, k} \mathbf{S}_{s, k, t-1}$ are defined above, and $\left(\beta_{s, k}, \gamma_{s, k}\right)$ provide first-order approximations to their analogs in Proposition 3 since $\left(\rho_{s, k}^{M}, \rho_{s, k}^{P}, \rho_{s, k}^{C}\right) \approx\left(\Psi_{s, k}^{M}, \Psi_{s, k}^{P}, \Psi_{s, k}^{C}\right)$.

\section{A.1.6 Selection bias}

In this appendix we provide a brief exposition of the theoretical arguments for the direction of the potential bias of the coefficient estimates in equation (21) due to sample selection. We also provide corroborating empirical evidence.

For simplicity, imagine an environment with no sunk cost and only fixed cost $F_{k, i}$ of supplying each market $k$ for firm $i$, and denote with $\Pi_{k, i}$ the operating profit of firm $i$ from serving market $k$. Then the selection equation is $\Pi_{k, i} \geq F_{k, i}$, or equivalently $\log \left(\Pi_{k, i} / F_{k, i}\right) \geq 0$. A general approximation to the profit function, which can also be derived from the structure of the profit maximization problem introduced in Section 2.3, results in the following selection condition:

$$
\log \frac{\Pi_{k, i, t}}{F_{k, i, t}} \approx \delta_{s, k}+\delta_{t}+\Delta_{k, i, t-1}+\theta \Delta e_{k, t}+v_{k, i, t} \geq 0
$$

where $\delta_{s, k}$ and $\delta_{t}$ are sector-destination and year dummies, $\Delta_{k, i, t-1}$ is a combination of firmdestination characteristics (such as productivity $\Omega_{i}$ and demand shifter $\xi_{k, i}$ ) and $v_{k, i, t}$ is an idiosyncratic firm-destination shock in period $t$. In words, approximation (A20) implies that firms are more likely to stay in the sample under favorable industry-destination-year conditions (high $\delta_{s, k}+\delta_{t}$ ), when the domestic exchange rate depreciates (high $\Delta e_{k, t}$ ), when firms have strong fundamentals (large $\Delta_{k, i, t-1}$ ), and when firms face a favorable idiosyncratic shock (large $v_{k, i, t}$ ). For our purposes we project $\Delta_{k, i, t-1}=a \varphi_{i, t-1}+b S_{k, i, t-1}+\xi_{k, i, t-1}$.

Next consider our empirical specification:

$$
\Delta p_{k, i, t}^{*}=\delta_{q}+\alpha_{q} \Delta e_{k, t}+u_{k, i, t}
$$

estimated within bins $q$ of import intensity and market share (analogous to Table 6). We assume that $u_{k, i, t}$ is negatively correlated with $v_{k, i, t}$. Intuitively, this implies that an adverse marginal cost shock (e.g., negative productivity shock) both reduces $v_{k, i, t}$ and increases $u_{k, i, t}$. This assumption can be formally derived from the structure of our model: we can decompose $v_{k, i, t}=z_{k, i, t}-\rho u_{k, i, t}$, where $\rho>0$ and $u_{k, i, t}$ and $z_{k, i, t}$ are uncorrelated. Then the selection equation (A20) can be rewritten as:

$u_{k, i, t} \leq \gamma_{k, i, t}+\frac{\theta}{\rho} \Delta e_{k, t}, \quad$ where $\quad \gamma_{k, i, t} \equiv \frac{1}{\rho}\left[\delta_{s, k}+\delta_{t}+a \varphi_{i, t-1}+b S_{k, i, t-1}+\xi_{k, i, t}+z_{k, i, t}\right]$.

We directly verify in the data that $a, b, \theta>0$ (see the table below). 
Given this econometric model, we can directly evaluate the magnitude of the bias of an OLS estimate of $\alpha_{q}$. First, for each bin $q$ we calculate:

$$
\mathbb{E}\left\{\Delta p_{k, i, t}^{*} \mid \Delta e_{k, t}\right\}=\delta_{q}+\alpha_{q} \Delta e_{k, t}+f_{q}\left(\Delta e_{k, t}\right),
$$

where

$$
f_{q}\left(\Delta e_{k, t}\right)=\mathbb{E}\left\{u_{k, i, t} \mid \Delta e_{k, t}, u_{k, i, t} \leq \gamma_{k, i, t}+\frac{\theta}{\rho} \Delta e_{k, t}\right\} .
$$

With $u_{k, i, t}$ unconditionally mean zero, we have the following properties (provided $\theta \geq 0$ ):

$$
f_{q}(\cdot) \leq 0, \quad f_{q}(\infty)=0, \quad f_{q}^{\prime}(\cdot) \geq 0, \quad f_{q^{\prime}}(\cdot) \geq f_{q}(\cdot), \quad f_{q^{\prime}}^{\prime}(\cdot) \leq f_{q}^{\prime}(\cdot)
$$

The last two properties come from the fact that in bin $q^{\prime}$ with higher $\varphi_{i, t-1}$ and/or $S_{k, i, t-1}$ the distribution of $\gamma_{k, i, t}$ is shifted to the right (first order stochastically dominates), relative to that for bin $q$. In the special case of $\theta=0$, we have $f_{q}(\cdot) \equiv f_{q}$, a $q$-specific constant.

Given this calculation, we can evaluate the bias in the OLS estimate of $\alpha_{q}$ as the standard omitted variable bias:

$$
\operatorname{bias}\left(\hat{\alpha}_{q}\right)=p \lim \left(\hat{\alpha}_{q}-\alpha_{q}\right)=\frac{\operatorname{cov}\left(\Delta p_{k, i, t}^{*}, \Delta e_{k, t}\right)}{\operatorname{var}\left(\Delta e_{k, t}\right)}-\alpha_{q}=\frac{\operatorname{cov}\left(f_{q}\left(\Delta e_{k, t}\right), \Delta e_{k, t}\right)}{\operatorname{var}\left(\Delta e_{k, t}\right)} \geq 0,
$$

since $f_{q}^{\prime}(\cdot) \geq 0$ whenever $\theta>0$. For $\theta=0$, the bias equals zero. Furthermore, the bias is (weakly) smaller (closer to zero) for bin $q^{\prime}$ than for bin $q$, if $\varphi_{i, t-1}$ and/or $S_{k, i, t-1}$ are higher in bin $q^{\prime}$ than in bin $q$.

To summarize, whenever $a, b, \theta>0$, the OLS estimates have an upward bias in $\alpha$ (downward bias in the level of pass-through), which diminishes with import intensity and market share. This in turn implies a downward bias in $\beta$ and $\gamma$.

The table below estimates a Probit regression for the probability of staying in the sample $\left(\iota_{f, t}=1\right)$ :

\begin{tabular}{lcccc}
\hline \hline $\mathbb{P}\left\{\iota_{f, t}=1 \mid \iota_{f, t-1}=1\right\}$ & $(1)$ & $(2)$ & $(3)$ & $(4)$ \\
\hline$\varphi_{f}$ & $0.066^{* * *}$ & $0.084^{* * *}$ & 0.025 & $0.284^{* * *}$ \\
& $(0.025)$ & $(0.025)$ & $(0.026)$ & $(0.027)$ \\
$S_{f, s, k, t-1}$ & $0.564^{* * *}$ & $0.558^{* * *}$ & $0.710^{* * *}$ & $0.777^{* * *}$ \\
& $(0.011)$ & $(0.011)$ & $(0.011)$ & $(0.013)$ \\
$\Delta e_{k, t}$ & $0.745^{* * *}$ & $0.354^{* * *}$ & 0.090 & 0.094 \\
& $(0.048)$ & $(0.065)$ & $(0.067)$ & $(0.068)$ \\
\hline Fixed Effects & - & $\delta_{t}$ & $\delta_{t}+\delta_{k}$ & $\delta_{t}+\delta_{k}+\delta_{s}$ \\
$\#$ obs. & 172,988 & 172,988 & 172,988 & 172,988 \\
\hline \hline
\end{tabular}

Note: $\delta_{t}, \delta_{k}, \delta_{s}$ are year, country and industry (HS 2-digit) fixed effects respectively. The dependent variable equals 1 in $67.6 \%$ of the observations.

This confirms that firms with high import intensity and market share are less likely to drop out of the sample $(a, b>0)$. Further, this table provides evidence that exit is more likely in response to exchange rate appreciation $\left(\Delta e_{k, t}<0\right)$, that is $\theta>0$. 


\section{A.2 Data Appendix}

Trade Data The import and export data are from the National Bank of Belgium, with the extra-EU transactions reported by Customs and the intra-EU trade by the Intrastat Inquiry. These data are reported at the firm level for each product classified at the 8-digit combined nomenclature $(\mathrm{CN})$ in values and weights or units. Note that the $\mathrm{CN}$ code is a Europe-based classification with the first 6-digits corresponding to the World Hamonized System (HS). We include all transactions that are considered as trade involving change of ownership with compensation (codes 1 and 11). These data are very comprehensive, covering all firms with a total extra-EU trade whose value is greater than 1,000 euros or whose weight is more than 1,000 kilograms. Since 2006, even smaller transactions are reported. However, for intra-EU trade, the thresholds are higher, with total intra-EU imports or exports above 250,000 euros in a year, and in 2006 this threshold was raised to 1,000,000 euros for exports and 400,000 for imports. Note that these thresholds result in changing cutoffs for countries that joined the EU during our sample period as their transactions move from being recorded by Customs to the Intrastat Inquiry.

Firm-level data The firm-level data are from the Belgian Business Registry, covering all incorporated firms. These annual accounts report information from balance sheets, income statements, and annexes to the annual accounts. Only large firms are required to provide full annual accounts whereas small firms have to only provide short annual accounts so that some variables such as sales, turnover, and material costs may not be provided for small firms. A large firm is defined as a company with an average annual workforce of at least 100 workers or when at least two of the followhing three thresholds are met: (i) annual average workforce of 50 workers, (ii) turnover (excluding VAT) amounts to at least 7,300,000 euros, or (iii) total assets exceeding 3,650,000 euros. Note that the last two thresholds are altered every four years to take account of inflation. Although less than 10 percent of the companies in Belgium report full annual accounts, for firms in the manufacturing sector these account for most of value added (89 percent) and employment (83 percent).

Each firm reports a 5-digit NACE code based on its main economic activity. The key variable of interest is the construction of $\varphi$ defined as the ratio of total non-Euro imports to total costs (equal to wages plus total material costs). These total cost variables are reported by 58 percent of exporters in the manufacturing sector. Combining this information with the import data, we can set $\varphi$ equal to zero when total non-Euro imports are zero even if total costs are not reported, giving us a $\varphi$ for 77 percent of manufacturing exporters, which account for 98 percent of all manufacturing exports. Note that in less than half a percent of the observations, total imports were greater than material costs in which case we treated $\varphi$ as missing.

Product Concordances We use SITC one-digit product codes (5 to 8 ) to identify a manuacturing export as it is not possible to do so directly from the CN 8-digit classifications nor from its corresponding HS 6-digit code. We construct a concordance between 
CN 8-digit codes and SITC Revision 3 by building on a concordance between HS 10-digit and SITC 5-digit from Peter Schott's website, which takes into account revisions to HS codes up to 2006 (see Pierce and Schott, 2012). We update this to take account of HS 6-digit revisions in 2007 using the concordance from the U.S. Foreign Census (see http: //www . census.gov/foreign-trade/reference/products/layouts/imhdb.html). We begin by taking the first 6-digits of the 8-digit CN code, which is effectively an HS 6-digit code, and we include only the corresponding SITC code when it is a unique mapping. Some HS 6-digit codes map to multiple SITC codes, so that in those cases we do not include a corresponding SITC code. This happens mainly when we get to the more disaggregated SITC codes and rarely at the one-digit SITC code.

Second, we need to match the CN codes to input-output (IO) codes. We use a 2005 Belgium IO matrix with $74 \mathrm{IO}$ codes of which 56 are within the manufacturing sector. The IO codes are based on the Statistical Classifications of Product by Activity, abbreviated as CPA, which in turn are linked to the CN 8-digit codes using the Eurostat correspondence tables. The matching of the IO codes to the CN 8-digit was not straightforward as we had to deal with the many-to-many concordance issues. We included an IO code only when the match from the CN code was clear.

Sample Our sample is for the years 2000 to 2008, beginning with the first year after the euro was formed. We keep all firms that report their main economic activity in manufacturing defined according to 2-digit NACE codes 15 to 36, thus excluding wholesalers, mining, and services. We restrict exports to those that are defined within the manufacturing sector (SITC one-digit codes 5 to 8 ). To address the multiproduct firm issue, we keep only the set of $\mathrm{CN}$ 8-digit codes that falls within a firm's major IO export, which we identify as follows. We select an IO code for each firm that reflects the firm's largest export share over the sample period and then keep all CN codes that fall within that IO code. For most of the analysis, we focus on exports to noneuro OECD countries that are defined as advanced by the IMF and high-income by the World Bank.

We keep all import product codes and all import source countries. For some robustness checks, we limit the set of imports to intermediate inputs defined either using the Belgium 2005 IO table or according to Broad Economic Codes (BEC). See http://unstats.un.org/ unsd/cr/registry/regcst.asp?Cl=10, where we define intermediate inputs as including codes $111,121,2,42,53,41$, and 521 .

Total Factor Productivity Measures We measure total factor productivity (TFP) for each firm by first estimating production functions for each 2-digit NACE sector separately. We note that a key problem in the estimation of production functions is the correlation between inputs and unobservable productivity shocks. To address this endogeneity problem we estimate TFP using two different methodologies. The first approach is based on Levinsohn and Petrin (2003) (LP), who propose a modification of the Olley and Pakes (1996) (OP) estimator. OP uses investment as a proxy for unobservable productivity shocks. However, LP finds evidence suggesting that investment is lumpy and hence that investment may not 
respond smoothly to a productivity shock. As an alternative, LP uses intermediate inputs, such as materials, as a proxy for unobserved productivity. In particular, we assume a Cobb Douglas production function,

$$
\nu_{f, t}=\beta_{0}+\beta_{l} l_{f, t}+\beta_{k} k_{f, t}+\omega_{f, t}+\eta_{f, t},
$$

where $\nu_{f, t}$ represents the $\log$ of value added, $l_{f, t}$ is the $\log$ of the freely available input, labor, and $k_{f, t}$ is the $\log$ of the state variable, capital. The error term consists of a component that reflects (unobserved) productivity shocks, $\omega_{f, t}$, and a white noise component, $\eta_{f, t}$, uncorrelated with the input factors. The former is a state variable, not observed by the econometrician but which can affect the choices of the input factors. This simultaneity problem can be solved by assuming that the demand for the intermediate inputs, $x_{f, t}$, depends on the state variables $k_{f, t}$ and $\omega_{f, t}$, and

$$
x_{f, t}=x_{f, t}\left(k_{f, t}, \omega_{f, t}\right) .
$$

LP shows that this demand function is monotonically increasing in $\omega_{f, t}$ and hence the intermediate demand function can be inverted such that the unobserved productivity shocks, $\omega_{f, t}$, can be written as a function of the observed inputs, $x_{f, t}$ and $k_{f, t}$, or $\omega_{f, t}=\omega\left(k_{f, t}, x_{f, t}\right)$. A two-step estimation method is followed where in the first step semi-parametric methods are used to estimate the coefficient on the variable input, labor. In the second step, the coefficient on capital is estimated by using the assumption, as in OP, that productivity follows a first-order Markov process.

However, as pointed out by Ackerberg, Caves, and Frazer (2006), a potential problem with LP is related to the timing assumption of the freely available input, labor. If labor is chosen optimally by the firm, it is also a function of the unobserved productivity shock and capital. Then the coefficient on the variable input cannot be identified. Wooldridge (2009) shows how the two-step semi-parametric approach can be implemented using a unified onestep Generalized Methods of Moments (GMM) framework. This is the second methodology that we adopt for estimating TFP. In particular $\omega_{f, t}=\omega\left(k_{f, t}, x_{f, t}\right)$ is proxied by a lagged polynomial in capital and materials, which controls for expected productivity in $t$. We use a third-order polynomial in capital and material in our estimation. To deal with the potential endogeneity of labor, we use its first lag as an instrument. A benefit of this method is that GMM uses the moment conditions implied by the LP assumptions more efficiently. The log of TFP measures are normalized relative to their 2-digit NACE sector mean to make them comparable across industries. The correlation between both measures is very high at 99 percent. 


\section{A.3 Additional Figures and Tables}
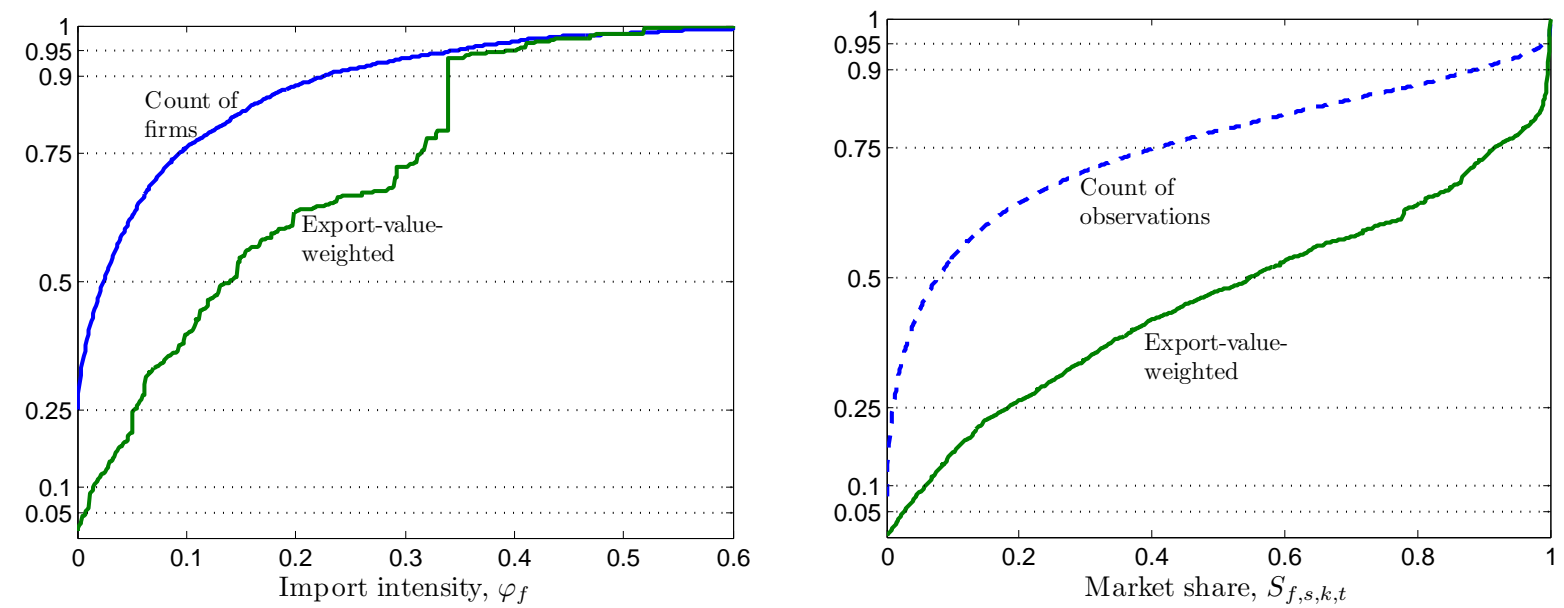

Figure A1: Cumulative distribution functions of import intensity $\varphi_{f}$ and market share $S_{f, s, k, t}$

Note: Estimated cumulative distribution functions. In the left panel, the upper cdf corresponds to the unweighted firm count, while the lower cdf weights firm observations by their export values. The unweighted distribution of $\varphi_{f}$ has a mass point of $24 \%$ at $\varphi_{f}=0$, while this mass point largely disappears in the valueweighted distribution, which in turn has a step $\varphi_{f}=0.33$ corresponding to the largest exporter in our sample with an export share of $14 \%$. In the right panel, the upper cdf corresponds to the count of firm-sectordestination-year observations, and it has small mass points at both $S_{f, s, k, t}=0$ and $S_{f, s, k, t}=1$, which largely correspond to small sectors in remote destinations. The lower cdf weights the observations by their export value, and this weighted distribution has no mass points, although the distribution becomes very steep at the very large market shares.

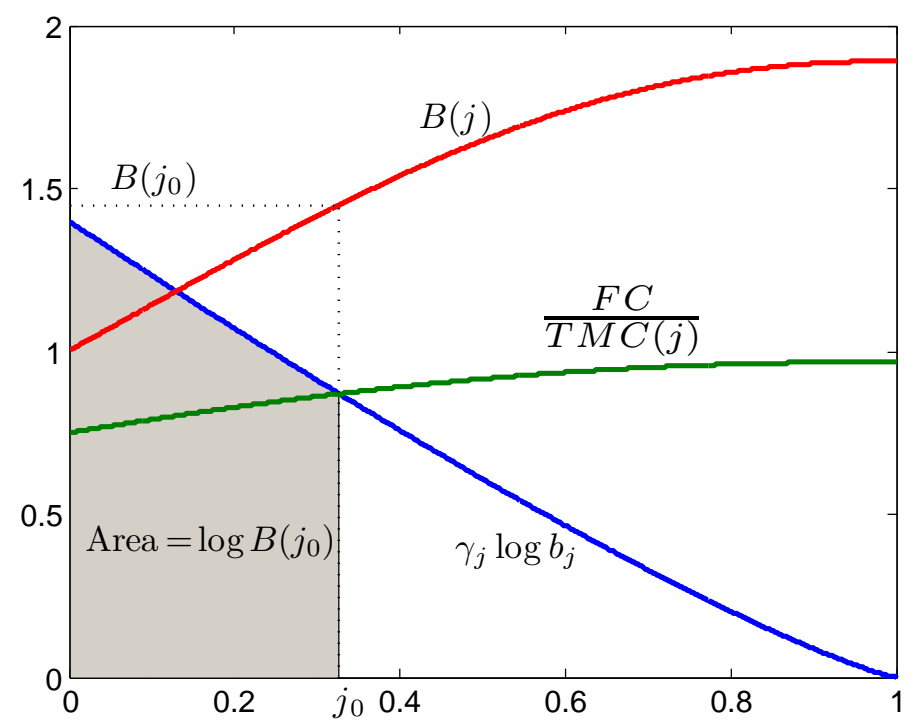

Figure A2: Import cutoff $j_{0}$ and cost-reduction factor $B\left(j_{0}\right)$

Note: $F C=W^{*} f_{i}$ is the fixed cost of importing an additional type of intermediate input. $T M C(j)=$ $C^{*} Y_{i} /\left[B(j)^{\phi} \Omega_{i}\right]$ is the total material cost of the firm, decreasing in $j$ holding output fixed due to cost-saving effect of importing. The intersection between $\gamma_{j} \log b_{j}$ and $F C / T M C(j)$ defines the import cutoff $j_{0}$, and the exponent of the area under $\gamma_{j} \log b_{j}$ curve determines the cost-reduction factor from importing. 
Table A1: Pass-through into producer prices and marginal cost by quartiles of import intensity

\begin{tabular}{|c|c|c|c|c|c|c|c|}
\hline \multirow[t]{2}{*}{ Dep. variable: } & \multicolumn{4}{|c|}{$\Delta p_{f, i, k, t}^{*}$} & \multicolumn{2}{|c|}{$\Delta m c_{f, t}^{*}$} & \multirow{2}{*}{$\frac{\Delta e_{f, t}^{M}}{(7)}$} \\
\hline & (1) & $(2)$ & $(3)$ & (4) & $(5)$ & $(6)$ & \\
\hline$\Delta e_{\ell, t} \cdot \delta_{1, f}$ & $\begin{array}{l}0.128^{* * *} \\
(0.034)\end{array}$ & $\begin{array}{l}0.115^{* * *} \\
(0.034)\end{array}$ & $\begin{array}{l}0.071^{* *} \\
(0.035)\end{array}$ & $\begin{array}{l}0.077^{* *} \\
(0.035)\end{array}$ & $\begin{array}{l}0.023^{* * *} \\
(0.007)\end{array}$ & $\begin{array}{l}0.054^{* * *} \\
(0.006)\end{array}$ & $\begin{array}{l}0.399^{* * *} \\
(0.065)\end{array}$ \\
\hline$\Delta e_{\ell, t} \cdot \delta_{2, f}$ & $\begin{array}{l}0.203^{* * *} \\
(0.036)\end{array}$ & $\begin{array}{l}0.176^{* * *} \\
(0.034)\end{array}$ & $\begin{array}{l}0.130^{* * * *} \\
(0.033)\end{array}$ & $\begin{array}{l}0.149^{* * *} \\
(0.035)\end{array}$ & $\begin{array}{l}0.047^{* * *} \\
(0.017)\end{array}$ & $\begin{array}{l}0.092^{* * *} \\
(0.011)\end{array}$ & $\begin{array}{l}0.434^{* * *} \\
(0.068)\end{array}$ \\
\hline$\Delta e_{\ell, t} \cdot \delta_{3, f}$ & $\begin{array}{l}0.239^{* * *} \\
(0.053)\end{array}$ & $\begin{array}{l}0.185^{* * *} \\
(0.049)\end{array}$ & $\begin{array}{c}0.113^{* *} \\
(0.048)\end{array}$ & $\begin{array}{l}0.154^{* * *} \\
(0.052)\end{array}$ & $\begin{array}{l}0.095^{* * *} \\
(0.022)\end{array}$ & $\begin{array}{l}0.145^{* * *} \\
(0.010)\end{array}$ & $\begin{array}{l}0.466^{* * *} \\
(0.070)\end{array}$ \\
\hline$\Delta e_{\ell, t} \cdot \delta_{4, f}$ & $\begin{array}{l}0.321^{\text {*** }} \\
(0.039)\end{array}$ & $\begin{array}{c}0.227^{* * *} \\
(0.040)\end{array}$ & $\begin{array}{l}0.152^{* * *} \\
(0.041)\end{array}$ & $\begin{array}{l}0.232^{* * *} \\
(0.035)\end{array}$ & $\begin{array}{l}0.165^{* * *} \\
(0.037)\end{array}$ & $\begin{array}{l}0.213^{* * *} \\
(0.018)\end{array}$ & $\begin{array}{l}0.421^{\text {*** }} \\
(0.084)\end{array}$ \\
\hline$\Delta e_{k, t} \cdot S_{f, s, k, t}$ & & & $\begin{array}{l}0.205^{\text {*** }} \\
(0.053)\end{array}$ & $\begin{array}{l}0.238^{* * *} \\
(0.059)\end{array}$ & & & \\
\hline$\Delta m c_{f, t}^{*}$ & & $\begin{array}{l}0.569^{* * *} \\
(0.031)\end{array}$ & $\begin{array}{c}0.565^{* * *} \\
(0.031)\end{array}$ & & & & \\
\hline$p$-value $\operatorname{Bin} 1$ vs 4 & $0.000^{* * *}$ & $0.014^{* *}$ & $0.081^{*}$ & $0.000^{* * *}$ & $0.000^{* * *}$ & $0.000^{* * *}$ & 0.479 \\
\hline $\begin{array}{l}\# \text { obs. } \\
R^{2}\end{array}$ & $\begin{array}{c}93,395 \\
0.003\end{array}$ & $\begin{array}{c}93,395 \\
0.010\end{array}$ & $\begin{array}{c}93,395 \\
0.010\end{array}$ & $\begin{array}{c}93,395 \\
0.003\end{array}$ & $\begin{array}{c}93,395 \\
0.025\end{array}$ & $\begin{array}{c}89,504 \\
0.045\end{array}$ & $\begin{array}{c}89,504 \\
0.214\end{array}$ \\
\hline
\end{tabular}

Note: Nonparametric regressions: firm-product-destination-year observations split into four equal-sized bins by value of import intensity $\varphi_{f}$, with $\delta_{q, f}$ denoting a dummy for respective bins (quartiles $q=1,2,3,4$ ). No fixed effects included in nonparametric specifications. Specifications (3) and (4) additionally control for the level of the market share $S_{f, s, k, t}$. In columns 1-5 and $7, \Delta e_{\ell, t} \equiv \Delta e_{k, t}$ is the destination-specific bilateral exchange rate; in column $6, \Delta e_{\ell, t} \equiv \Delta e_{f, t}^{M}$ is the firm-level import-weighted exchange rate (excluding imports from the Euro Zone). In column 7, firm-level import-weighted exchange rate $\Delta e_{f, t}^{M}$ is regressed on the destination-specific bilateral exchange rate $\Delta e_{k, t} . p$-value for the F-test of equality of the coefficients for quartiles 1 and 4. Standard errors clustered at the destination-year level. 
Table A2: High exchange rate correlation source-destination pairs

\begin{tabular}{|c|c|c|c|c|}
\hline \multirow[b]{2}{*}{ Destination } & \multicolumn{2}{|c|}{ \# of source countries } & \multicolumn{2}{|c|}{ Share of imports from } \\
\hline & pegs & $\operatorname{corr} \geq 0.7$ & destination & corr $\geq 0.7$ \\
\hline Australia & 1 & 6 & $0.5 \%$ & $5.2 \%$ \\
\hline Canada & 0 & 79 & $2.5 \%$ & $58.7 \%$ \\
\hline Iceland & 0 & 6 & $0.1 \%$ & $2.3 \%$ \\
\hline Israel & 0 & 77 & $0.5 \%$ & $41.2 \%$ \\
\hline Japan & 0 & 22 & $5.1 \%$ & $16.0 \%$ \\
\hline Korea & 0 & 24 & $1.6 \%$ & $33.9 \%$ \\
\hline New Zealand & 0 & 3 & $0.3 \%$ & $0.6 \%$ \\
\hline Norway & 0 & 1 & $1.2 \%$ & $1.3 \%$ \\
\hline Sweden & 0 & 4 & $5.0 \%$ & $6.8 \%$ \\
\hline Switzerland & 0 & 1 & $6.3 \%$ & $6.7 \%$ \\
\hline United Kingdom & 0 & 12 & $23.0 \%$ & $30.3 \%$ \\
\hline United States & 20 & 79 & $17.6 \%$ & $38.0 \%$ \\
\hline
\end{tabular}

Note: Total number of non-Euro source countries: 210. Number of countries in the first two columns excludes destination itself, while the share of imports in the last column includes imports from the destination country.

Table A3: High and low pass-through import source countries

\begin{tabular}{|c|c|c|c|c|c|}
\hline \multicolumn{3}{|c|}{ "High pass-through $(\geq 0.50)$} & \multicolumn{3}{|c|}{ Low pass-through $(<0.50)$} \\
\hline Country & $\begin{array}{l}\text { Pass- } \\
\text { through }\end{array}$ & $\begin{array}{l}\text { Import } \\
\text { share }\end{array}$ & Country & $\begin{array}{l}\text { Pass- } \\
\text { through }\end{array}$ & $\begin{array}{l}\text { Import } \\
\text { share }\end{array}$ \\
\hline Peru & $1.20^{* * *}$ & $0.5 \%$ & Israel $^{\dagger}$ & $0.45^{* * *}$ & $0.2 \%$ \\
\hline Bangladesh & $0.93^{* * *}$ & $0.2 \%$ & India & $0.42^{* * *}$ & $1.0 \%$ \\
\hline Chile & $0.75^{* * *}$ & $0.2 \%$ & Brazil & $0.41^{* * *}$ & $3.1 \%$ \\
\hline Taiwan & $0.74^{* * *}$ & $0.5 \%$ & Thailand & $0.41^{* * *}$ & $1.0 \%$ \\
\hline Canada $^{\dagger}$ & $0.71^{* * *}$ & $1.8 \%$ & Sri Lanka & $0.40^{* *}$ & $0.2 \%$ \\
\hline Australia $^{\dagger}$ & $0.69^{* *}$ & $1.5 \%$ & Malaysia & $0.40^{* * *}$ & $0.3 \%$ \\
\hline Saudi Arabia & $0.67^{* *}$ & $1.3 \%$ & Egypt & $0.39^{* * *}$ & $0.4 \%$ \\
\hline China & $0.67^{* * *}$ & $3.8 \%$ & Philippines & $0.39^{*}$ & $0.5 \%$ \\
\hline United States $^{\dagger}$ & $0.63^{* * *}$ & $16.6 \%$ & Venezuela & $0.36^{* *}$ & $0.4 \%$ \\
\hline Russia & $0.62^{* * *}$ & $3.8 \%$ & Singapore & 0.31 & $0.2 \%$ \\
\hline Hong Kong & $0.61^{* * *}$ & $0.2 \%$ & Sweden $^{\dagger}$ & $0.31^{* * *}$ & $14.3 \%$ \\
\hline $\operatorname{Japan}^{\dagger}$ & $0.55^{* * *}$ & $5.4 \%$ & South Korea $^{\dagger}$ & $0.24^{* * *}$ & $0.9 \%$ \\
\hline Colombia & $0.55^{* * *}$ & $0.3 \%$ & United Kingdom ${ }^{\dagger}$ & $0.19^{* * *}$ & $15.7 \%$ \\
\hline Switzerland $^{\dagger}$ & $0.53^{* * *}$ & $1.5 \%$ & Indonesia & $0.18^{* *}$ & $0.6 \%$ \\
\hline Mexico & $0.50^{* * *}$ & $0.4 \%$ & Ukraine & 0.15 & $0.2 \%$ \\
\hline & & & Argentina & $0.08^{* *}$ & $0.3 \%$ \\
\hline & & & Turkey & 0.02 & $1.5 \%$ \\
\hline & & & Pakistan & -0.02 & $0.2 \%$ \\
\hline & & & Vietnam & -0.03 & $0.3 \%$ \\
\hline & & & South Africa & -0.09 & $1.0 \%$ \\
\hline
\end{tabular}

Note: Non-OECD import source countries with a share in Belgian imports above 0.2\% and precisely estimated pass-through into import prices of Belgian firms, split into high and low pass-through bins with a threshold pass-through of 0.5. † marks high-income OECD countries. High-pass-through countries also include Guatemala, Macao, Uganda and United Arab Emirates; Low-pass-through countries also include Belarus, Congo, Dominican Republic, Ethiopia, Ghana, Honduras, Madagascar, New Zealand ${ }^{\dagger}$, Paraguay, Uruguay, Zambia, Zimbabwe. For the remaining of the 210 countries in our sample, most of which are very small sources of imports for Belgian firms, pass-through is imprecisely estimated. 


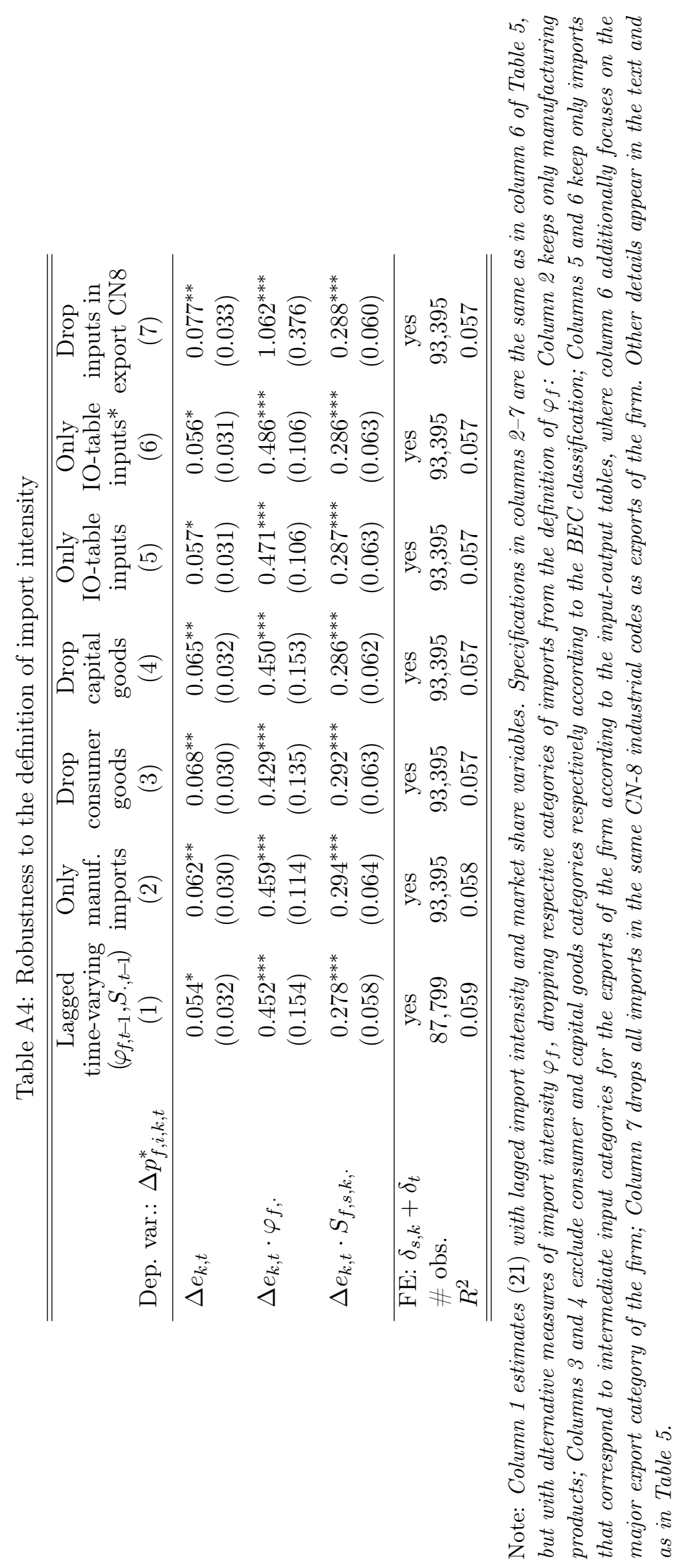




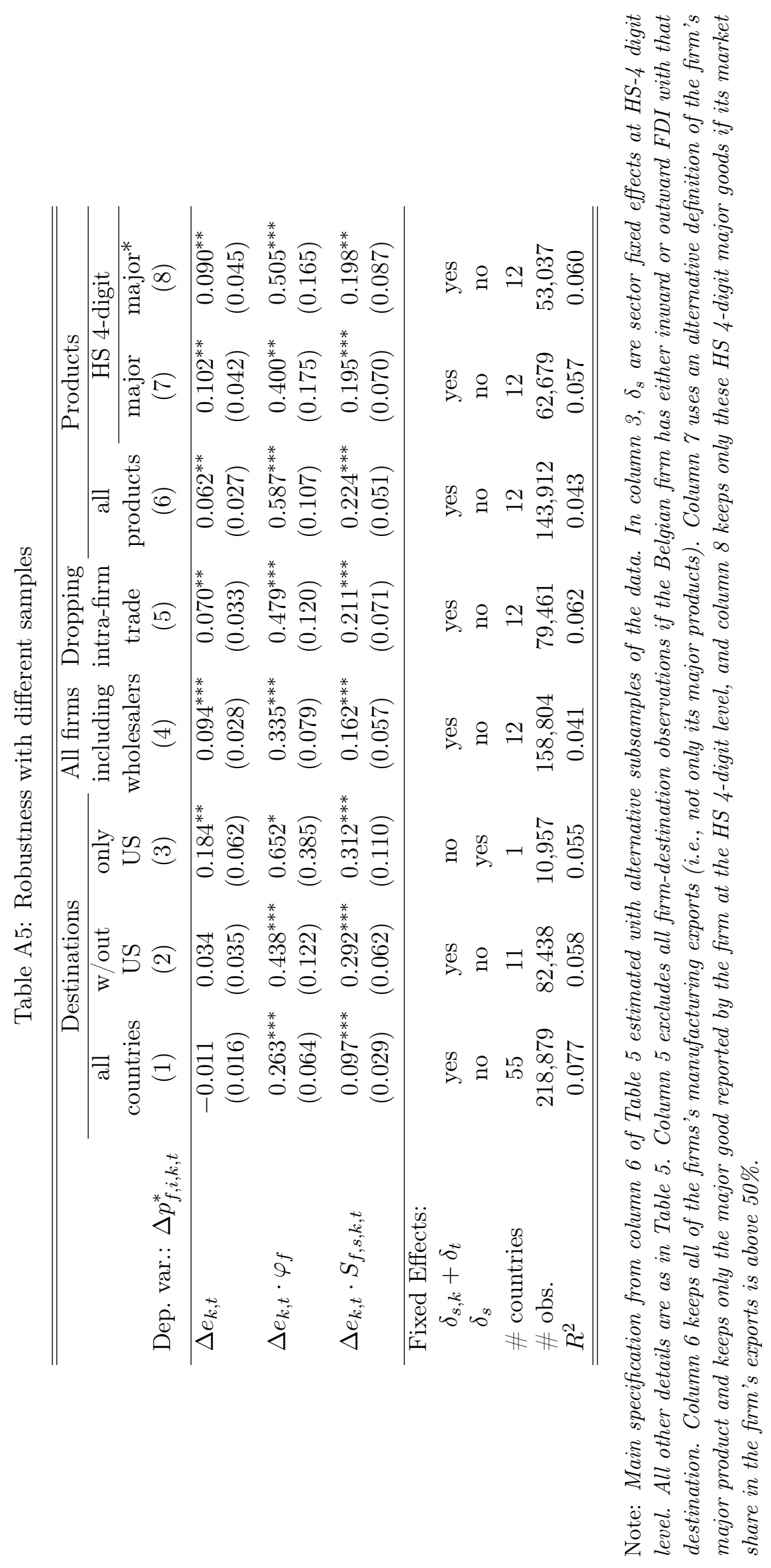

